\section{SANDIA REPORT}

SAND97-1275/2 • UC-1350

Unlimited Release

Printed September 1997

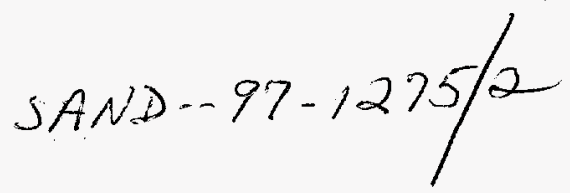

\title{
Battery Energy Storage Market Feasibility Study - Expanded Report
}

\author{
RECEIVED \\ NOW 031997 \\ OSTI
}

Abbas Akhil, Steve Kraft

Prepared by

Sandia National Laboratories

Albuquerque, New Mexico 87185 and Livermore, California 94550

Sandia is a multiprogram laboratory operated by Sandia Corporation, a Lockheed Martin Company, for the United States Department of

Energy under Contract DE-AC04-94AL85000.

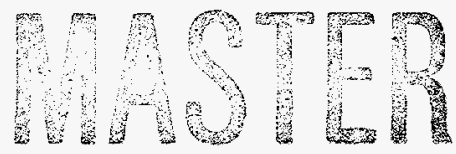

Approved for public release; distribution is unlimited.

Aandia National Laboratories 
Issued by Sandia National Laboratories, operated for the United States Department of Energy by Sandia Corporation.

NOTICE: This report was prepared as an account of work sponsored by an agency of the United States Government. Neither the United States Government nor any agency thereof, nor any of their employees, nor any of their contractors, subcontractors, or their employees, makes any warranty, express or implied, or assumes any legal liability or responsibility for the accuracy, completeness, or usefulness of any information, apparatus, product, or process disclosed, or represents that its use would not infringe privately owned rights. Reference herein to any specific commercial product, process, or service by trade name, trademark, manufacturer, or otherwise, does not necessarily constitute or imply its endorsement, recommendation, or favoring by the United States Government, any agency thereof, or any of their contractors or subcontractors. The views and opinions expressed herein do not necessarily state or reflect those of the United States Government, any agency thereof, or any of their contractors.

Printed in the United States of America. This report has been reproduced directly from the best available copy.

Available to DOE and DOE contractors from

Office of Scientific and Technical Information

P.O. Box 62

Oak Ridge, TN 37831

Prices available from (615) 576-8401, FTS 626-8401

Available to the public from

National Technical Information Service

U.S. Department of Commerce

5285 Port Royal Rd

Springfield, VA 22161

NTIS price codes

Printed copy: A09

Microfiche copy: A01 
DISCLAMIER

Portions of this document may be illegible in electronic image products. Images are produced from the best available original document. 


\title{
Battery Energy Storage Market Feasibility Study- Expanded Report
}

\author{
Steve Kraft \\ Frost \& Sullivan \\ 2525 Charleston Road \\ Mountain View, California 94043
}

Abbas Akhil

Energy Storage Systems Analysis and Development Department

Sandia National Laboratories

P.O. Box 5800

Albuquerque, New Mexico 87185-0613

\begin{abstract}
Under the sponsorship of the U.S. Department of Energy's Office of Utility Technologies, the Energy Storage Systems Analysis and Development Department at Sandia National Laboratories (SNL) contracted Frost \& Sullivan to conduct a market feasibility study of energy storage systems. The study was designed specifically to quantify the battery energy storage market for utility applications. This study was based on the SNL Opportunities Analysis performed earlier. Many of the groups surveyed, which included electricity providers, battery energy storage vendors, regulators, consultants, and technology advocates, viewed battery storage as an important technology to enable increased use of renewable energy and as a means to solve power quality and asset utilization issues. There are two versions of the document available, an expanded version (approximately 200 pages, SAND97-1275/2) and a short version (approximately 25 pages, SAND97-1275/1).
\end{abstract}




\section{Acknowledgments}

Sandia National Laboratories would like to acknowledge and thank Dr. Christine E. Platt of the U.S. Department of Energy's Office of Utility Technologies for the support and funding of this work. We also gratefully acknowledge all of the contributing utilities, electricity providers, product suppliers, regulators, industry advocates, and professional and academic associations who responded to the survey.

The principal investigator for this study was Steve Kraft from Frost \& Sullivan. The Frost \& Sullivan team included David Coleman and Ken Herbert.

We also wish to thank the following individuals for participating in a review panel that provided valuable technical comment before the final study was published.

\begin{tabular}{|l|l|}
\hline \multicolumn{2}{|c|}{ Review Panel Members } \\
\hline $\begin{array}{l}\text { Mr. Mike Hinga } \\
\text { Delphi Energy and Engine Management Sys- } \\
\text { tems }\end{array}$ & $\begin{array}{l}\text { Mr. Bob Fleming } \\
\text { AC Battery Corporation }\end{array}$ \\
\hline $\begin{array}{l}\text { Mr. Gene Cook } \\
\text { Yuasa-Exide }\end{array}$ & $\begin{array}{l}\text { Mr. George Hunt } \\
\text { GNB Technologies }\end{array}$ \\
\hline $\begin{array}{l}\text { Dr. Rajat Sen } \\
\text { R.K. Sen and Associates }\end{array}$ & $\begin{array}{l}\text { Mr. Paul Klimas } \\
\text { Sandia National Laboratories }\end{array}$ \\
\hline $\begin{array}{l}\text { Dr. Philip C. Symons } \\
\text { Symons/EECl }\end{array}$ & $\begin{array}{l}\text { Mr. Howard Lowitt } \\
\text { Energetics }\end{array}$ \\
\hline $\begin{array}{l}\text { Mr. Steve Eckroad } \\
\text { Electric Power Research Institute (EPRI) }\end{array}$ & $\begin{array}{l}\text { Mr. Carl Parker } \\
\text { International Lead Zinc Research Organization } \\
\text { (ILZRO) }\end{array}$ \\
\hline $\begin{array}{l}\text { Mr. Richard Schweinberg } \\
\text { Southern California Edison }\end{array}$ & $\begin{array}{l}\text { Ms. Denise Zurn } \\
\text { Northern States Power }\end{array}$ \\
\hline $\begin{array}{l}\text { Mr. Bradley Johnson } \\
\text { Potomac Electric Power Company (PEPCO) }\end{array}$ & $\begin{array}{l}\text { Mr. Jon Hurwitch } \\
\text { Switch Technologies }\end{array}$ \\
\hline
\end{tabular}




\section{Contents}

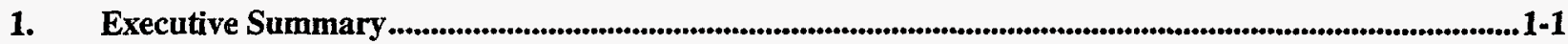

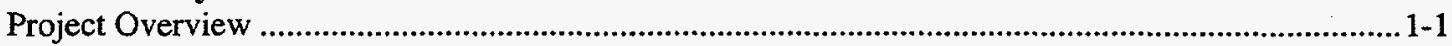

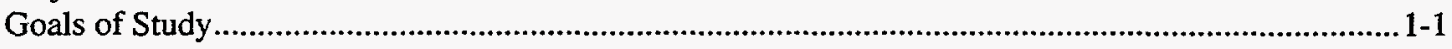

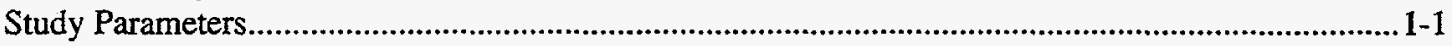

Selection of Respondents ............................................................................................................. 1-2

Surveying Process ................................................................................................................................... 1-3

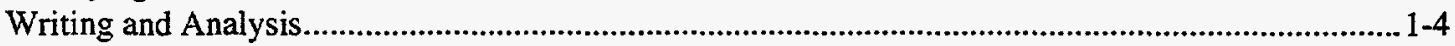

Assumptions and Risk Assessment ....................................................................................................... 1-4

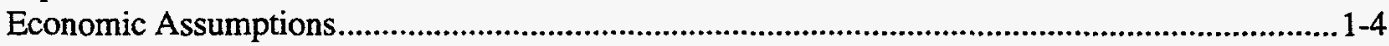

Deregulation of the Electric Power Industry ......................................................................... 1-4

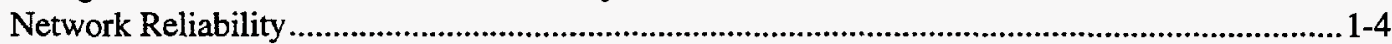

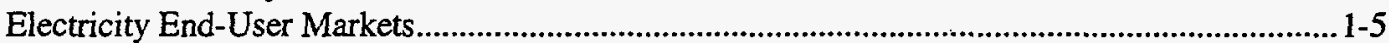

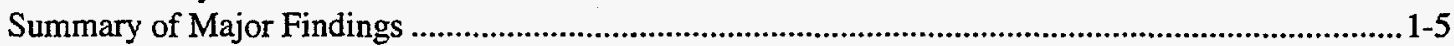

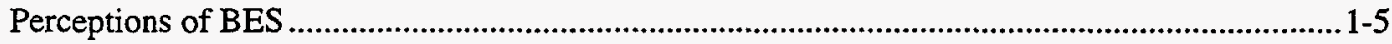

BES Market Opportunities and Forecasts ............................................................................. 1-8

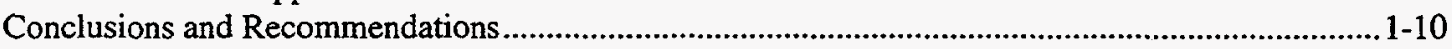

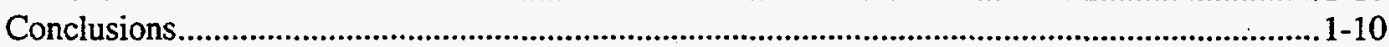

Recommendations .......................................................................................................1-12

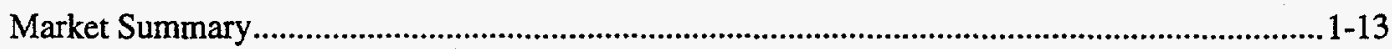

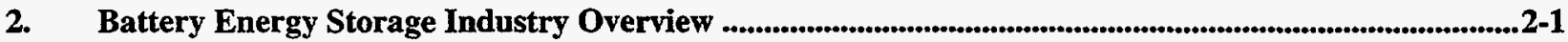

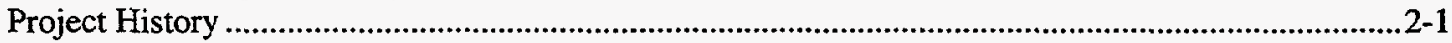

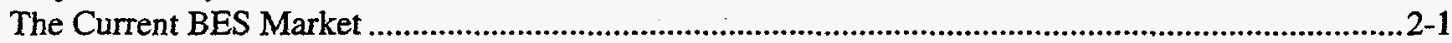

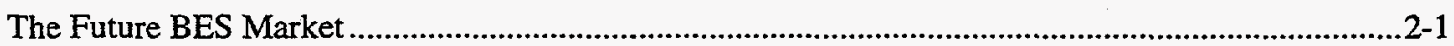

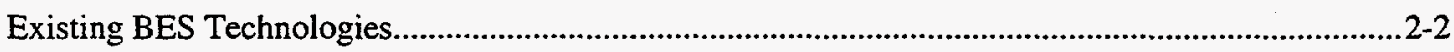

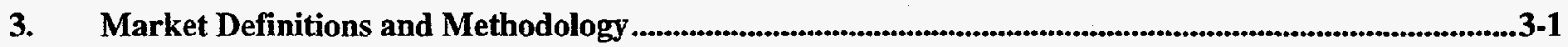

Market Definitions ............................................................................................................................

Market Feasibility Study Contact List and Methodology .................................................................3-1

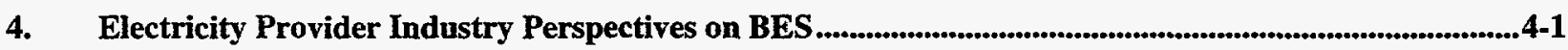

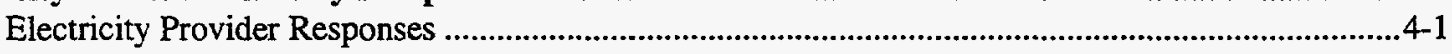

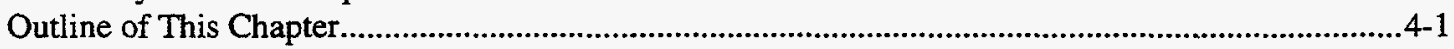

General Opinions of BES.

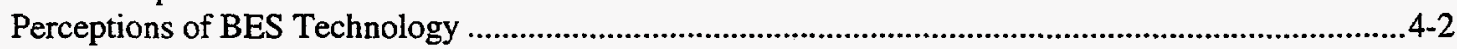

Organizational Structure and BES Procurement ...............................................................................4-4

BES Versus Other Advanced Storage Technologies..........................................................................4-5

BES Versus Central Energy Storage Technologies......................................................................................4-6

BES Versus Generation Technologies ..............................................................................................

Industry Comparisons of Other Generation and Storage Options to BES..............................................4-7

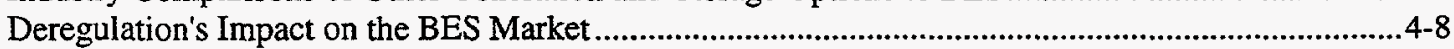

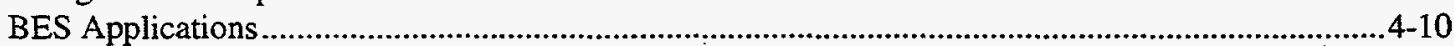

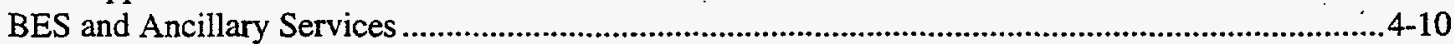

Additional BES Applications Important to Respondents ................................................................12

Additional BES Applications Important to the Electricity Provider Industry .......................................4-12

Desired BES Technical and Product Characteristics ...................................................................4-12

Estimates of Load Growth and Transmission and Distribution Expansion .........................................4-14

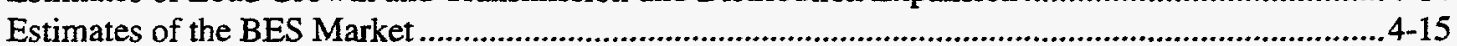

Projected Effects of Lower-Cost BES Technology ....................................................................

5. Supplier and Consultant Perspectives on Battery Energy Storage ...............................................................5-1

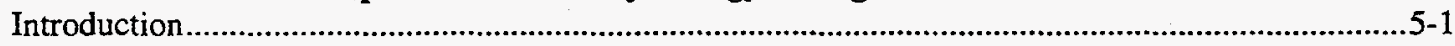




\section{Contents (Continued)}

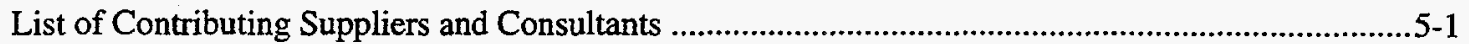

Products and Services Offered to BES Market …...............................................................................

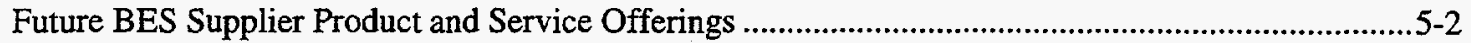

Vendor Perspectives on Other Energy Storage Technologies ..............................................................5-2

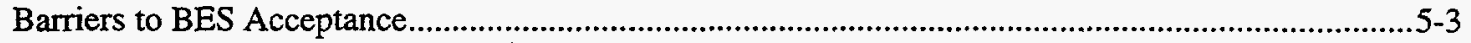

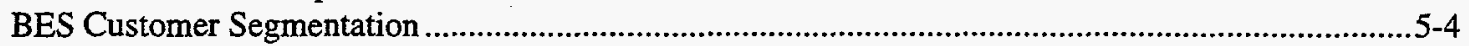

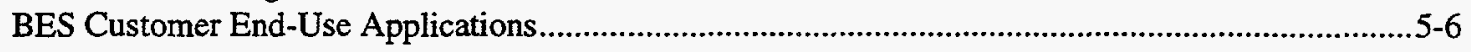

Barriers to BES Acceptance Among Electricity End Users .........................................................

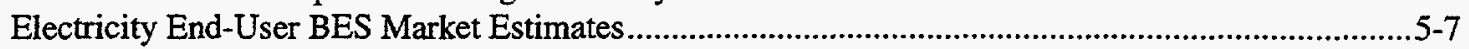

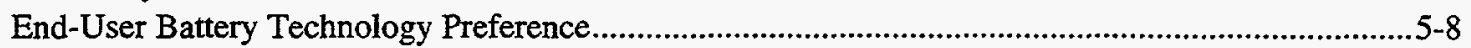

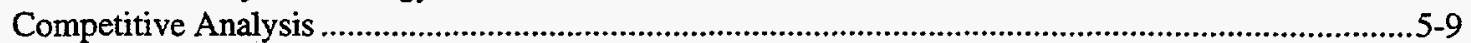

Vendor Perspectives On Existing BES Projects ..............................................................................

BES Manufacturing Developments ................................................................................................5-11

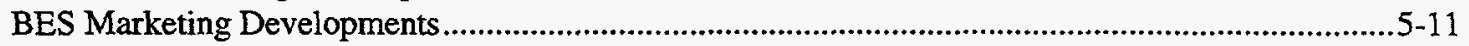

6. Regulatory Agency and Industry Group Perspectives on Battery Energy Storage.....................................6-1

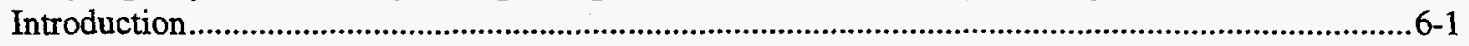

List of Contributing Regulatory Agencies, Industry Advocates, and Professional/

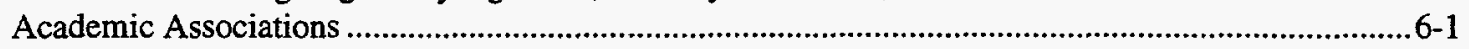

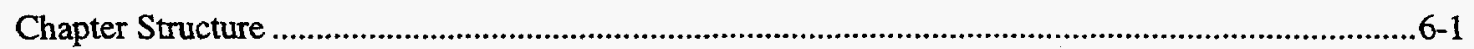

Regulatory Agency, Industry Advocate, and Professional/Academic Opinions of BES .......................6-1

Regulatory Agency, Industry Advocate, and Professional/Academic Promotion of BES .....................6-2

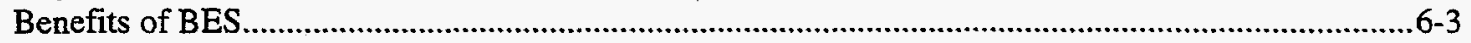

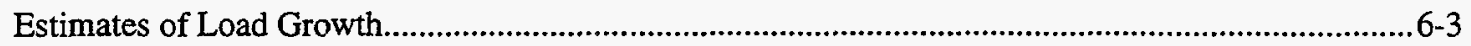

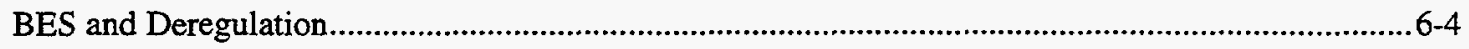

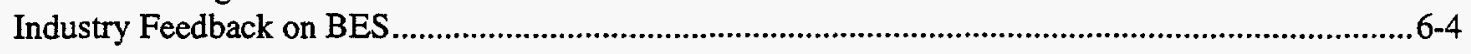

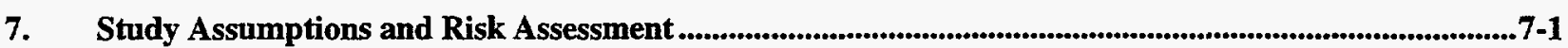

Explanation of Assumptions and Risk Assessment ......................................................................

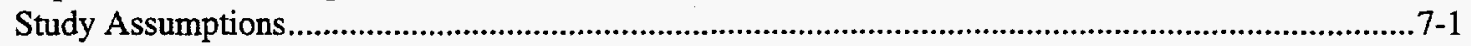

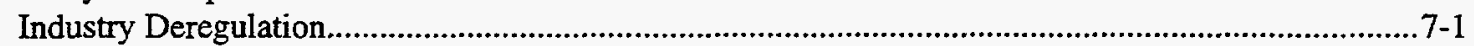

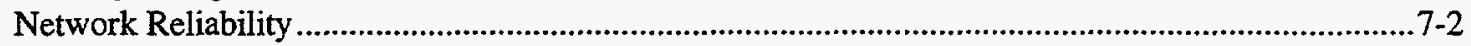

Electricity End Users ........................................................................................................................

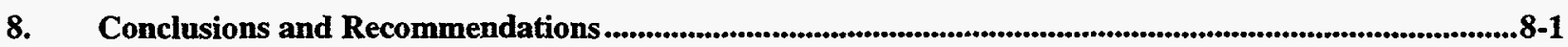

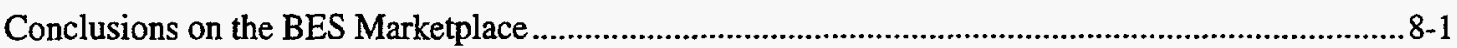

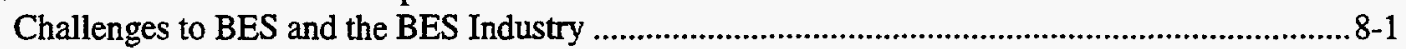

Improving BES Cost, Life Cycle, and Maintenance ....................................................................... 8-1

Increasing BES Energy Density ...............................................................................................

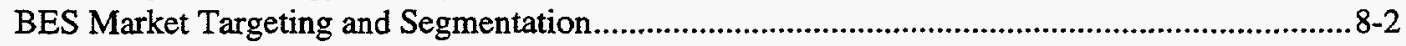

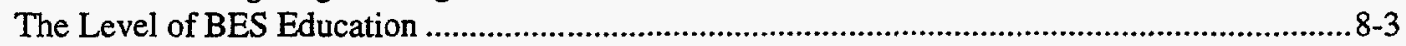

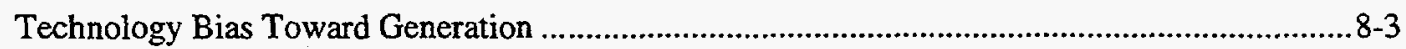

Organizational Obstacles to BES Procurement...................................................................... 8

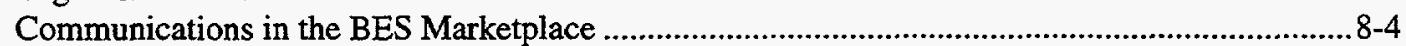

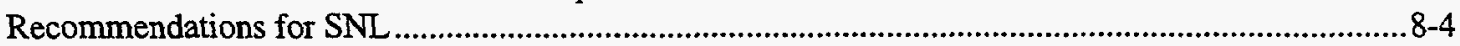

Focus on Potential BES Applications and Products.......................................................................... 8-4

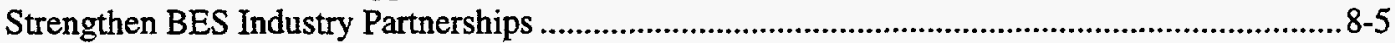

Focus on Lower-Cost, Higher-Density Battery Technologies............................................................ 8-6

Facilitate Clearer Communications within the BES Industry ............................................................. 8-6

Perform Studies of Electricity End Users and Cooperatives ...........................................................8-8

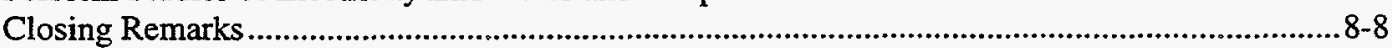




\section{Contents (Continued)}

Appendix A: Electricity Provider Questionnaire A-1

Appendix B: BES Vendor Questionnaire B-1

Appendix C: Regulator/Advocate/Professional Organization Questionnaire C-1

Appendix D: Battery Energy Storage Applications List D-1

\section{Figures}

1-1 Applications Identified by Electricity Providers (30 Companies), 1996 $1-6$

4-1 Applications Identified by Electricity Providers (30 Companies), 1996

\section{Tables}

1-1 BES Market: Organizations Contacted By Type (U.S.), 1996 $1-2$

1-2 BES Market: Individuals Contacted by Utility Type and Job Title (U.S.), 1996 .. Applications Identified by Electricity Providers (30 Companies), 1996.

1-5 BES Market Predictions by BES Suppliers and Consultants for Electricity End Users (U.S.), 2000, 2005 , and 2010 .

4-1 Opinion Survey Results: Likelihood of BES Deployment Predicted by U.S. Electricity Providers (37 Companies), Years 2000, 2005, and 2010

4-2 Applications Identified by Electricity Providers (30 Companies), 1996.

4-3 Estimate of Capacity Additions and Load Growth (in Megawatts): Provided by Electricity Provider Sample (21 Companies), Years 2000, 2005, and 2010.

4-4 Extrapolation of Capacity Additions and Load Growth (in Megawatts): Electricity Provider Industry (U.S. and Puerto Rico), Years 2000, 2005, and 2010 .....................................................................4-15

4-5 Mean Estimated Percentage of New Capacity Additions Being Met by BES: By Electricity Providers (21 Companies), Years 2000, 2005, and $2010 .$.

4-6 Estimated BES Capacity Additions (in Megawatts): By Electricity Providers (21 Companies), Years 2000, 2005, and 2010.

4-7 Extrapolation of BES Capacity Additions (in Megawatts): Electricity Provider Industry (U.S. and Puerto Rico), Years 2000, 2005, and 2010

4-8 Estimated BES Market (in Dollars): Electricity Provider Industry (U.S. and Puerto Rico), Years 2000, 2005, and 2010 . $.4-16$

5-1 BES Market: Supplier and Consultant Estimates of the Electricity End-User Market (in Megawatts) (U.S. and Puerto Rico), Years 2000, 2005, and 2010 


\section{Acronyms and Abbreviations}

\begin{tabular}{|c|c|}
\hline BES & battery energy storage \\
\hline BESS & battery energy storage system \\
\hline CAES & compressed-air energy storage \\
\hline DOE & U.S. Department of Energy \\
\hline DSM & demand-side management \\
\hline DVR & dynamic voltage regulator \\
\hline EMC & Electric Membership Cooperative \\
\hline EPRI & Electric Power Research Institute \\
\hline ESA & Energy Storage Association \\
\hline ESS & Energy Storage Systems \\
\hline FERC & Federal Energy Regulatory Commission \\
\hline ILZRO & International Lead/Zinc Research Organization \\
\hline IOU & investor-owned utility \\
\hline IPP & independent power producer \\
\hline IRP & integrated resource plan \\
\hline ISO & independent system operator \\
\hline NRECA & National Rural Electric Cooperative Association \\
\hline NUG & nonutility generator \\
\hline PREPA & Puerto Rico Electric Power Authority \\
\hline PV & photovoltaics \\
\hline $\mathrm{R} \& \mathrm{D}$ & research \& development \\
\hline RFP & request for proposal \\
\hline SCE & Southern California Edison \\
\hline SDG\&E & San Diego Gas \& Electric \\
\hline SMES & superconducting magnetic energy storage \\
\hline SNL & Sandia National Laboratories \\
\hline $\mathrm{T} \& \mathrm{D}$ & transmission \& distribution \\
\hline UPS & uninterruptible power supply \\
\hline VAR & volt-amp reactive \\
\hline VRLA & valve-regulated lead-acid \\
\hline
\end{tabular}




\section{Executive Summary}

\section{Project Overview}

Battery energy storage (BES) consists of modern battery and electronics technologies used in stationary applications. BES is now being applied to the needs of the electric power industry. In these applications, BES can be used to increase system reliability, improve power quality, defer capital investments, and improve the economics of power generation and energy consumption. Currently, the BES market is in a developmental stage, as are some of the battery and power conditioning subsystems integrated into BES systems.

Sandia National Laboratories (SNL) and the U.S. Department of Energy (DOE) are developing BES technology and encouraging its commercialization. This study is a part of those development efforts.

To better orient BES development efforts to the needs of the BES marketplace, SNL began developing the request for proposal (RFP) for this study in 1995, coordinating RFP development with the Energy Storage Association (ESA). Release of the RFP to the public occurred in Fall 1995.

Among the bidders on the RFP distribution list was Frost \& Sullivan, a market research and consulting company. In March 1996, Frost \& Sullivan was officially retained by SNL to conduct this study, with research commencing in May 1996.

\section{Goals of Study}

SNL had three principal goals in conducting this study. The first was to gather BES industry perceptions, especially among utilities and nonutility generators (NUGs), referred to in this report as "electricity providers." Additional perspectives were also gathered from BES suppliers and suppliers of BES components, utility regulatory agencies, and electric power industry trade and advocacy groups.

The perceptions gathered were to include information on desired product features, comparisons of BES with other electricity storage and supply options, and many more qualitative topics. The qualitative findings provide the most interesting results of this study.
The second major goal of this study was to generate an estimate of the electricity provider BES market through 2010. Specifically, this forecast was to include estimates of BES market activity for the years 2000,2005 , and 2010. These forecasts were derived from information gathered from the electricity provider sample and are year-on estimates (as opposed to cumulative) for 2000,2005 , and 2010 only. Therefore, these estimates do not measure any market activity occurring in years other than 2000,2005 , and 2010.

The third major goal was to provide SNL and the DOE with valuable input into its Energy Storage Systems (ESS) program management efforts. The ESS program strives to improve its customer orientation, and the results of this study were expected to be of significant aid in that direction.

\section{Study Parameters}

This study was limited to the estimation of the BES market at the electricity provider level. Because of resource limitations, a more thorough research of the BES market among end users of electric power, such as large industrial and commercial customers, was not undertaken.

End-user estimates are included in the study, but these are based on BES supplier organizations' perceptions. A market study of BES demand at the electricity end-user level may be undertaken in the future, and such a study is recommended to SNL later in this report.

The study forecast period is another important parameter. The decision was made during the writing of the RFP that this study should provide BES market estimates through 2010. This would give SNL and the rest of the BES industry a chance to review forecasts in time to develop the technologies, organizations, and infrastructure needed to serve and improve forecast future BES demand. The RFP for this study requested year-on BES market estimates, not cumulative estimates.

An additional parameter was the number of interviews that could be completed using allocated 
resources. For this study, 60 to 80 interviews with member organizations within the BES community were expected, and 68 were completed.

Geographically, this study was limited to the U.S. BES market. All of the organizations contacted for this study were asked about their activities in the U.S. market. Their operations outside of the United States were excluded. The market penetration estimates given later in this study include only activity in the United States and its territories, such as Puerto Rico. They do not include any figures for BES export from the United States to foreign markets.

\section{Selection of Respondents}

SNL and Frost \& Sullivan decided through mutual consultation on the organizations to be contacted for this study. As stated earlier, these organizations included utilities, NUGs, BES suppliers, regulatory agencies, and other organizations whose actions influence the BES market. Table 1-1 shows the breakdown of the 68 organizations that were ultimately contacted. More specific information on the organizations included can be found in a later chapter of this report.

Table 1-2 shows the individuals contacted at electricity provider companies for this study by job title and type of electricity provider. Table 1-2 shows that the electricity provider sample is relatively "engineeringheavy." This is partly due to the nature of the interviewing process. Many of the electricity providers interviewed had existing contacts with SNL or the ESA, and these people provided the initial point of contact for Frost \& Sullivan in its research efforts. Because BES is a developing technology, and SNL is a research and development organization, most of these existing contacts tended to fit into technical vocations such as engineering.

Efforts were also made during the study to draw input from other departments within the electricity provider organizations. These contacts account for the number of planning and marketing personnel in the sample.

Table 1-1. BES Market: Organizations Contacted By Type (U.S.), 1996

\begin{tabular}{lc}
\hline \multicolumn{1}{c}{ Organization Type } & Number Contacted \\
\hline Electricity Providers & 38 \\
Investor-Owned Utilities (IOUs) & 24 \\
Independent Power Producers (IPPs) & 5 \\
Municipals & 2 \\
Cooperatives & 3 \\
Federal, State, or District Utilities & 4 \\
BES Suppliers & 11 \\
BES Consultants & 6 \\
Regulatory Bodies & 6 \\
Electric Power Industry Groups & 6 \\
TOTAL & 67
\end{tabular}




\section{Table 1-2. BES Market: Individuals Contacted by Utility Type and Job Title (U.S.), 1996}

\begin{tabular}{|c|c|c|}
\hline Utility & Job Title & Number Contacted \\
\hline IOUs: & $\begin{array}{l}\text { Chemist } \\
\text { Engineer } \\
\text { Engineer (Manager) } \\
\text { Engineer (Senior) } \\
\text { Engineer (Senior Research) } \\
\text { Integrated Resource Planner } \\
\text { Manager of Advanced Market } \\
\text { Development } \\
\text { Manager of Conservation } \\
\text { Power Quality } \\
\text { Product Development Manager } \\
\text { Technical Analyst Coordinator }\end{array}$ & $\begin{array}{l}\text { (1) } \\
(5) \\
(1) \\
(5) \\
(2) \\
(3) \\
(1) \\
(1) \\
(1) \\
(2) \\
(2)\end{array}$ \\
\hline Municipal Utilities: & $\begin{array}{l}\text { General Manager } \\
\text { Mechanical Engineering }\end{array}$ & $\begin{array}{l}\text { (1) } \\
\text { (1) }\end{array}$ \\
\hline $\begin{array}{l}\text { Electric } \\
\text { Cooperatives: }\end{array}$ & $\begin{array}{l}\text { Assistant Manager } \\
\text { Engineer } \\
\text { Engineer (Planning) }\end{array}$ & $\begin{array}{l}(1) \\
(1) \\
(1)\end{array}$ \\
\hline $\begin{array}{l}\text { Federal, State, and } \\
\text { District Utilities: }\end{array}$ & $\begin{array}{l}\text { Assistant Head, Planning and } \\
\text { Research Division } \\
\text { Engineer (Principal) } \\
\text { Manager of Electric Transporta- } \\
\text { tion } \\
\text { Project Specialist }\end{array}$ & $\begin{array}{l}(1) \\
(1) \\
(1) \\
(1)\end{array}$ \\
\hline IPPs: & $\begin{array}{l}\text { Director of Technology Re- } \\
\text { search and Development } \\
\text { Manager of Power Systems } \\
\text { Project Marketing Manager } \\
\text { Vice President }\end{array}$ & $\begin{array}{l}\text { (1) } \\
(1) \\
(1) \\
(1)\end{array}$ \\
\hline Power Marketer and IPP: & Development Director & (1) \\
\hline
\end{tabular}

\section{Surveying Process}

Frost \& Sullivan relies on primary research to gather the data for its reports. The BES study was no exception. This report was based on information gained from primary research contacts made during the surveying process or in other activities related to the production of the report. Secondary research of preexisting information sources provided little more than answers to technical questions related to BES and battery technologies.

Specifically, the surveying process for the study entailed Frost \& Sullivan analysts contacting organizations that had been placed on the contact list on the basis of consultations with SNL and the ESA. In the case of most of these companies, an initial individual contact had been identified based on that individual's past involvement with BES or with SNL.

Once contacted, these individuals were apprised of the nature of this study and asked who at their organization would be best able to provide a response that could be used in the preparation of this report. In many cases, the initial contact provided a response, but, in other cases, the contact referred the research team to another contact or group of contacts. This process continued until a viable respondent was reached at each organization. 
At this time, the respondent was faxed the proper questionnaire or interviewed over the telephone. Three basic questionnaires were developed, aimed at three distinct groups within the BES industry: BES suppliers and consultants, electricity providers, and regulatory bodies and industry groups. The questionnaires were developed by Frost \& Sullivan in conjunction with SNL.

\section{Writing and Analysis}

Upon receipt of the interview results, transcription of the results was performed if necessary. After transcription, the results were collated and analyzed by Frost \& Sullivan analysts. At that point, the writing of the report began.

\section{Assumptions and Risk Assess- ment}

All market research or forecast studies contain some form of assumption, whether implicit or explicit. These assumptions can have a dramatic effect on the outcome of a study.

Additionally, assumptions are affected by factors that are difficult or impossible to predict. In this report, these factors are referred to as "risk assessment" items. This section of the executive summary describes both the assumptions and the risk assessment items for this study.

\section{Economic Assumptions}

The three principal economic assumptions used in this study are that normal economic cycles will continue, normal load growth patterns will apply, and per-kilowatt $B E S$ costs will continue decreasing.

Frost \& Sullivan defines normal economic cycles as periods of economic expansion punctuated by occasional recessions or periods of stagnation. This is the historical pattern of the U.S. economy over the last 50 years, with expansions lasting 3 or more years and recessions lasting 18 or fewer months.

The second major assumption is the continuation of historical levels of load growth. In times of expansion, load growth is roughly $1.5 \%$ per year. If this number were to increase or decrease significantly, a corresponding effect on the need for BES would occur.
Decreasing per-kilowatt BES costs constitute the last major assumption of this report. This assumption is found in the parameters Frost \& Sullivan used to frame the questions asked in the electricity provider questionnaire found in Appendix A of this report. In short, Frost \& Sullivan and SNL expect the per-kilowatt price of BES to decrease in constant 1996 dollars from between $\$ 700$ and $\$ 1,100$ in 2000 to between $\$ 400$ and $\$ 600$ in 2010 .

Not every organization in the BES industry agrees with this assumption. However, during the course of the study, Frost \& Sullivan found evidence that price reductions of this magnitude are already under way.

\section{Deregulation of the Electric Power Industry}

The biggest variable affecting the electric power industry in the United States is the advent of deregulation. Currently, deregulation is occurring in isolated states with high electric costs. Even though some of these states are very large, most of the U.S. electricity market is still regulated.

This may change rapidly. Not only are individual states in the United States examining deregulation, but national deregulation bills have been introduced in the U.S. Congress. If pending national legislation were passed, the entire U.S. electric power market would be deregulated by 2003 .

The effects of deregulation depend on many variables, including the recovery of stranded costs and the success the current group of electricity providers has in making the transition into a deregulated environment. The outcome of these issues should influence the BES market in the new deregulated environment.

Frost \& Sullivan received much conflicting information on the specific effects of deregulation on the BES market. Some respondents said that deregulation would force expensive BES systems out of the market. Others stated that a greater appreciation for customer service and storage-based economic opportunities would enhance BES's attractiveness.

\section{Network Reliability}

Another impact of deregulation has been the concern over the reliability of the transmission and distribution grid in the United States. Two serious disruptions of the western grid in the summer and fall of 
1996 caused significant economic side effects and raised some public safety concerns. Fortunately, the worst of these disruptions happened on a weekend, which reduced the potential losses and associated risks.

If disruptions continue or increase, more pressure will likely be placed on electricity end users and providers to implement technologies to improve power quality. In such a case, BES demand will likely increase to meet power quality needs.

\section{Electricity End-User Markets}

As previously stated, electricity end-user markets were not included in this study. Despite this exclusion, BES suppliers view electricity end users as their major existing market. To reflect this, Frost \& Sullivan incorporated BES supplier estimates of the enduser market into the market penetration estimates found in the Market Opportunities and Forecasts section of this report.

\section{Summary of Major Findings}

\section{Perceptions of BES}

The perceptions of the present and future roles for BES differ significantly depending on the group or organization. This section covers the various perspectives provided by the three distinct BES industry groups surveyed for this study: electricity providers, BES suppliers and consultants, and industry groups and regulators.

\section{Electricity Provider Perspective}

The electricity providers' perspective can be best categorized as cautiously optimistic. On the whole; electricity providers see roles for BES, especially in distributed generation and power quality, but they expressed significant concerns about BES costs, life span, maintenance, and energy density.

In the future, electricity providers expect to increase their use of BES, but they would like to see the shortcomings of the technology addressed and believe this is necessary before widespread deployment of BES becomes possible. As a result of concerns about the technology's shortcomings, BES is not currently viewed as competitive with most generation technologies. In particular, electricity providers expect combustion turbines to provide better functionality over time than BES. Interest in fuel cells was high, and batteries received considerable support because of their modularity, responsiveness, and especially their environmental friendliness.

BES fares favorably when compared with most planned and existing storage technologies, although it is not viewed by the sample as a central station technology. Central station storage technologies, such as pumped hydro and compressed air energy storage (CAES), were viewed as too environmentally destructive or too geographically limited. However, respondents with existing pumped hydro units do not see BES replacing those units. Also, some electricity providers viewed their current amount of storage as adequate because of their existing pumped hydro resources.

Compared with advanced storage technologies, BES is viewed favorably as well. BES has a greater storage capacity in terms of hours of storage than superconducting magnetic energy storage (SMES) or flywheels. SMES and flywheels are also less developed than BES, making potential customers more hesitant to support these technologies. Some electricity providers in the sample, however, viewed flywheels as a lower-cost option over the Iong term.

During the survey process, respondents were questioned four times on the potential applications for which they might use BES. Table 1-3 and Figure 1-1 illustrate some of the responses to this question. The responses are arranged alphabetically in the figure, but an examination of the chart shows that power quality and reliability were the most commonly cited applications for BES.

Additionally, electricity providers were asked about the use of BES to provide the ancillary services necessary to maintain power system reliability on an ongoing basis. However, no significant responses were received on this subject. Deregulation appears to not have advanced enough to create more than an academic interest in the provision of ancillary services. Furthermore, a few respondents seemed to feel that the provision of these services has never been a problem in the past and is unlikely to become so in the future. 
Table 1-3. Applications Identified by Electricity Providers (30 Companies), 1996

\begin{tabular}{lc}
\hline \multicolumn{1}{c}{ Application } & $\begin{array}{c}\text { Times Application } \\
\text { Mentioned }\end{array}$ \\
\hline Area/Frequency Control & 3 \\
Black Start & 1 \\
Customer Demand Peak Reduction & 5 \\
Distribution Facility Deferral & 6 \\
Emergency Shutdown Power & 1 \\
Frequency Control & 1 \\
Frequency Regulation & 2 \\
Generation Capacity Deferral & 5 \\
Generation Dispatching & 4 \\
Load Conditioning & 1 \\
Load Following & 1 \\
Load Leveling & 10 \\
Out of Step Prevention & 1 \\
Peak Reduction & 2 \\
Power Quality & 14 \\
Reliability & 12 \\
Renewables & 5 \\
Spinning Reserve & 8 \\
Transmission Facility Deferral & 5 \\
Transmission Line Stability & 2 \\
Transmission Stability Enhancement & 2 \\
Transmission Volt-Amp Reactive (VAR) & 2 \\
Support & \\
Uninterruptible Power Supply (UPS) & 10 \\
Voltage Regulation & 7
\end{tabular}

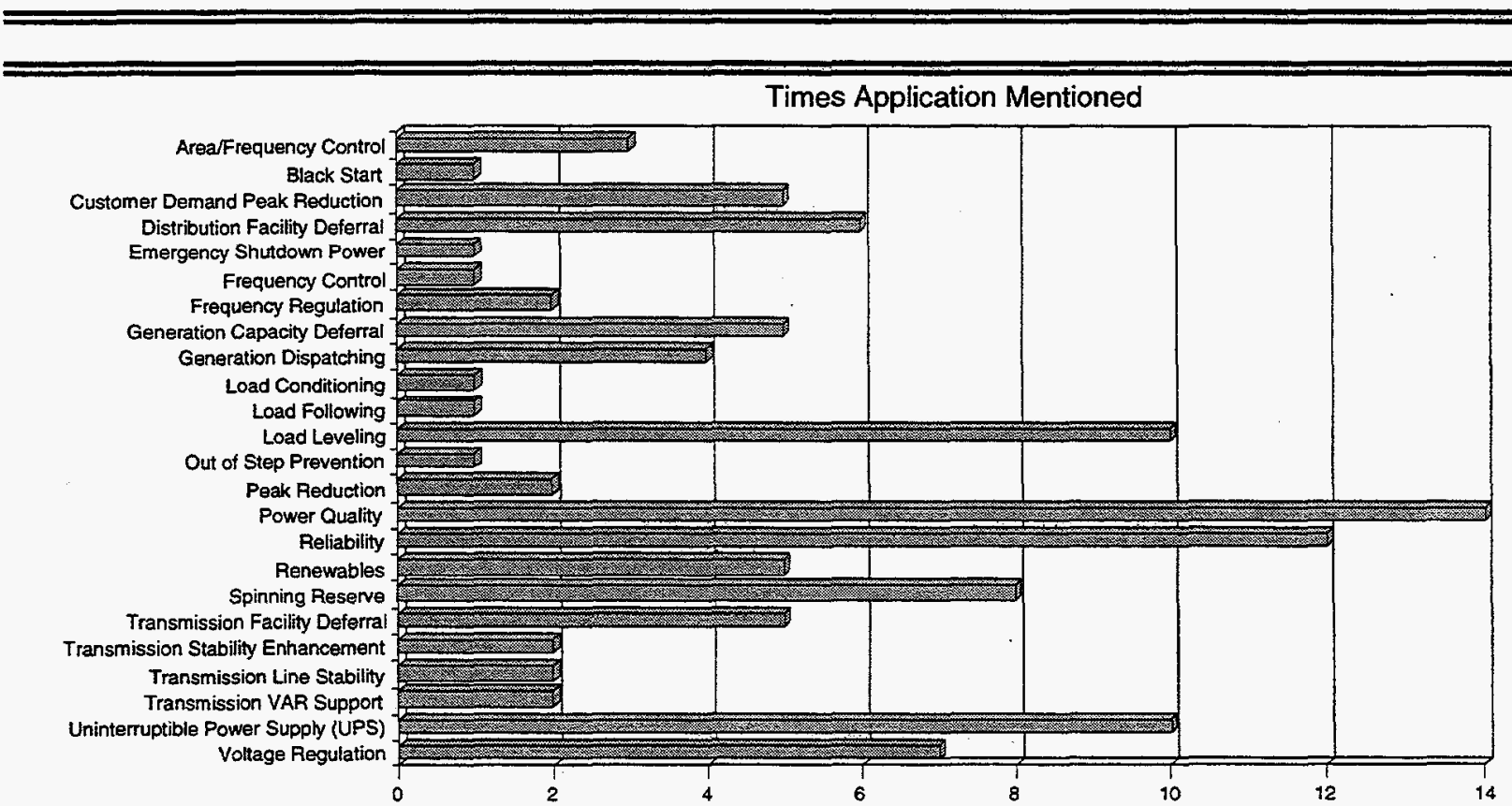

Figure 1-1. Applications Identified by Electricity Providers (30 Companies), 1996. 
The final issue addressed was that of organizational structure and BES procurement. Respondents were asked which departments within their organizations were responsible for BES procurement. The results are as follows:

- Investor-Owned Utilities (IOUs):

- Generation

- Energy Supply Planning

- Financial Studies

- Fossil Generation

- Fossil/Hydro

- Integrated Resource Planning

- Mechanical Engineering

- Power Supply Planning

- $\quad$ Research and Development (R\&D)

- Transmission and Distribution

- Customer Services

- Distribution Engineering

- Energy Services Company (ESCO) (for pertinent IOU)

- Engineering

- Grid Customer Services

- Marketing Commercia//Industrial Departments

- Substation Engineering

- Technical and Construction Services

- Transmission and Distribution (T\&D)

- Transmission Engineering

- Municipal Utilities:

- Board of Directors

- Bulk Power Business Unit

- City Council

- Generation Business Unit

- Electric Cooperatives:

- Board of Directors

- Engineering

- General Management

- Production

- Federal, State, and District Utilities:

- Distribution Planning

- Operations and Finance Senior Executives

- Planning

- Planning and Research Division

- Power Operations

- Power Quality

- R\&D

- Transmission and Power Supply
- Independent Power Producers (IPPs):

- Executive Department

- Contracts Department

- Power Marketer and IPP:

- Development Department

- Engineering Department

Respondents were also asked how deregulation of their utility might affect departmental responsibilities for BES procurement. Responses indicated much interest in deregulation as an economic event but showed little appreciation or awareness of possible organizational changes that might result.

\section{BES Supplier Perspective}

In addition to electricity providers, BES suppliers and consultants working in the BES industry were contacted to obtain their views on the BES market. In particular, they were questioned on their view of existing BES projects and which markets they serve.

Currently, BES products in the marketplace are based on either flooded lead-acid or valve-regulated leadacid battery technologies. In the near future, through 2000 , most BES suppliers do not expect to move to different battery technologies, although they expect to further refine their power conversion technologies.

Also, no true BES integrators currently exist in the marketplace. This is a disadvantage because it places more pressure on BES customers to obtain the integration services they need or perform them in-house. Few BES suppliers contacted in this study believed they would make the transition to full-service integrator by 2000 . Instead, most companies viewed themselves as suppliers of components or developers of BES technologies.

The competitive structure of the BES industry is fairly rigid. Most of the BES suppliers contacted were divisions, subsidiaries, or business units of large battery and electrotechnology manufacturers. As such, these organizations have a great deal of potential resources behind them although they do not operate in a core business of their parent organization.

The remaining small, independent companies are technology developers, not BES suppliers. These companies are not marketing organizations and do not maintain extensive contacts with potential BES customers. 
Supplier and consultant perceptions of the BES market were mixed. Depending on the organization contacted, perceptions of the market varied from fairly positive to very negative. Patterns were difficult to detect, although BES manufacturers were more positive about the industry than most consulting organizations.

Perceptions of BES technology also varied widely between those that felt that existing BES technology was adequate and those that felt it was inadequate. As expected, those that supported existing BES technology tended to be organizations that were not aggressively developing advanced batteries and power conditioning equipment. Most respondents agreed that further advances in power conditioning and utility connection equipment could be made.

BES suppliers and consultants also provided Frost \& Sullivan with their estimates of the BES market in 2000,2005 , and 2010. These estimates are discussed in more detail in the Market Opportunities and Forecasts section of this report.

\section{Other Industry Perspectives}

Regulatory agencies and industry groups provided the other industry perspectives in this study. Input from both types of organizations provides important supporting information to the conclusions reached in this study.

The responses received from regulatory agencies indicate that they do not have an established position on BES. Regulatory agencies receive little information or feedback from utilities, BES suppliers, or other organizations and do not view BES as a major issue. When they do receive information, it is primarily about combustion turbine and renewable technologies.

Moreover, the regulatory agencies stated that as the power industry deregulates, they will likely stop supporting BES technology to the extent that they have in the past. They will probably hesitate in the future to encourage utilities to deploy specific technologies and participate in particular programs. Instead, market-based solutions focusing on economic costs and benefits will likely prevail, and the prospects of regulatory agencies using their influence to champion BES deployment are minimal.

The other industry groups that Frost \& Sullivan contacted during this study were various organizations with an interest in the electric power industry and the use of BES. Examples of such organizations are the National Rural Electric Cooperative Association, the Environmental Defense Fund, and the National Association of Utility Regulatory Commissioners. These industry groups had more specific perceptions of BES than the regulatory agencies.

Many of the groups viewed BES as an important enabling technology to facilitate the use of renewable energy or to solve power quality and asset utilization issues. These groups tended to be more focused on BES and maintained personnel that attempted to keep track of developments in BES markets and technologies.

\section{BES Market Opportunities and Fore- casts}

\section{BES Market Definitions}

As stated earlier, this report was restricted to a study of the U.S. market for BES. For purposes of this study, the U.S. market consists of the 50 states and Puerto Rico. In addition, this is a study of the BES market among electricity providers, with information on electricity end-user BES markets provided by BES suppliers and consultants.

In all, 21 electricity providers returned enough information for Frost \& Sullivan to use their responses in estimating BES market penetration and activity in 2000,2005 , and 2010 . These 21 electricity providers represent between 27 and 33 percent of the U.S. electric power industry's 1994 capacity in terms of megawatt-hours sold, megawatt-hours generated, revenues from electricity sales, and generating capacity. Thus, even though the number of utilities may seem small compared to the industry as a whole, these companies make up a large proportion of the U.S. electric power industry.

The responses from the 21 utilities were compiled and extrapolated to the U.S. industry as a whole. The extrapolation used a formula based on the percentages of industry output and capacity. These results were then deflated to counteract the natural tendency of respondents to exaggerate future behavior. Such exaggeration has been encountered by Frost \& Sullivan in the past and is especially prevalent in studies such as this, with long forecast periods.

A similar extrapolation method was used to compile the electricity end-user BES demand estimates that Frost \& Sullivan received from BES suppliers and 
consultants. These figures are presented with the electricity provider estimates (Tables $1-4$ and 1-5) to give a clearer picture of the entire BES market in a given year.

\section{BES Market Penetration Estimates}

Table 1-4 shows the estimated penetration of BES in the electricity provider industry. Sales are projected to climb from about $\$ 24$ million in 2000 to about $\$ 287$ million in 2010.

Table 1-5 shows the estimated penetration of BES for electricity end-users. These results are based on projections given to Frost \& Sullivan by BES suppliers. BES revenues in this segment are forecast to be about $\$ 372$ million in 2000 and about $\$ 434$ million in 2010 .

\section{Primary Market Drivers}

The principal drivers of the growth anticipated in BES market penetration among electricity providers and end users include the following:

- Power quality

- Distributed generation

- Technological advances in BES
- Improving customer focus of electricity providers

- Environmental benefits of BES

- Fuel supply issues

- Increasing use of renewables

Power quality was already identified by respondents as the major application for BES. This application will probably become even more important as electronics are increasingly used in businesses and global competition places a greater emphasis on avoiding downtime. BES is already used in this application in the form of existing uninterruptible power supply (UPS) systems and serial power systems.

Distributed generation is another driver of the BES market. BES's modularity makes it more appropriate for deployment in distributed sites. Although not many distributed generation projects are currently being conducted, the number of these projects should increase in the future.

Respondents expect technological advances to occur in BES. Addressing some or all of the technology's current shortcomings should make BES more attractive compared to other options.

\section{Table 1-4. BES Market Predictions by Electricity Providers (U.S.), 2000, 2005, and 2010}

\begin{tabular}{ccc}
\hline Year & MW & (\$ Million) \\
\hline 2000 & 27 & 24 \\
2005 & 215 & 129 \\
2010 & 573 & 287 \\
\hline Note: All figures are rounded. & \\
\hline
\end{tabular}

\section{Table 1-5. BES Market Predictions by BES \\ Suppliers and Consultants for Electricity End Users (U.S.), 2000, 2005, and 2010}

\begin{tabular}{ccc}
\hline Year & MW & (\$ Million) \\
\hline 2000 & 496 & 372 \\
2005 & 805 & 443 \\
2010 & 965 & 434 \\
\hline Note: All figures are rounded. & \\
\hline
\end{tabular}


Currently, most electricity providers function in a regulated monopoly environment in which customers are allotted by geographic location. This is different from the future deregulated environment, where electricity providers will probably have to be more customer-focused to survive. This customer focus should include efforts to address local power quality and reliability issues, areas in which BES can serve a constructive role.

BES is a technology that does not produce noise or harmful emissions. It can be used in settings and environments where current generation technologies would be difficult or impossible to site. Electricity providers cited these benefits as some of the major advantages of BES.

Another advantage of BES cited by electricity providers is the elimination of fuel supply issues associated with generation technologies. This is because BES, by definition, does not require fuel.

Growth in the use of renewable energy should also drive the BES market. BES can be used in conjunction with renewable energy sources to "firm" electric power delivery from these sources. For example, BES could store power generated from solar generation to maintain a constant power output even at night.

\section{Conclusions and Recommen- dations}

\section{Conclusions}

Frost \& Sullivan has based the following conclusions on the responses obtained from organizations and individuals interviewed for this study and from interactions with the BES community related to this study.

\section{BES Cost Reductions Desired}

The first and foremost conclusion of this study is that an overwhelming consensus exists among the electricity providers surveyed that significant reductions in BES costs are needed.

In particular, issues pertaining to the capital cost of BES are considered paramount. Currently available per-kilowatt BES costs run two to three times the perkilowatt cost of combustion turbines. Although the two technologies are not directly comparable, they are similar enough in the minds of electricity provid- ers that the disparity in cost reduces market interest in deploying BES systems.

Maintenance costs are also of interest to electricity providers. These costs include not only the actual costs of maintaining a BES system but the perceived costs as well. These perceived costs can best be thought of as the "headaches" that respondents expect from a BES system. For example, several electricity providers said in their responses that even though the organizations had no direct experience with BES, they had heard that the maintenance issues associated with maintaining the batteries in a BES system made the cost prohibitive.

As stated earlier, significant BES cost reductions are one of the assumptions of this study. Although a large proportion of the BES supplier community does not share SNL's expectation that these cost reductions can be realistically delivered, evidence uncovered in the study indicates that significant downward pressure on BES prices has already begun.

\section{BES Performance Improvements Desired}

The results of the survey also show that electricity providers desire improvements in BES energy density, maintenance characteristics, and life span.

These technical issues are secondary to BES cost issues, although they are important in their own right. Energy density affects capital cost and the use of BES in some applications and sites. Maintenance issues center on improvements in BES battery technology. To better offset high capital costs and be more competitive with other distributed generation technologies, current expected BES life spans of 6 to $10 \mathrm{yr}$ must be improved.

\section{BES Market Targeting and Segmentation}

Results of this study indicate that potential BES markets are not currently targeted or segmented. This affects both product and technology development. The BES industry seems to be trying to develop BES markets across a wide range of applications even though markets may not actually exist.

The area of ancillary services demonstrates this dynamic. Responses to queries about the need for BES in ancillary services indicate that the electricity provider sample views ancillary services neither as an area of concern nor as a potential market for BES. Almost no feedback was received from electricity providers on ancillary services, even when they were 
directly questioned on the subject. Despite this, the BES community is expending considerable intellectual energy on this area.

Despite the lack of responses, it cannot be assumed that utilities have not given any thought to the ancillary services issue. This is especially true given that many of the electricity providers surveyed are industry leaders within the U.S. electric power industry. As such, their opinions on this subject are likely based on sound data and cannot be dismissed.

On the product side, the lack of targeting spreads BES marketing efforts thinly over a broad array of applications and prevents BES from better penetrating applications where it has been more successful. The only truly targeted product available in the BES market is AC Battery's PQ2000 system, designed to provide cheap, short-term, backup power to ride customers through a 10 - to 15 -second outage. Other products still suffer from trying to be all things to all people, therefore pleasing nobody.

\section{BES Educational Efforts}

Despite the fact that this study concentrated on electricity providers, organizations, and individuals with past involvement in BES projects or forums, the survey of the BES-related educational level of the organizations revealed that respondents were not entirely knowledgeable on recent developments in BES.

An example of the level of education is shown by the high number of individuals that mentioned load leveling as a BES application in Table 1-3. Studies conducted over the past several years have shown that load leveling is a marginal BES application at best. Clearly, educational efforts within the BES community must be enhanced.

\section{Bias Toward Generation Technologies}

A significant bias toward generation technologies was also found within the electricity provider industry. Often, respondents made comments that equated BES to generation technologies, usually leading to negative perceptions of BES compared to these technologies. In reality, BES is not a generation technology but a complementary storage technology. This bias toward generation technology is largely an educational issue. However, other dynamics are at work.

Electricity providers were questioned on what their preferred electricity supply options might be in the future and what would happen if BES were to match the cost of these preferred options. Even in this situation, some respondents stated that they would continue to favor more "familiar" options over BES. However, other respondents expressed a dramatically heightened interest in BES under such circumstances.

\section{Organizational Obstacles to BES Procure- ment}

The organizational structures of both electricity providers and BES suppliers create some barriers to BES market penetration.

On the utility side, the need to coordinate and fund BES purchases among disparate customer service, transmission, distribution, generation, and engineering business functions creates serious problems for BES manufacturers and technology developers. Developers and suppliers must identify and contact key decision makers and then develop and maintain relations over the sales or development cycle. These are extremely difficult tasks given the opaque nature of many utility organizations.

On the BES supplier side, the existing group of suppliers is largely made up of large battery and electrotechnology companies that receive a minute portion of their revenues from the BES market. The BES units of these companies compete for resources with other company units that are more related to the core business of those firms. This makes large BES development expenditures difficult to justify and leads to a situation in which BES suppliers try to make existing products and technologies fit the new BES market, often without success.

\section{Communications in the BES Industry}

The results of this study indicate that communications within the BES industry are inadequate on several levels. Specifically, the low level of BES knowledge and education exhibited in many of the responses gathered during this study shows that educational communications within the BES community need to be improved.

Also, significant impediments to clear and understandable communication between BES suppliers and developers and electricity providers exist. This is probably more important than the educational issue because it significantly affects the fundamental way in which many industry parties relate to and perceive each other. These communications difficulties may 
be hindering the proper development of the BES market.

\section{Need More BES Innovation}

The BES industry suffers from a lack of innovation in terms of products, marketing, communications, educational efforts, and technology. Results of this study show that marketing and product development efforts need to be more tightly focused; educational and communications efforts need to be expanded and improved; and new technologies need to be developed, especially on the battery side of the industry.

Some BES projects have been successful. The Puerto Rico Electric Power Authority (PREPA) system is foremost.among them. The PREPA system was chosen over combustion turbines, which seem to be the greatest threat to BES's success. However, even in the PREPA case, the utility itself had to perform the project integration, using equipment from several manufacturers, including some that will not offer those products in the future.

The result is a successful system, but one that no BES supplier is likely to provide to customers. Because nobody but PREPA has "ownership" of the product in use at PREPA, no organization is marketing it. This is the case even though the PREPA frequency regulation/spinning-reserve application is one that many utilities in the United States need and might be interested in.

Both SNL and the ESA are being more aggressive in expanding their industry outreach for both communications and educational efforts. BES prices are falling, and some promising developments in various advanced battery technologies have been made. More effort must be undertaken, but progress is being made on many fronts.

\section{Recommendations}

\section{Improving BES Economics, Storage, and En- ergy Density}

Listed in this section are the major issues that electricity providers raised when discussing their misgivings about BES. Frost \& Sullivan recommends that every effort be made to upgrade battery performance in terms of hours of storage and energy density. Also, reducing capital and maintenance costs is a major issue that should affect BES purchases at the utility level. Applications for current BES technology exist, but the costs are too high to take advantage of most of them. Frost \& Sullivan expects that meeting the full demands of the electricity provider industry will probably entail developing a new generation of BES technologies. Therefore, BES developers and suppliers should examine the feasibility of such development and whether they want to be a part of such an effort.

\section{Improving Communications Within the BES Community}

The previously discussed communications problems within the BES industry are complex and stem from the rivalry between various vendors and developers and the technologies they are backing. Also contributing to some of these problems are the nature and organization of the utility industry and of BES suppliers.

While realizing the constraints, Frost \& Sullivan recommends that SNL make greater efforts to expand the level of communication within the industry and discourage some of the dissonance and acrimony occurring in some parts. With a developing technology such as BES, the dissonant environment may confuse and alienate potential customers and other important parties.

\section{Strengthening Industry Partnerships}

Frost \& Sullivan recommends that SNL strengthen its industry partnerships to achieve the long-term goals that SNL has identified for itself. Past BES projects have been affected by the partners having incompatible or unidentified goals.

The decommissioning of Southern California Edison's (SCE's) Chino facility left much of the electricity provider industry with a negative perception of BES. Had greater efforts been made to synchronize goals among the various parties with stakes in the Chino facility, the results might have been more positive for the BES industry.

In the future, Frost \& Sullivan recommends that SNL spend more time and effort identifying and synchronizing its goals with those of its partners. This should limit some of the negative consequences stemming from projects such as the Chino project. 


\section{Focusing on BES Applications and Product Development}

Current BES marketing and development efforts are too broad in focus. Marketing and development need to be more narrowly focused to gain better efficiencies and produce better results. Frost \& Sullivan recommends that SNL accurately identify the applications that need to be served by BES and develop technologies and programs needed to serve those applications. In addition, SNL should select and encourage partners to take advantage of those technologies and programs in the development of focused products for the BES industry.

\section{Performing Additional Market Research}

Commercializing a developing technology is difficult. In the case of BES, this difficulty is heightened by the turmoil within the U.S. electric power industry and the pressure for results that many important BES research and development organizations, including SNL, are experiencing. Given these factors, Frost \& Sullivan recommends that SNL and its partners perform additional research to understand the market.

The following topics seem promising areas for market research:

- BES demand in electric cooperatives

- BES demand among electricity end users
- Identification of high-priority BES applications

- Identification of project opportunities for the placement of BES systems

- Identification of key decision makers at target companies

- Identification of desired BES product features

In particular, the studies of the electricity end user and possibly the cooperative markets appear to be valuable. However, there also appears to be no shortage of potential research topics.

\section{Market Summary}

The BES market is currently developmental, and because of the factors that have been discussed in this executive summary, the industry faces significant challenges. Nonetheless, the results of this study indicate that a market for BES at the electricity provider level does exist. This market is currently selfperpetuating at the national level, but at a lower than desired level of activity.

Projects such as those currently in place or planned in Puerto Rico and Alaska should continue into the foreseeable future. With the development of better BES technologies and the resolution of concerns and issues, the BES market has the potential to be significantly larger. 
Intentionally Left Blank

$1-14$ 


\section{Battery Energy Storage Industry Overview}

\section{Project History}

In March of 1996, Frost \& Sullivan contracted with SNL to perform a market feasibility study on BES. The goal of this study was to determine the market for BES in the U.S. electricity provider industry. This market measurement was made for the years 2000 , 2005 , and 2010. The study also gathered industry perspectives on the development, competitiveness, deployment, and applications of BES.

The nature of the study was defined by the resources available, and it was decided not to devote any research effort to studying the potential market for BES at the electricity end-user point-of-use level. At this level of the BES market, UPS applications predominate, although customer demand peak shaving is also a possible application.

The ultimate goal of the study is to guide the DOE and SNL in their research into BES technologies. Currently, SNL's ability to support BES research is being reduced by budgetary pressures, necessitating market research both to identify research priorities and to justify increased investment in BES research.

\section{The Current BES Market}

As of the summer of 1996, four major BES projects were in operation in the United States and Puerto Rico, with an additional project being installed in Metlakatla, Alaska. The four operational BES projects, in the order in which they were installed, and the organizations using them are listed below:

- Crescent Electric Membership Cooperative (EMC)

- Delphi (formerly Delco), Muncie, Indiana

- PREPA

- GNB Resource Recovery, Vernon Facility

SCE's project in Chino, California, was decommissioned in mid 1996 after eight years of operation. San Diego Gas \& Electric Company decommissioned its small BES demonstration system in 1995.
The BES industry is emerging from the developmental stages of BES technology to a product commercialization stage. Evidence is mounting that BES technology will likely be commercially successful in electricity end-user applications. As of the fall of 1996, AC Battery was tracking nine projects for its PQ2000 product, and GNB/General Electric is pursuing commercialization of its system, as are other BES system vendors.

At the utility and power producer level, the future of BES is a little more mixed. The management at PREPA is very pleased with the operation of its 20-MW system, installed in late 1994. PREPA plans to acquire more systems in the future but must wait until after 2000 because of the need to add new generating capacity in the interim. Other utilities with specialized geographic needs, such as Metlakatla Power \& Light and Golden Valley Electric Association, are purchasing systems, but the number of utilities with similar needs is low within the highly interconnected grid of the lower 48 contiguous states.

Currently the majority of the utility and power producer industry views BES as having several crucial shortcomings: high capital cost, comparatively short lifespan, low energy density, and maintenance concerns. However, they also cite several potential strengths that BES possesses, including operational flexibility, favorable environmental characteristics, and modular construction.

The current market conditions strongly indicate that for the present, very little BES is going to be deployed at the utility level. Other technologies provide many of the same applications that BES can and at a lower price and with a longer lifespan.

\section{The Future BES Market}

Responses gathered from the surveys show that utilities and electricity providers maintain a distinct interest in distributed generation technologies. Greater competition for customers, congested T\&D corridors, more favorable distributed generation economics, and increasing power quality concerns are all factors pushing the electric power industry in this direction. 
Responses also indicate that electricity providers do not view BES as being competitive in central station applications. In such applications, other storage technologies-such as pumped hydro and compressed-air energy storage-are preferred.

These results indicate the best hope for BES at the utility level is the advent of widespread distributed generation. Currently, there is a great deal of interest in the concept of distributed generation among utilities and power producers, but plans for large-scale use of distributed generation are still in the formative stage. Eventually, as distributed generation technologies become more polished and plans are better developed, rapid growth in the deployment of distributed generation will likely occur.

Distributed generation's reliance on small, dispersed power plants located at or near load centers is what makes BES a potentially valuable distributed generation technology. Since most load centers are in densely populated areas, the use of technologies such as diesel generating sets and microturbines can create noise and air pollution problems. BES has neither of these disadvantages.

BES also benefits from its modular construction and operational flexibility. BES systems are already in development for use in shaving peak loads at overloaded substations. These systems might eventually be moved from substation to substation as needed, relieving system bottlenecks and deferring expensive substation and distribution upgrades. The operational flexibility of BES allows it to respond with extreme rapidity to sudden spikes and dips in local load, usually created by industrial customers using machinery and manufacturing processes.

Another possible future BES market is the use of BES in conjunction with renewable energy sources, such as wind power and photovoltaics. A characteristic of renewable sources is their lack of predictable availability at any given time. BES can be applied to store energy from renewable sources during periods when conditions favor production, then dispatching the stored electricity at periods when it is needed. In this mode, BES can significantly increase the value of renewable energy resources.

\section{Existing BES Technologies}

At the request of SNL, the battery technologies that were covered by this study were limited to four battery chemistries; flooded lead-acid, valve-regulated lead-acid (VRLA), sodium/sulfur and zinc/bromine. Each of these technologies has particular strengths and weaknesses, but only the two lead-acid technologies are currently available in the BES marketplace. The zinc/bromine and sodium/sulfur technologies are still under development.

Flooded lead-acid batteries are by far the most developed of existing battery technologies. Basically, this battery technology is the large-scale application of a technology similar to that found in automobile batteries. While flooded lead-acid batteries are manufactured in large numbers for many uses, and their operating characteristics and technology are well understood by both manufacturers and users, they have several key limitations.

The first of these limitations is that some flooded lead-acid batteries require relatively frequent maintenance to replace water lost in operation. This reduces the economic benefits of using flooded lead-acid batteries. The second significant limitation is that flooded lead-acid batteries are relatively expensive compared to other nonstorage options.

This would not be a major concern if flooded leadacid technology were more developmental, like the other battery technologies discussed in this section. Developmental technologies usually experience dramatic decreases in price as demand, production infrastructure, and production know-how rise. However, flooded lead-acid batteries have been in widespread production and use for so long that further reduction in battery cost because of improvements in these areas is unlikely to occur.

Also, because of their use of lead, flooded lead-acid batteries are extremely heavy. This reduces their portability and increases construction costs for the foundation and pad that the BES system must be placed on.

The strengths of flooded lead-acid batteries center around their relatively long life span and the familiarity of the technology. This allows flooded lead-acid customers to better justify their acquisitions and amortize the cost of their BES systems over a longer period. All of the existing BES projects in the U.S. have used flooded lead-acid technology, with the exception of the most recent GNB facility in Vernon, California, which uses VRLA.

The second most developed BES technology is oxygen-recombinant VRLA. VRLAs use the same basic electrolytic technology as flooded lead-acid batteries, 
but these batteries are sealed with a valve and the acid electrolyte is immobilized. This eliminates the need to add water to the cells to keep the electrolyte functioning properly or to mix the electrolyte to prevent stratification. The oxygen recombination and the valves of VRLAs prevent the venting of hydrogen gas and the ingress of air into the cells.

VRLA is currently a relatively expensive technology, costing significantly more than flooded lead-acid. Also, VRLA's expected lifespan is shorter than the expected lifespan of a flooded battery, further increasing the levelized cost of the system. However, advances are being made in both of these areas as VRLA technology improves and becomes better understood.

VRLA's major advantage over flooded lead-acid cells is the dramatic reduction in the maintenance that is necessary to keep the battery in operation. Also, VRLA cells are smaller than flooded cells, reducing the size and weight of the battery, although VRLAbased systems are not portable.

Sodium/sulfur batteries were at one time a major battery technology for BES applications. However, $B E S$ vendors no longer view sodium/sulfur batteries as a feasible battery storage option. Sodium/sulfur batteries rely on sealed unipolar cells that are combined into modules that are then combined into a battery. These cells must be hermetically sealed, because sodium/sulfur batteries must operate at an internal temperature of 320 to $360^{\circ} \mathrm{C}$ for optimal efficiency.

Sodium/sulfur batteries are transportable, have a high energy (charging) efficiency, and can operate very flexibly. However, the thermal management problems of keeping the battery at the correct operating temperature can be severe if the battery is not operated frequently. If the battery is operated at a low temperature (below $250^{\circ} \mathrm{C}$ ), sodium/sulfur batteries are susceptible to damage. Also, because the battery cells are hermetically sealed, it is impossible to service individual cells without shutting down the entire module.

Zinc/bromine batteries are the last of the four major BES technologies. Zinc/bromine batteries use a flowing aqueous zinc bromide electrolyte with zinc and bromine as the active materials. During charging the zinc bromide is electrolyzed, with metallic zinc being deposited on the negative electrode, while the bromine produced at the positive is stored in external tanks.

The advantages of zinc/bromine battery technology center around four areas: low cost, modularity, transportability, and flexible operation.

Some experts think zinc/bromine batteries will be the easiest of the battery technologies to produce. $\mathrm{Be}$ cause of the nature of the reactants and the lack of a high operating temperature, cells can be constructed from molded plastic and carbon materials. There is every reason to believe that once production of zinc/bromine batteries is perfected, production costs for this technology will be the lowest of any of the four BES battery technologies being discussed in this section.

Zinc/bromine batteries are also very modular in construction and maintenance and are highly transportable. These attributes should make zinc/bromine batteries well-suited for transmission and distribution deferral applications, where batteries might be transported from substation to substation or load center in order to provide the local capacity needed to defer expensive $T \& D$ upgrades. The modular nature of zinc/bromine batteries also significantly eases maintenance of the individual battery modules.

Another major advantage of zinc/bromine batteries is their flexibility. Zinc/bromine batteries can be discharged completely without damaging the cells. This gives zinc bromide cells a decided advantage over the lead-acid technologies.

The major disadvantages of zinc/bromine batteries center around the maintenance requirements, including upkeep of pumps needed to circulate the electrolyte, and the low electrical efficiency. Also, the zinc deposited on the electrode during the charging process must be completely removed periodically.

In short, the battery technologies covered in this study fall into two categories: first-generation BES technologies that in a utility system would be restricted to niche roles, or second-generation technologies that are in need of further development before commercialization. However, survey results do indicate that there is a viable role and market for BES in the electric power industry. Current shortcomings of available battery and BES technologies must be resolved to reach this viable market. 
Intentionally Left Blank

$2-4$ 


\section{Market Definitions and Methodology}

\section{Market Definitions}

The central purpose of this study is to quantify the U.S. grid-connected BES market in the years 2000 , 2005 , and 2010. This long forecast period was chosen in order to provide SNL with time to adjust its long-term research efforts to meet the projected needs of the BES industry.

The market quantification is to be provided both in terms of megawatts of BES capacity and in terms of dollar value. Consideration was given to quantifying the number of hours of storage capacity, but surveying energy provider personnel in these terms over such a long forecast period was felt to be too imprecise.

For purposes of this study, the United States market is made up of the 50 states of the United States and the island of Puerto Rico. Puerto Rico was included because of its unique role in the BES market-it is currently home to the highest-power BES facility in the world. The U.S. market figures presented include purchases of BES within the United States but do not include any estimates of exports of BES products from the United States to other nations.

\section{Market Feasibility Study Con- tact List and Methodology}

This study is the product of primary research conducted on several different classes of organizations, all of which are important members of the electric power industry and are expected to have a significant impact on the BES market. In total, 67 organizations provided responses for this study. The types of organizations responding included:

- BES suppliers

- Consultants

- Electric utilities

- Energy industry advocates

- IPPs

- Power marketers

- Professional and trade organizations
- Regulatory bodies

For purposes of this study, the electric utilities, IPPs, and power marketers were combined into one group, titled "energy providers," and were surveyed using a questionnaire geared towards their particular role in the BES market (see Appendix A).

Consultant and BES supplier organizations were also surveyed using a second questionnaire (see Appendix B) designed to gather their perspectives on the BES market. Similarly, energy industry advocates, regulatory bodies, and professional and trade organizations were surveyed using a separate questionnaire to gather their input on BES (see Appendix C).

Most of these surveys were prequalified in advance of the actual interview/data gathering process. Contacts at target organizations were contacted to determine their role in promoting or procuring BES systems or were identified in advance through industry organizations.

At the energy provider level, the types of personnel contacted varied quite widely. This approach was taken to solicit new viewpoints about BES other than those from the research and development staff personnel that have traditionally made up the core of the electricity provider customer base for BES information dissemination.

Personnel contacted for this study worked in areas such as:

- Resource planning

- Generation planning

- Transmission and distribution planning

- Transmission and distribution engineering

- Senior and line management

- Power quality

- Marketing

- Conservation and demand-side management

- Transmission management

- BES product development 
- Project analysis

- Environmental affairs

In addition to these, numerous utility and IPP research and development personnel also provided responses for this survey.

In surveying the BES vendor community, Frost \& Sullivan contacted a variety of corporate management figures and consultants to provide input for this study. Most of the management contacts were senior managers or business managers in either BES companies or subsidiaries or divisions of large multinational firms.

Consultants tended to be more engineering-oriented by their very nature, although a few had moved into management within their firms.

With regulatory bodies, trade and professional organizations, and advocates, surveying was aimed either at analysts or program managers involved in renewable energy and batteries, or, in the case of regulators, at managerial personnel within electric utility regulatory groups or divisions.

This, of course, meant that, in the advocates and trade organizations, contacts were surveyed who were knowledgeable about BES, while in the regulatory bodies discussions were held with contacts who were largely uninformed on BES.

The actual surveying was conducted over the telephone, except in the case of the energy providers, most of whom were prequalified and then faxed their questionnaires. This was necessary because of the size and complexity of the electricity provider questionnaire. Once the questionnaire responses were collected and compiled, they were incorporated into this document by Frost \& Sullivan analysts. 


\section{Electricity Provider Industry Perspectives on BES}

\section{Electricity Provider Responses}

The primary goal of this study was to determine the condition of the BES market in the electricity provider industry. To achieve this, Frost \& Sullivan surveyed 38 electricity provider organizations:

- IOUs:

- American Electric Power

- Boston Edison Company

- Central \& Southwest

- Commonwealth Edison

- Delmarva Power

- Detroit Edison*

- Duke Power

- Entergy

- Florida Power \& Light

- Hawaii Electric Light

- Indianapolis Power and Light

- Niagara Mohawk Power

- Northern States Power*

- Northeast Utilities

- PacifiCorp

- Pacific Gas \& Electric*

- Potomac Electric Power Company*

- Public Service of New Mexico

- San Diego Gas \& Electric*

- Southern California Edison*

- Southern Company Services

- Texas Utilities*

- Union Electric Company

- Virginia Electric and Power Company

- Municipal Utilities:

- Los Angeles Department of Water and Power

- Metlakatla Power \& Light

- Electric Cooperatives:

- Chugach Electric Association

- Corn Belt Electric Membership Cooperative

- Golden Valley Electric Association

- Federal, State, and District Utilities:

- New York Power Authority

- PREPA*

- Salt River Project*

- Tennessee Valley Authority
- IPPs:

- Calpine Energy

- Edison Mission Energy (subsidiary of Edison International)

- Foster-Wheeler USA

- Kennetech Windpower

- Power Marketer and IPP:

- Enron

The asterisk (*) denotes that the organization is an ESA member.

As can be seen from this list, the electricity providers that were surveyed for this study come from all sectors of the electric power industry, from traditional utilities to organizations involved in developing electric power businesses such as energy marketing. Gaining this kind of diversity in the industry sample was the intent of both Frost \& Sullivan and SNL.

This diversity is intended to define potential differences in the perception of and demand for BES among different classes of electricity providers. Also, the survey results reflect differences in the economics, organizational structure, and mission of these organizations, leading to a better understanding of the viewpoints and needs of each of these different classes of electricity providers. This would be extremely valuable to both SNL and the BES supplier community.

These electricity providers were surveyed using a questionnaire developed jointly by Frost $\&$ Sullivan and SNL (see Appendix A). Because of the complexity of the survey and the nature of the information requested, it was necessary to prequalify survey contacts and to fax them copies of the questionnaire.

Following this, Frost \& Sullivan analysts followed up with survey respondents to answer their questions about the questionnaire and to retrieve responses by either telephone interviews or fax and mail responses.

\section{Outline of This Chapter}

Each of the following sections in this chapter discusses the response to one of the questions on the electricity provider questionnaire. There are $16 \mathrm{sec}$ tions in total. These sections are: 
- General Opinions of BES

- Perceptions of BES Technology

- Organizational Structure and BES Procurement

- BES Versus Other Advanced Storage Options

- BES Versus Central Energy Storage Options

- BES Versus Generation Options

- Industry Comparison of Other Generation and Storage Options to BES

- Deregulation's Impact on the BES Market

- BES Applications

- BES and Ancillary Services

- Additional BES Applications Important to Respondents

- Additional BES Applications Important to the Electricity Provider Industry

- Desired BES Technical and Product Characteristics

- Respondents' Estimates of Load Growth and Transmission and Distribution Expansion

- Estimates of the BES Market

- Effects of Lower-Cost BES Technology

Each of these sections summarizes the questionnaire responses received on the relevant question, in addition to drawing conclusions from and discussing the results.

\section{General Opinions of BES}

To gauge the respondent organizations' general opinions of BES, the first question posed asked respondents to characterize their interest in deploying BES in numerical terms. Responses were given on a scale of 1 through 10 , with 10 indicating the greatest likelihood and 1 the lowest likelihood of deploying BES.
The answers provided by this process were averaged and then rounded to the nearest hundredth of a decimal point; the results are shown in Table 4-1.

These results show that respondent interest in deploying BES will likely gradually increase over the forecast period of this study. However, responses varied widely, with the greatest interest shown by those electricity providers currently engaged in a project or that employed BES. Furthermore, IOUs had a lower overall opinion of BES than other types of electricity providers.

\section{Perceptions of BES Technology}

The next question solicited opinions on current battery storage technology and yielded 33 separate opinions out of the total of 38 electricity providers contacted. The general tone of the responses was as follows:

- Positive responses: 4

- Negative responses: 20

- Neutral responses: 9

Respondents' negative opinions of BES usually centered on cost-citing the high cost of the BES system. These opinions were based on the consideration of both competing technologies and return on investment. Additionally, cost was sometimes viewed relative to the benefits derived from its use. As stated by one utility:

Either cost needs to come down or value of protection against an outage has to go upBES needs to improve cycle life and reliability of valve regulated batteries.

The opinions on BES given by electricity providers often incorporated formal and informal cost-tobenefit analysis.

Table 4-1. Opinion Survey Results: Likelihood of BES Deployment Predicted by U.S. Electricity Providers (37 Companies), Years 2000, 2005, and 2010 (on a scale of 1-10)

\begin{tabular}{ll}
\hline 2000 & 3.14 \\
2005 & 4.30 \\
2010 & 5.27
\end{tabular}


To illustrate this point, and to show the difficulty of weighing BES value at one particular company, an IPP interviewee stated:

A strength and weakness is the complexity of incorporating the numerous abilities of a BES into a specific project. BES are still a significant incremental cost to a power generator project. To optimize the use of this capital expenditure much effort needs to be given to sizing and design. Even then, the capacity of payment received for stored energy is unlikely to cover the BES cost.

Although technological opinions commonly pointed back to cost, performance profiles were another common reference point for opinions. Interviews showed that contributors were aware of BES performance deficiencies, which included replacement frequency for cells, inadequate cell life, and low energy density.

When phrased as possible areas of improvement, respondents mentioned the need for improved cycle life, improved energy density, and rectifying batteries' susceptibility to deep cycling. In addition to batteryspecific components, system components that were mentioned as being in need of improvement included the power conditioning system. Rarely, though, was this mentioned; respondents' perceptions generally focused on battery-specific characteristics.

Although many people were aware of the overriding cost factor associated with BES, other opinions formed a consensus that held BES as being technologically feasible and adequate for its applications. In addition to the negative perceptions, many quickly pointed out positive factors about BES, such as environmental friendliness, multiple benefits, and the ability of BES to fit in niche applications.

In opposition, some electricity providers stated that BES would not constitute a proper fit at their company, or that competing technologies could provide equal or better service. One utility respondent replied:

[BES is] not a cost-competitive option and not needed right now. Gas turbines are "very cheap" right now and offer considerable flexibility.

As in the case of many other respondents, this person also pointed out:
On a small scale, power quality benefits at certain locations [are a strength of BES]. Could be merged with $\mathrm{PV}$ or various renewables to improve reliability/capacity once both technologies are much more cost effective.

In regard to the BES energy profile, one utility pointed out that the BES system offers:

Too little energy storage....[We] need 2 to $4 \mathrm{MW}$ for 8 to 12 hours for distribution system or grid deferral.

This respondent offered concrete figures as a basis for the utility's opinion. This provision of concrete figures was not often found in other responses.

One person brought to light use of BES in distributed resource applications, stating:

[Dollars per kilowatt] price [is] too high as a distributed resource for long term T\&D deferral. Modularity is promising, but size may be a limiting factor.

The depth to which electricity providers immersed themselves in technology comparisons varied. On the issue of BES technology perceptions, the majority of people surveyed did not indicate the frequency of their company's technology knowledge refreshment rate.

Impressions accumulated during interviews indicate that companies maintain a relatively current working knowledge of BES performance and profile characteristics. These impressions are supported by the fact that electricity providers reviewed existing technologies when reviewing their integrated resource plans (IRPs).

As one utility pointed out:

It is a technology we review regularly to determine its economic value in comparison to other peaking-type technologies. It is not currently competitive with other conventional peaking technologies.

In conclusion, respondents seemed versed on the interrelation between the overall system, its cost, the adequacy/deficiency of its components, and component costs. Areas that BES needs to improve such as improved cycle life and improved energy density are known to the respondents. 


\section{Organizational Structure and BES Procurement}

Based on information collected during a preliminary phase of this project, Frost \& Sullivan discovered that the departmental location of surveyed respondents varied. Essentially, using a rule of thumb to locate an electricity provider's BES specialists proved unreliable.

The following is a list of the job classifications of the individuals that were asked questions for this study. In parentheses are the number of respondents in each title/description category:

- IOUs:

- Chemist (1)

- Engineer (5)

- Engineer (Manager) (1)

- Engineer (Senior) (5)

- Engineer (Senior Research) (2)

- Integrated Resource Planner (3)

- Manager of Advanced Market Development (1)

- Manager of Conservation (1)

- Power Quality (1)

- Product Development Manager (2)

- Technical Analyst Coordinator (2)

- Municipal Utilities:

- General Manager (1)

- Mechanical Engineering (1)

- Electric Cooperatives:

- Assistant Manager (1)

- Engineer (1)

- Engineer (Planning) (1)

- Federal, State, and District Utilities:

- Assistant Head, Planning and Research Division (1)

- Engineer (Principal) (1)

- Manager of Electric Transportation (1)

- Project Specialist (1)

- IPPs:

- Director of Technology Research and Development (1)

- Manager of Power Systems (1)

- Project Marketing Manager (1)

- Vice President (1)
- Power Marketer and IPP:

- Development Director (1)

Responsibilities for BES procurement varied between companies, although common trends did emerge. In almost all companies, the responsibility of BES procurement was shared by several different departments.

Departments involved in the procurement of BES at individual companies are categorized in this discussion by electricity provider type (that is, IPP, IOU, cooperative, or others). Most department titles were mentioned repeatedly in the course of all interviews; each department title is listed here for representation and brevity:

- IOUs:

$$
\begin{aligned}
& \text { - Generation } \\
& \text { - Energy Supply Planning } \\
& \text { - Financial Studies } \\
& \text { - Fossil Generation } \\
& \text { - Fossil/Hydro } \\
& \text { - Integrated Resource Planning } \\
& \text { - Mechanical Engineering } \\
& \text { - Power Supply Planning } \\
& \text { - R\&D }
\end{aligned}
$$

- Municipal Utilities:

- Board of Directors

- Bulk Power Business Unit

- City Council

- Generation Business Unit

- Electric Cooperatives:

- Board of Directors

- Engineering

- General Management

- Production 
- Federal, State, and District Utilities:

- Distribution Planning

- Operations and Finance Senior Executives

- Planning

- Planning and Research Division

- Power Operations

- Power Quality

- R\&D

- Transmission and Power Supply

- IPPs:

- Contracts Department

- Executive Department

- Power Marketer and IPP:

- Development Department

- Engineering Department

In most interviewee responses, the procuring department or departments were those that would utilize BES. Secondly, through the course of this study a relatively frequent dilemma has surfaced. Although the dilemma has been discussed in other chapters, it would be appropriate to further highlight it here. BES can be used by generation, transmission, and distribution. Often, the capital purchase of a BES system can only be justified by its ability to serve multiple purposes; however, cooperation by those three departments is often a barrier to BES procurement.

Procurement in the future may change for several reasons. Contributing factors may include mergers and acquisitions, legislation, and deregulation. As a factor influencing the procurement of BES, deregulation was selected as another topic for response in this part of the questionnaire. This was intended to gauge electricity provider impressions of deregulation and its influence on BES procurement.

Surprisingly no respondents gave any concrete responses as to how deregulation would affect BES procurement from the organizational standpoint covered in this section. Instead, most respondents felt that existing in a deregulated environment would have either no effect on the organizational aspects of BES procurement, or they provided answers discussing the economic and systemic effects of deregulation. These discussions of economic and systemic effects have been moved to the section of this chapter dealing with deregulation's impact on the BES market.

\section{BES Versus Other Advanced Storage Technologies}

Advanced storage technologies mentioned during Frost \& Sullivan interviews included SMES, supercapacitors, and flywheels. Most respondents recognized these three technologies as energy storage technologies and competitors of BES. However, the majority of electricity providers interviewed for this study viewed BES as a superior storage technology compared to other advanced storage technologies. Technologies mentioned that are not technically "advanced storage technologies" included CAES and pumped storage hydro.

As the discussion turned to comparative analysis, respondents did not mention CAES and pumped storage hydro as frequently as SMES and flywheels. This is presumably because utilization of CAES and pumped storage hydro is limited to certain geographic regions. Because of geographic restrictions attached to these two storage options, respondents generally discounted these technologies as competition for BES.

Although BES received positive opinions when compared to other advanced technologies, factors supporting BES were quite diverse.

One common thread was that BES is more familiar technology than flywheels or SMES. As noted in other sections of this study, BES has been demonstrated in Chino, Vernon, Puerto Rico, and several other places. Flywheel and SMES projects on the scale of demonstrated BES systems are virtually nonexistent. Secondly, BES is regarded as being mature compared to flywheels, SMES, or any of the other advanced technologies. One IOU pointed out that, irrespective of cost, confidence in other advanced storage technologies is low.

Opinions, directed at technical issues pointed out that most competing advanced storage technologies have relatively low storage capacity compared to BES. In addition, empirical demonstration of BES systems may help BES develop more rapidly, allowing the value of the technology to be realized sooner than for other technologies. One electricity provider also pointed out that BES systems should have lower operating expenses than SMES.

One IOU thought that BES could provide peak load relief on the T\&D system as well as load leveling and T\&D deferral. SMES and flywheels have lacked 
sufficient demonstration of their performance in those areas. Furthermore, another IOU thought the overall deficiencies with other advanced storage technologies were split between their unavailability and cost. In contrast, this second IOU's opinion held BES as a reliable, low-cost, and currently available technology.

An additional IOU stated:

We can buy integrated BES or SMES-not flywheels or [supercapacitors]. At this time, [we] would buy on price and application between BES and SMES.

Counter to many positive comparisons made for BES against other advanced storage technologies, several respondents offered negative individual assessments.

One electricity provider stated:

Flywheels have a greater potential due to its higher round trip efficiency.

In conclusion, many see BES as a familiar technology compared to advanced storage technologies. Other technologies such as flywheels, SMES, and supercapacitors are advancing, but there is a lack of proven demonstration projects and awareness. BES received a favorable opinion with approximately 65 percent of contributing electricity providers. On the other hand, 15 percent of the electricity providers held negative opinions. The remaining respondents were split equally between neutrality and no response.

\section{BES Versus Central Energy Storage Technologies}

As in the case of BES when compared to advanced energy storage technologies, discussed above, most electricity providers viewed BES positively when compared to central energy storage technologiesCAES and pumped storage hydro. The positive opinions of BES compared to CAES and pumped storage hydro were usually substantiated by one or two supporting facts given by each electricity provider. Some electricity providers offered no opinions.

CAES and pumped storage hydro are preferred over BES when the geography of a region is suitable for CAES and pumped storage hydro. For example, electricity providers such as Southern Company Services can use CAES, whereas at Golden Valley, CAES is not an option. In many cases, geographic constraints obviating the utilization of CAES and pumped storage hydro by many electricity providers were factored into their responses.

Most opinions in this discussion demonstrated awareness of geographic siting limitations of CAES and pumped storage hydro. BES, alternatively, can be located near a load center, and a large number of electricity providers noted this fact. Another value attributable to BES is its "instantaneous response" capabilities, as indicated by several electricity providers.

Multiple electricity providers cited geographic availability as a factor limiting the employment of CAES and pumped storage hydro. One electricity provider expanded this topic to include economics:

CAES and pumped hydro are not modular and therefore are not cost-effective in the lower power levels (one to ten megawatts) in which we have interest.

This response was offered by an IPP.

A renewable type of application was also offered for a comparison of BES and central storage options:

Our organization has spent some six months analyzing various storage options for our intermittent solar electricity. We believe that BES and pumped storage [hydro] are the only two cost-efficient choices available in today's commercial market.

Before this discussion moves to opposing arguments, a comment made by one electricity provider should be mentioned. The person stated that even if pumped storage hydro was available, economics of peak pricing may preclude its use. This person stated that in that provider's service territory, the value of pumped storage hydro was not viable enough to offset the on-peak-to-off-peak pricing differential. This comment was supported by two similar opinions.

The two most prevalent arguments against BES when compared to CAES and pumped storage hydro were size and maintenance. Compared to the two selected technologies, dissenting opinions of BES also alluded to its lack of storage capacity in terms of hours of storage.

Further, once installed, several people pointed out that maintenance is greater for BES than it is for CAES or pumped storage hydro. However, 
respondents agreed on the greater environmental impact of CAES and pumped storage hydro.

In conclusion, BES is generally viewed as having a quicker response than CAES and pumped storage. Geographic location is a major factor that limits CAES and pumped hydro deployment. In addition, BES is viewed favorably with regard to its transportable properties (others lack modularity), though the number of hours of storage is a limiting factor compared to the other two technologies.

\section{BES Versus Generation Tech- nologies}

Electricity providers interviewed for this study offered their opinions on BES versus generation technologies at both dispersed and central generation sites. Technologies popularly held as generation technologies used at both sites included gas turbines, diesel generators, and fuel cells.

Approximately one-half of the respondents interviewed by Frost \& Sullivan offered negative opinions of BES in a central or dispersed generation setting. Respondents did not view BES as a primary electricity supply technology. Respondents held relatively clear opinions on the roles to which BES is most appropriately suited. The generation technology overwhelmingly preferred in central generation applications was combustion turbines, while diesel generators, and, in the future, fuel cells and microturbines were cited as being the leading contenders in distributed generation.

At a central generation facility, BES is regarded as having value for applications such as spinning reserve. As stated by one IPP:

It is for back-up and peaking. GTs [gas turbines], diesel, and fuel cells can also be used for backup and peaking, but the capital costs and fuel hassles exceed that of BES.

Furthermore, this opinion was supported by an electricity provider:

BES is a more economic option than gas turbines and diesel generators in such applications as spinning reserve and frequency regulation. However, battery storage is more expensive for supplying peak loading demands.
Responses from electricity providers indicate that opinions are largely split on whether BES is more effective than other central generation technologies for peaking.

One electricity provider supported this idea:

They could be a good complement to these generation technologies. BES has the energy capacity to allow discharge for several minutes. Under unscheduled outage conditions, a BES could provide continuity of service while one of these technologies are started and brought on line.

Considerable attention was given to fuel cells. Taken collectively input from respondents indicates that fuel cells are viewed as a technology competing with BES at generation and distributed sites. One opinion is included to support this claim:

Gas turbines [are] much more reliable and efficient. Fuel cells could eventually become the most rapidly growing generation source. Diesel generators [are] too expensive to operate and environmentally not friendly.

The next opinion also included BES and fuel cells, but here the respondent gave his opinion on distributed applications. This person stated distributed sites would favor fuel cells and BES because of noise and emission concerns. He added that gas turbines utilized for central generation or larger dispersed applications would be difficult to beat in cost.

In conclusion, BES is not viewed as a generation technology, though it has value for spinning reserve, frequency control, and load leveling at the generation site. As a distributed resource technology, BES is viewed as being cleaner, environmentally friendly, and offering power quality services unmatched by other technologies.

\section{Industry Comparisons of Other Generation and Storage Options to BES}

The ensuing discourse centers on the generation and energy storage technologies perceived by the contributors as providing superior performance when compared to BES. 
Technologies offered by interviewees for purposes of this discussion included combustion turbines (13), fuel cells (7), pumped storage hydro (6), flywheels (4), CAES (4), SMES (2), conventional hydro (2), diesel generators (2), combined cycle (1), microturbines (1), dynamic voltage regulators (DVRs) (1), and photovoltaics (PV) (1).

The technologies listed above are ranked by the number of times they were mentioned as being a technology more favorable than BES. In some responses more than one technology was mentioned. Combustion turbines were cited as a technology superior to BES more often than the other technologies listed. Additionally, fuel cells were thought of as being better than BES by a small handful of respondents. Combustion turbines, which were mentioned frequently, are the only technology viewed as having a clear advantage over BES.

One utility, in regard to combustion turbines, stated:

Currently, combustion turbines are superior to all other sources of capacity in the analysis we have performed. [The local IOU] is not currently concerned with energy sources in the near term. As long as natural gas prices remain moderate, storage does not appear to be a viable alternative to combustion turbine based generation for peak capacity.

Another prominent IOU stated:

Gas turbines, diesel generators, hydro, and pumped hydro are technologies which provide superior performance in meeting spinning reserve, frequency regulation, generation dispatch, and other system operating considerations.

Several respondents pointed out that selection and subsequent employment of technology depends largely on the application.

One IOU stated that the situation:

Depends on the application. For dispersed generation emergency backup applications, leasing diesel gensets looks attractive when compared to other options.

A different person from the same IOU provided additional input:
$50 \mathrm{MW}+$ [megawatt plus] gas turbines [are] also [used] for seasonal peak demand.

One expanding IPP offered insight into the potential for developmental generation and storage technologies:

Fuel cells will most likely be the first new technology to compete. Kinetic power is low tech enough to be a competitor in the very near future.

Kinetic power, meaning flywheels, was not frequently addressed as a strong competitor in the responses received for this section. SMES and CAES were also mentioned by several contributors but not by a majority of them.

In conclusion, it is important to stress that both classes of applications, generation and energy storage technologies, were included in this discussion. The occurrence of technologies and arguments made against BES were individually selected to cover a range of views. To say that nobody thought pumped storage hydro was superior to BES is erroneousactually six electricity providers said pumped hydro was superior to BES.

Additionally, many electricity providers stated their belief that more than one technology was superior to BES. Approximately one third of electricity providers, in aggregate, offered no opinion to this discussion, or stated that no technology was superior to BES.

\section{Deregulation's Impact on the BES Market}

Even though the full effects of deregulation have not been experienced completely by all electricity providers, general perceptions of and speculations on its impact have already been formed by the electricity providers surveyed. The immediate response to the uncertain fallout of deregulation has resulted in two general types of answers-first, the observation of cost and its impact, and second, the arrangement, or vertical rearrangement, of the industry with the introduction of power marketing and separate generation and wire companies.

As stated previously, questioning respondents on deregulation caused some themes to emerge, cost being the main one. 
One electricity provider, while agreeing that cost is an issue to be dealt with in a deregulated environment, also offered the opinion that cost is not the sole factor behind procurement:

Deregulation will cause the commodity price of energy to drop. And it will close the gap between on peak and off peak price. This will hurt BES on pure economic justification for installation. [We] believe that BES's application is not necessarily a pure economic decision. Reliability and convenience are the key factors.

One electricity generator stated that deregulation will force his company to focus on least-cost technologies and alternatives at a company-wide level. BES, still being an eligible technology for deployment by a company, would have to prove its value to the electricity provider.

This is the same scenario that currently exists in the relatively regulated environment, but it will likely become even more critical after deregulation.

Expanding on this theme of cost, one IOU stated:

Minimization of cost (maximizing profit) by selecting projects having shorter pay back periods would be paramount. In a deregulated environment, technologies having similar operating characteristics with a cost premium in comparison to other technologies would be less likely to be selected, especially if there are no significant nonprice benefits.

This next view was offered by a municipal electricity provider but was frequently repeated in feedback from almost all electricity providers:

Deregulation [means] everything must be cost-effective. Batteries must compete cost wise with gas turbines or other sources of energy.

To add to this theme, a different electricity provider plainly stated that BES, in a deregulated environment, will need to compete against installed gas turbine prices of $\$ 300$ to $\$ 400$ per kilowatt.

Besides this, several other responses supported the claim that cost will not be the sole factor driving BES procurement. A great deal of importance was placed on distributed generation and customer applications.
One respondent brought to the study his view on the diversity of effects distributed generation and customer applications may have on electricity providers. He stated that BES procurement in a deregulated environment might look. "promising" because the distribution portion of his company's system may remain "monopolized."

A different electricity provider stated, with no other discourse or explanation, that in a deregulated environment peak-shaving opportunities will be easier to identify.

The effects of restructuring make BES cost a factor affecting its deployment, but restructuring may also create a noncost environment conducive to BES deployment. Distributed generation at the customer level is another theme, besides cost, that deserves recognition.

Stated one electricity provider:

Deregulation would result in our deployment of more distributed generation projects, so energy storage would be evaluated much more carefully.

Some respondents felt BES may be used by electricity providers as a tool for differentiating themselves from their competitors:

A deregulated environment quickly shifts interests to value-added services with greater profit potential than the commodity business of providing $\mathrm{kW}$ (kilowatts) and $\mathrm{kWh}$ [kilowatt-hours]. This will enhance interest in energy storage in dispersed applications.

As stated by electricity providers interviewed by Frost \& Sullivan, the awakening of power quality services, power marketing, and distributed generation will critically impact the electricity providing industry.

Additionally, one electricity provider stated:

Deregulation strongly affects customer site applications. Marketing takes the leadperhaps with our ESCO. No foreseeable effect on distribution system or grid uses because of cost and other tradeoffs with conventional solutions.

Regarding BES in island geographic settings, such as Puerto Rico or Hawaii, almost all respondents felt 
deregulation will have no effect in those places in the foreseeable future. One IPP stated:

Given current generation capacity in the U.S. and emerging wheeling abilities, BES systems are likely to be devalued by IPPs in the continental U.S. given deregulation. [The local IPP] believes BES may prove viable to IPPs in off-shore island projects where electricity rates are more favorable.

In conclusion, two main themes appear to be prevalent, besides responses aimed at geographic exceptions. The primary theme is competition with other power supply technologies. Some contributors who focused their opinions on technologies saw BES as not being competitive with other technologies. The main reason given was cost-with the cost of technologies becoming an increasingly relevant factor after deregulation, compared to the current regulated environment.

The second theme centered on a possible surge of interest in BES as energy services and marketing are used to add value and product differentiation to commodity bulk power.

\section{BES Applications}

Electricity providers interviewed by Frost \& Sullivan were asked to identify, from a list of applications provided by SNL (see Appendix D), those that BES could best serve for their companies. Common themes were evident in the responses although variations were found in the exact terminology different respondents used to describe the same applications.

The applications electricity providers named included:

- Black start*

- Customer demand peak reduction*

- Distribution facility deferral

- Distribution volt-amp reactive (VAR) support and voltage regulation

- Emergency power to shut down power plants*

- Frequency control

- Generation capacity deferral

- Generation scheduling/dispatching

- Load conditioning
- Load following

- Load leveling

- Reliability

- Renewables

- Spinning reserve

- Transmission facility deferral

- Transmission line stability

- Transmission voltage control/VAR support

- UPS/power quality

The asterisk $\left(^{*}\right)$ indicates an application not proposed by SNL (see Appendix D).

In conclusion, some electricity providers offered no opinion in response to this question, while others listed several possible applications for BES. Most prominent among the applications listed were power quality and reliability, cited by 14 and 12 respondents, respectively (see Table 4-2 and Figure 4-1).

Power quality and reliability were chief among the 24 separate BES applications listed by respondents, this being 12 more applications than were suggested to respondents on the list of applications found in Appendix D.

\section{BES and Ancillary Services}

This discussion centers on the provision of services to an independent system operator (ISO) by a BES owner. Note that the electricity providers who contributed to this discussion reviewed a list of possible ancillary services. This list is included in the electricity provider questionnaire in Appendix A.

Electricity providers chose applications from the list and also provided some additional applications not listed. The original and appended list follows:

- Backup reliability

- Demand cost control

- Energy imbalance

- Generation voltage control

- Help with voltage regulation

- Load following

- Real power loss replacement

- Reliability

- Supplemental operating

- Transmission voltage control 
Table 4-2. Applications Identified by Electricity Providers (30 Companies), 1996

\begin{tabular}{lc}
\hline \multicolumn{1}{c}{ Application } & $\begin{array}{c}\text { Times Application } \\
\text { Mentioned }\end{array}$ \\
\hline Area/Frequency Control & 3 \\
Black Start & 1 \\
Customer Demand Peak Reduction & 5 \\
Distribution Facility Deferral & 6 \\
Emergency Shutdown Power & 1 \\
Frequency Control & 1 \\
Frequency Regulation & 2 \\
Generation Capacity Deferral & 5 \\
Generation Dispatching & 4 \\
Load Conditioning & 1 \\
Load Following & 1 \\
Load Leveling & 10 \\
Out of Step Prevention & 1 \\
Peak Reduction & 2 \\
Power Quality & 14 \\
Reliability & 12 \\
Renewables & 5 \\
Spinning Reserve & 8 \\
Transmission Facility Deferral & 5 \\
Transmission Line Stability & 2 \\
Transmission Stability Enhancement & 2 \\
Transmission VAR Support & 2 \\
UPS & 10 \\
Voltage Regulation & 7
\end{tabular}

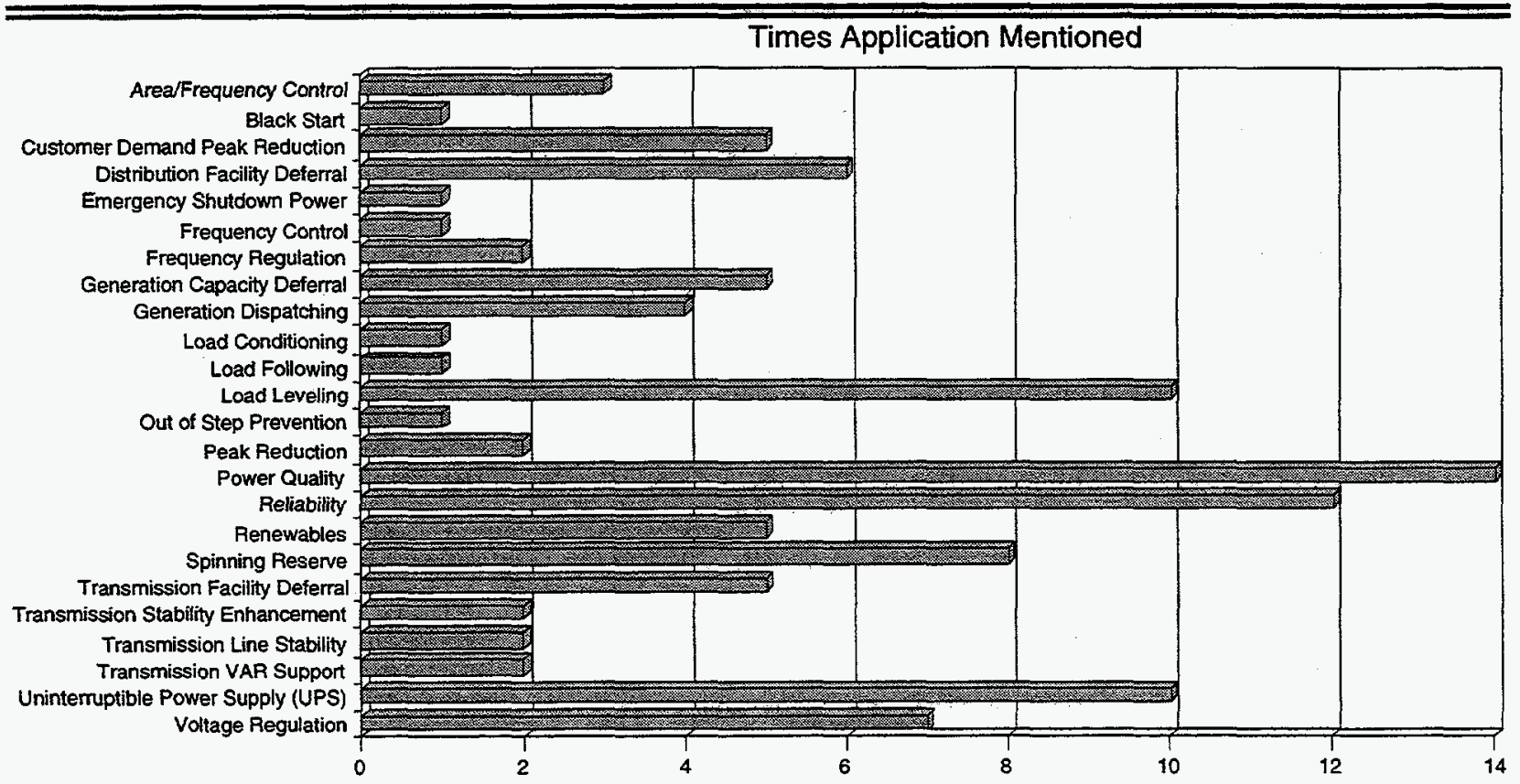

Figure 4-1. Applications Identified by Electricity Providers (30 Companies), 1996. 
The opinions in this section were contributed by only a small fraction of the electricity providers responding to the questionnaire. Moreover, 11 of 38 electricity providers either offered no opinion or little input.

Of the limited input by electricity providers, only the two following quotes have any depth.

One IPP stated:

In a deregulated environment, who becomes the utility is still unclear. To the extent an energy supplier also becomes responsible for $T \& D$, utilizing BES to assist in the above areas would be beneficial. However, as wheeling becomes easier, the net effect on BES may be a lower importance or value to the "utility" given current costs.

An IOU stated:

I do not foresee BES playing a role in the next five years. The southeast has a surplus of generation capacity. In a deregulated environment, potential generation pools could form and maximize the economic benefits of the current excess generation capacity. Sharing the dispatch of existing generation may enable lower reserve margins and would push out the need for additional generation. Beyond five years, the role of BES depends on load growth, technological advances, and demonstration of the technology. All the listed items would be viable services BES could provide. However, the question still remains on whether an adequate market would exist for these services.

In conclusion, the lack of input in this discussion may be an indication that electricity providers either have not considered BES in an ISO role or have not fully realized the potential for ISOs.

\section{Additional BES Applications Important to Respondents}

This section discusses additional specific BES applications provided by electricity provider respondents. Although the list of applications given to electricity providers with the questionnaire was thought to be comprehensive, further queries were made to elicit overlooked or innovative applications not covered in the original list found in Appendix D.

After reviewing the collective input of opinions to this discussion, responses proved that feedback was limited compared to other topics covered in the surveying of electricity providers.

Electric vehicle applications (charging stations) gained two responses. Other applications offered for discussion included photovoltaics (also discussed in Appendix D), environmental emission reduction, backup for distributed generation, and black start for nuclear generation.

In conclusion, this category revealed several possible applications not included but which several electricity providers considered relevant. Secondly, the list of applications generated by our respondents included only one application given by multiple respondents, electric vehicle charging.

\section{Additional BES Applications Important to the Electricity Provider Industry}

Electricity providers were asked for input that collectively formed a list of applications important to the electricity providing industry. The applications offered by contributors were not necessarily applications that were relevant to that particular electricity provider, but were applications that respondents believed were important to the industry as a whole. The majority of contributing electricity providers did not answer our inquiries or offer conclusive opinions for the discussion.

The list included electric vehicle quick charge storage applications, power quality improvement for particularly sensitive customers, and remote metering and telecommunication power services.

\section{Desired BES Technical and Product Characteristics}

Electricity providers were asked to comment on BES technological and product characteristics. Additionally, surveyed respondents were asked for opinions that might point to areas of potential BES technical improvement.

During the course of the interviews, common themes emerged. Cost, cell life, maintenance, and footprint 
were the most commonly repeated BES characteristics with room for improvement.

A list of less important characteristics also in need of improvement included lower maintenance (8), longer cell life (8), smaller footprint (6), environmental concerns (3), energy density (2), larger sizes (2), longer storage capacity (2), system reliability (2), increased operational flexibility (1), inexpensive inverters (1), portability (1), quicker recharge (1), voltage stability (1), quicker discharge (1), and reduced effects of operational profiles on equipment (1). Parentheses indicate the number of times each characteristic was mentioned. Twenty-nine respondents out of a total of 38 contributed answers. Cost, although not technically a technical or product characteristic, was mentioned by 18 respondents.

Only a small proportion of respondents felt BES was adequately equipped to serve current needs effectively. One respondent offered support to this minority consensus, though perceiving one common limitation:

The technology is here today, I wouldn't worry about it, except for extending the life of the batteries.

Specific battery characteristics were commonly addressed. Actual constructive input varied, however. One electricity provider offered considerable input:

BES needs to be able to discharge quickly at a higher rating and at the same time be used for longer discharge periods, i.e., rating of $6 \mathrm{MW}$ for 10 to 20 cycles and $1 \mathrm{MW}$ for a longer period of time of 1 to $2 \mathrm{hr}$. This may be possible, but the cost may be prohibitive.

An additional comment provided by one electricity provider continues this theme. The respondent stated:

Battery storage systems, primarily the batteries themselves, need substantial further development to improve cost, increase power and energy density, increase energy efficiency, and to reduce the effects of operational profiles (sudden discharge/ charge) on equipment performance and lifetime. Governmental investments in additional battery R\&D must be traded against additional investments in flywheel and SMES technologies. All three need further development before seeing substantial mar- ket growth for the applications described [earlier].

Several electricity providers addressed nontechnical issues. One participant addressed industry-wide training, stating in his opinion that BES is "not a normal tool used to solve a specific problem."

Another respondent offered valuable insight by bringing together several common themes addressed in this section-capital cost, footprint, and energy density. He stated:

Capital costs for battery energy storage plants are a function of the capacity of the plant as well as the number of discharging hours required. An increase in production volume would most likely achieve lower mature market costs.

On the subject of availability of suppliers offering competitive BES system solutions, one electricity provider stated that BES improvements could include:

Small space, automatic, modular, continuous status and event monitoring, voltage selections, low cost. There may be others. I think most of these characteristics are available, but there is a limited number of suppliers that offer all of the features.

Although this response was not repeated, it may indicate that this electricity provider is waiting for a vendor to create a new product mix.

One electricity provider included a comparison to a perceived competing technology, stating that BES needs to be:

Less than $\$ 400 / \mathrm{kW}$ with capability to store 12 hours of energy, $2,000+$ cycles. Need to compete with a CT [combustion turbine] or genset.

Furthermore, the point was raised that when BES reaches technological maturity, fuel cells may be very popular, thereby nullifying BES gains.

In conclusion, a minority of electricity providers offering input to this discussion felt BES is technologically prepared to meet current demand. Many felt that only after significant investment in research and development would BES gain the characteristics 
needed to provide significant value to electricity providers.

\section{Estimates of Load Growth and Transmission and Distribution Expansion}

The numbers in Table 4-3 represent the total number of megawatts that 21 of the 38 contributing energy providers in the sample projected would be added to meet their load growth and other needs in the years 2000,2005 , and 2010.

These numbers were then extrapolated from the sample by dividing statistical measurements for the 21 sample energy providers by the statistical measurements of the entire U.S. electricity provider industry.

The following statistical measurements were used:

- 1994 megawatt-hours sold (industry = $2,936,085,000 \mathrm{MWh}$, sample $=945,579,000$ MWh)

- 1994 megawatt-hours generated (industry $=$ $3,254,081,000 \mathrm{MWh}$, sample $=919,691,000$ MWh)

- 1994 revenues from electric sales (industry = $\$ 203.48$ billion, sample $=\$ 58.89$ billion)

- 1994 generating capacity in megawatts (industry $=773,916 \mathrm{MW}$, sample $=211,346$ MW)

After executing these equations, it was found that the sample group represented the following percentages:

- 32.21 percent of 1994 U.S. MWh sold

- 28.26 percent of 1994 U.S. MWh generated

- 28.94 percent of 1994 U.S. revenues from electricity sales

- 27.31 percent of 1994 U.S. electric generating capacity

When the industry statistics were divided by the sample statistics, the following multipliers were achieved. Again, these are presented carried to two decimal places:

- 3.11 for 1994 megawatt-hours sold
- 3.54 for 1994 megawatt-hours generated

- 3.46 for 1994 revenues from electricity sales

- 3.66 for 1994 generating capacity

These multipliers were added together and then divided by the number of multipliers (four). This resulted in the master multiplier, hereafter known as the master extrapolation factor, of 3.44 .

To arrive at estimates, the cumulative responses for the years 2000,2005 , and 2010 were multiplied by the master extrapolation factor.

The products of the master extrapolation factor and the sample megawatt capacity estimates for these years were then deflated to account for the natural tendency among survey respondents to provide inflated estimates. This tendency is especially prevalent when estimates are provided for times in the distant future. The deflation factors used were 0.9 for the year $2000,0.8$ for the year 2005 , and 0.7 for the year 2010.

The resulting equation for the extrapolation of the sample projected megawatt capacity additions in the year 2000 to the electricity provider industry as a whole is as follows:

- Year 2000 sample megawatt capacity addition estimate $(3,210 \mathrm{MW}) \times$ master extrapolation factor (3.44) $\times$ year 2000 deflation factor $(0.9)=$ industry megawatt capacity addition estimate of $9,938 \mathrm{MW}$

Similar equations resulted in industry-wide capacity addition estimates of $12,709 \mathrm{MW}$ in 2005 and $14,553 \mathrm{MW}$ in 2010 (see Table 4-4). All three of these estimates represent 1 to $2 \%$ load growth when applied to projections of industry generating capacity through 2010.

This level of load growth is commonly found within the electricity provider industry, indicating that this model behaves in a manner that makes it viable for the purpose of making the projections needed for this study. This same model has been applied to the extrapolation process resulting from the responses found in the next section. 
Table 4-3. Estimate of Capacity Additions and Load Growth (in Megawatts): Provided by Electricity Provider Sample (21 Companies), Years 2000, 2005, and 2010

\begin{tabular}{cc}
\hline Year & Megawatts (MW) \\
\hline 2000 & 3,210 \\
2005 & 4,618 \\
2010 & 6,035 \\
\hline
\end{tabular}

Note: All figures are rounded.

Table 4-4. Extrapolation of Capacity Additions and Load Growth (in Megawatts): Electricity Provider Industry (U.S. and Puerto Rico), Years 2000, 2005, and 2010

\begin{tabular}{cc}
\hline Year & Megawatts (MW) \\
\hline 2000 & 9,900 \\
2005 & 12,700 \\
2010 & 14,500 \\
\hline
\end{tabular}

Note: All figures are rounded.

\section{Estimates of the BES Market}

Table 4-5 represents the mean percentage of new capacity added in each year that respondents projected would be met using BES. These mean numbers are immaterial for true statistical purposes because a large percentage given as a response would affect the mean percentage score in the same manner regardless of the size of the utility giving the response. However, on a purely qualitative basis, the mean percentage is an indicator of the rising interest that energy providers show in BES in the out years of this market assessment.

These figures gain their true value when a respondent's estimate of the percentage of new capacity devoted to BES is multiplied against the expected capacity additions given by the same respondent. These individual estimates are then added together to form an estimate for the 21 sample utilities as a whole. This process resulted in the estimates of BES demand in the 21 sample electricity providers (see Table 4-6).

Putting these estimates through the same extrapolation process that was discussed in the previous section of this chapter, estimates of industry-wide demand for BES were derived (see Table 4-7).
These estimates were then multiplied by the mean price per kilowatt of installed BES capacity for complete systems. The following figures were provided by SNL for 2000,2005 , and 2010 :

2000: $\$ 900$ per kilowatt

2005: \$600 per kilowatt

2010: $\$ 500$ per kilowatt

These per-kilowatt prices were then multiplied by 1,000 to arrive at a per-megawatt price and then multiplied by the estimate of the number of megawatts of BES needed in each year to come up with estimates of the value of the U.S. BES market in each year (see Table 4-8).

The obvious conclusion drawn from these estimates is that BES systems will likely gain greater use and deployment in coming years. However, this conclusion does have limitations. Foremost among them is that advancements in BES component technology, component price changes, and the effect of macroenvironmental factors in the electricity providing industry cannot be fully accounted for when making critical forecasts. 
Table 4-5. Mean Estimated Percentage of New Capacity Additions

Being Met by BES: By Electricity Providers (21 Companies), Years 2000, 2005, and 2010

\begin{tabular}{cc}
\hline Year & Percentage \\
\hline 2000 & 1.73 \\
2005 & 4.10 \\
2010 & 7.58 \\
\hline
\end{tabular}

Note: All figures are rounded.

Table 4-6. Estimated BES Capacity Additions (in Megawatts): By Electricity Providers (21 Companies), Years 2000, 2005, and 2010

\begin{tabular}{cc}
\hline Year & Megawatts \\
\hline 2000 & 8 \\
2005 & 62 \\
2010 & 166 \\
\hline
\end{tabular}

Note: All figures are rounded.

Table 4-7. Extrapolation of BES Capacity Additions (in Megawatts): Electricity Provider Industry (U.S. and Puerto Rico), Years 2000, 2005, and 2010

\begin{tabular}{cc}
\hline Year & Megawatts \\
\hline 2000 & 27 \\
2005 & 215 \\
2010 & 573 \\
\hline
\end{tabular}

Note: All figures are rounded.

Table 4-8. Estimated BES Market (in Dollars): Electricity Provider Industry (U.S. and Puerto Rico), Years 2000, 2005, and 2010

\begin{tabular}{cc}
\hline Year & $\begin{array}{c}\text { Market } \\
\text { (\$ Million) }\end{array}$ \\
\hline 2000 & 24 \\
2005 & 129 \\
2010 & 287 \\
\hline Note: All figures are rounded.
\end{tabular}




\section{Projected Effects of Lower-Cost BES Technology}

Electricity providers formed opinions for this discussion based on the prospect of BES being comparable to their preferred technology in 2010. Respondents were asked which technology(s) would provide their central and/or distributed energy source(s) in 2010, and if in 2010 the cost of BES were comparable to their preferred option, how much BES they would install.

The uncertainty of making accurate projections into the future precluded many from offering opinions. Factors such as deregulation, future technologies, and uncertain customer bases added to the uncertainty of making credible projections.

One opinion offered by an IOU spokesperson summarized the common line of thought regarding this discussion. She stated:

All depends on how much need there is. Possibly also the operating characteristics of that technology. From what I've seen its basically a peaking type technology. So it would have to be competitive with the combustion turbines. As to how much?...It depends on the market. Who knows what deregulation will look like that far out in time. Then also what our needs will be, whether or not we retain, gain, or lose customers. It's very hard to say how much we will specifically [give] to a certain technology.

This quote identified BES as a peaking technology. In addition, many other respondents shaped their opinions in reference to BES as a technology suited for distributed siting, mainly for prospective customer applications.

To confirm electricity providers' uncertain technology forecasting, some offered no opinions on future technologies. Alternatively, those who did contribute offered one or two opinions. Technologies such as gas turbines, combustion turbines, combined cycle, and fuel cells were mentioned more frequently than other technologies. In addition, these technologies are likely candidates for central and/or distributed energy sources in 2010.

Other technologies electricity providers thought might be used included advanced combustion tur- bines; coal (all different types of generation, such as pulverized or supercritical); combustion regurgitation (exhaust gas recycling); diesel fuel; flywheels; liquidfuel-fired, natural-gas-fired, and oil-fired units; and renewables. Opinions holding these technologies as likely candidates were few-often only one or two respondents sponsored them.

One opinion by an electricity provider underscores the popularity of gas technologies:

Relatively strict solicitation requirements will partly determine mix of technologies to be used. Estimated 90 percent gas combined cycle type, 10 percent renewable or DSM.

Gathering quantifiable estimates of the respondents' preferred option to BES was difficult, mainly because the respondents felt uncomfortable forecasting future technology demands. Although some electricity providers did give estimates, many electricity providers use IRPs to help forecast their company's technology, and IRPs do not usually forecast 14 years into the future.

Given the scenario envisioned in this section of the study, where BES would match the cost of the respondent's preferred energy supply options, estimates of BES purchases varied widely. Some respondents felt that this event would only marginally increase the percentage of new capacity met by BES purchases, maybe increasing this percentage into the 5 to $10 \%$ range from their previous estimates of below $5 \%$.

Other respondents offered estimates in the form of hard figures, with a cooperative stating that it might purchase about $2.4 \mathrm{MW}$, and a major utility projecting that such an event happening within the next few years might inspire them to purchase as much as 2,000 MW of BES capacity between 2005 and 2010 .

In conclusion, many electricity providers were open to the prospect of considering BES in 2010, if it were comparable to their preferred option. 
Intentionally Left Blank

$4-18$ 


\section{Supplier and Consultant Perspectives on Battery Energy Storage}

\section{Introduction}

This chapter discusses the perspectives of BES suppliers and independent consultants who participated in the BES market study. The responses discussed in this chapter were obtained during interviews with prominent BES suppliers and consultants using the questionnaire found in Appendix B of this report.

\section{List of Contributing Suppliers and Consultants}

Suppliers and consultants that contributed insights to this study are included in the list below.

\section{Suppliers}

- AC Battery

- ABB Power Systems

- C\&D Charter Power Systems

- Delphi (formerly Delco)

- GNB Battery Technology

- Johnson Controls Battery Group

- Powercell Corporation

- Silent Power Systems

- Westinghouse

- Yuasa-Exide

- ZBB Technologies, Inc.

Consultants

- Bechtel

- Decision Focus

- El Camino Real Engineering, Inc.

- Energy and Environmental Economics

- Power Engineers, Inc.

- Zaininger Engineering Company, Inc.

\section{Products and Services Offered to BES Market}

The current BES product and service infrastructure is composed of independent consultants and manufacturers; offerings may range from BES consulting to fully integrated BES system design and implementation.
Completely integrated BES system suppliers are few, and those that have produced systems are typically supported by revenues outside the BES market. Successfully installed systems may offset large research and development expenses, but insufficient electricity provider demand has forced several BES competitors to scale back their product offerings.

One company that previously offered a fully integrated BES system commented:

At this point in time we don't make any products for that market [for Alaska and Puerto Rico type BES systems]. We used to make complete systems, but the market is such a small niche, and it's so politically driven, and utilities buy demo systems when they buy one...it's really not a profitable endeavor for a company to get in. We have withdrawn from that niche.

Companies that do not offer fully integrated BES systems are sometimes horizontally integrated. These companies offer products in other more lucrative electricity markets such as end-user power quality systems. Power electronic inverters, as an example, can be tailored to meet the requirements of most systems types.

In fact, they have to-utility designed BES systems lack standardization. In today's BES market, system offerings are showing the first signs of standardization within companies. This is a break from traditional pilot-type BES systems, yet no industry-wide BES product or service standardization appears to be on the horizon.

Current battery technology offered by BES suppliers is entirely lead-acid, including both flooded and VRLA cells.

Consulting services in the BES market may range from power quality consulting services to economic analysis and system design. Because of the limited market for utility-scale BES systems, consultants, like 
product suppliers, typically diversify their consulting over a range of electricity markets.

\section{Future BES Supplier Product and Service Offerings}

Until 2010, products and services offered to the BES market by suppliers and consultants are expected to evolve to meet market demand requirements. Some suppliers and consultants do not foresee changes in their areas of expertise. For instance, they believe lead-acid batteries are proven and point only to cost as an area of improvement. It is possible that by the year 2000 sodium/sulfur and zinc/bromine batteries might be offered in the BES market, assuming existing technological obstacles are overcome.

Some people think great technological advancements in advanced batteries will bring about the greatest BES system cost cutting. This remains to be proven. Others are more skeptical of advanced batteries, favoring traditional lead-acid batteries.

The majority of others included in this study foresee, and expect, changes in both batteries and other system components by the turn of the century. Several companies see improved developments in nonbattery BES system components as being likely:

My guess is that [two major components] would change before the end of the century. One would be the inverter/converter technology for higher efficiency/lower cost. Secondly, probably next generation battery technology [would change].

This response may indicate a shift from the relatively cost-insensitive mindset of demonstration or pilot system construction. A different respondent indicated

We will continuously [be] improving our PCS (power conditioning systems) for this market.

Battery technology is expected to change over the forecast period. Expansion of battery storage capacity and refined deep-discharge life cycle are two areas for potential improvement, as indicated by several suppliers.

This mainly concerns existing battery technologies. Although several participants expect improvement of existing battery technology, others anticipate ad- vanced batteries having a greater presence, one stating:

[Our company will offer] a BES product based on advanced battery technology.

Independent consultants who currently work with BES may adapt to changes in that market but many indicate little change in their service offerings.

In the 1980s, Decision Focus performed commercialization analysis of energy storage technologies. CAES, fuel cells, and BES were their areas of expertise. Now, they have scaled back this type of analysis and perform these services only when requested.

Of the consultants interviewed for this study, those currently working in the BES market are actively engaged on projects; BES does not create an environment commensurate with widespread, full-time consulting, in general.

One consultant explained his outlook:

We do battery storage, but we do other things such as solar and wind power. Right now these kinds of technologies have different impacts on utility systems than conventional type technologies. What I just said is this restructuring...is going to change not only these kinds of technologies, but other kinds of technologies, like transmission technologies and other kinds of generation technologies.

Renewable energy sources are expected to use batteries to a greater degree. To accommodate this change, the flexibility of BES systems may be tested. As indicated by one contributor, an avenue for this may be achieved by using "hybrid large scale energy storage devices that couple batteries together with ultracapacitors.".

\section{Vendor Perspectives on Other Energy Storage Technologies}

On this topic, many responses mentioned SMES, pumped hydro, advanced batteries, CAES, and flywheels.

The majority of contributors view these competing technologies, with the exception of pumped hydro, as either technologically immature or lacking storage capacity and duration. Several people offering 
opinions felt flywheels and SMES will probably not become commercially available for about five years, with SMES being further out than flywheels. Two common complaints about SMES technology are its cost and failure to provide support for sustained periods of time.

In the responses on which this section is based, several people appeared hopeful for the eventual arrival of marketable SMES and, possibly, flywheels. However, despite the possible future acceptance of flywheels, one person pointed out:

Now I don't see rotating equipment fitting into that at all because it is not long enough durations at all. SMES doesn't fit into that category [spinning reserve, utility standby, customer use outage protection]. It fits into power quality, but it does not fit into the categories we have defined here.

Another supplier felt an increase in SMES discharge capacity was not likely to occur.

One respondent looked to the potential of advanced batteries. The respondent mentioned advanced batteries as having outstanding problems, as do many other energy storage technologies. One is cost, and another is that the lack of technological advancement may deprive the technology of widespread practical application other than for the purposes of demonstration. Although this comment was mainly directed at advanced batteries, the respondent believes the cost of traditional batteries and the power conditioner component of the system need to come down.

An alternative view to the previous comment was that:

Lead-acid technology needs to demonstrate longer life or focus on applications that have little or no effect on the life of the battery [power quality].

Negative perceptions of energy storage must be rectified for these technologies to satisfy the market. As has been indicated in other areas of discussion, people are hesitant to adopt technologies deemed to raise safety concerns. These concerns may include chemical, mechanical, or electrical hazards.

One supplier suggests:

Part of developing the market is instilling confidence on the part of the customer for the product. Confidence in the quality and reliability of the product, confidence in the cost effectiveness of energy storage-but my sense [is that BES] technology is further along than the other stuff.

Two opinions dissented from this opinion. Thus far, most respondents had focused their opinions on cost, awareness, and technology. However, some respondents felt a development that might lead to market acceptance would be integrated energy storage systems. Therefore, extended power outages that cannot be handled by single SMES coils might need a combination of two energy storage technologies; "longer disturbances might be best solved by putting a SMES coil with a battery." Overall, though, not many respondents alluded to hybrid technology solutions.

A different respondent, this one also a supplier, added to the previous opinion. This respondent saw customers wanting their energy storage needs provided by a turnkey operator. Likewise, he pointed out that most companies acquiring large capital assets are accustomed to having installation provided by others.

\section{Barriers to BES Acceptance}

Cost, lack of utility support and organizational cohesion, industry awareness, and perceived inadequacy of technology are the common barriers to BES acceptance. This section discusses these four popularly perceived barriers to BES acceptance, yet neither suppliers nor consultants targeted any one particular barrier. Suppliers pointed to cost, technology, and the electric utilities. On the other hand, no consultants included in this study acknowledged utilities as being a barrier. Furthermore, consultants referred only to cost and technology as being barriers.

Production of a battery (the supplier) to deployment of the total system at the end-user site (the utility) involves a linear process-addressing a market and providing a product to serve that market. BES suppliers have invested large capital and research and development costs to prepare for the BES market. To date, the BES market has lacked adequate demand to fully compensate all suppliers for their internal investment.

From one supplier's perspective, utilities may lose revenue if BES systems are to be used:

[One barrier to BES acceptance is] lack of utility support...And utilities look at this as 
perhaps cutting into their revenues in the area of peak shaving.

The discussion of BES barriers to acceptance should not focus on lack of utility interest as the singular barrier. Each utility is confronted by unique internal dilemmas such as technology selection, as well as external industrial factors such as deregulation, in the day-to-day operation of a utility.

One barrier to BES acceptance is the internal process of technology selection by utilities. Industrial electrical technologies are intended for use in either generation, transmission, or distribution, with procurement processes generally surrounding the individual area where that technology will be used. Rarely does one find a technology suitable for use in all of the three areas.

An exception to this rule is the deployment of generation technologies at the substation level. BES is fairly unique because of the flexibility of its simultaneous contribution to generation, transmission, and distribution-all from one location.

BES could play a part in generation, transmission, or distribution. However, marketing BES as being useful in all three of these areas would bolster its image as a multitasking technology-which many perceive to be one of BES's greatest marketing assets. Procurement must therefore rely on the coordinated efforts of three internal areas, which can be difficult. One respondent stated:

The other barrier is what I specialize in, is that you have to deal with multiple types of entities in different parts of the power system. For storage to be a viable alternative it just can't have one application; it has to be more than one application and you have to deal with transmission, distribution, and generation people. It has to perform all these functions in order to be a viable alternative. That's a barrier when you have to deal with multiple people.

One supplier perception about utilities is their failure to conduct internal research. As one person responded:

I think another barrier is that utilities don't have money to experiment, and they...need to consolidate $R \& D$ activities, something like an EPRI sort of methodology.
This statement assumes that utilities should direct effort towards studying and identifying single or multiple technologies. Utilities may have studied or currently study technologies such as BES, but with little or no investment. Utilities can employ traditional generation technologies in applications suitable for BES.

Lack of utility interest in BES may create negative feelings toward utilities, as one participant remarked:

For storage and power quality with BES systems that the industrial and commercial user will use, they're being unsold by utilities because they don't think they're a forward thinking technology.

Perceived technical barriers are mainly aimed at battery lifetime and energy density. One respondent stated:

The first barrier is no capability to supply a mature product.

A battery capable of delivering energy with low capital costs might be considered mature. Yet, leadacid technology has existed for decades. People will continue moving toward technologies that maintain better cost-to-benefit ratios. In addition to perceived technical barriers, BES cost has always been a large barrier to acceptance.

Some people feel the increased delivery of BES units will help lower the overall cost of the system. Others see reducing the cost of system technology, mainly system components other than the battery, as a solution.

A third method to possibly reduce barriers to BES acceptance is not through technology changes or volume shipments-instead, it is thought that highlighting the value and benefit stream of the BES system in comparison to cost would help. Highlighting the benefits and value underscores the larger issue relating to overall awareness of BES.

\section{BES Customer Segmentation}

BES suppliers and consultants were asked to identify any types of electricity providers that might become BES customers (see Appendix $B$ for the questionnaire). The same suppliers and consultants were asked which electricity providers they target now and which ones they plan to target in the future. 
The list of potential BES customers included but was not limited to cooperatives, municipalities, IOUs, and IPPs. Alternatively, customers can also be segmented depending on their particular needs irrespective of their formal title.

Although fewer than a half a dozen large BES systems are currently installed in the United States, vendors and consultants have identified market segments.

Entities with high demand charges and those with critical loads have been identified as one potential BES customer segment. Several contributors whose opinions parallel these thoughts felt these characteristics could be found in specific markets or rural electricity providers. Secondly, the contributors felt the electricity providers who are more attuned with their customers needs could fit in this group.

Although high demand charges and critical loads have been identified as common characteristics that may be reasons for segmentation, several contributors had different feelings on particular entities with these needs. One person felt that the market that could be characterized by SCE with their Chino, California, plant would "dry up." Average-sized cooperatives and rural electric associations are often not perceived to be potential BES customers, mainly because of lack of adequate funding.

Discussion in this category raised much attention on serving end-user needs. To a certain degree, some contributors expressed their feeling that innovative electricity providers may be more inclined to be BES customers. This category of entities would include utilities aware of end-user needs, IPPs, and electricity providers serving niche markets.

IPPs and PV electricity providers are viewed as being potential BES customers. It is possible these views are generated by thoughts on deregulation and how IPPs may or may not be affected. Although utilities were scarcely mentioned by class in this discussion, one person gave his views with regard to utilities and IPPs:

A utility is being pushed. For example, because of competition neighboring utilities might be a big [BES] user, especially if they are all electric. If there's gas and electric, they're going to look to the gas side. Most utilities are looking at generation, and not storage. PVs and renewables, and IPPs interested in those sort of things usually have incentives in terms of long term contracts from utility purchasers.

In response to that argument, emerging power quality and end-user pressures may evolve to the point where utilities address those issues more fully:

I'm talking about those things that are spinning reserve, peak shaving, and things like that [with regard to distributed generation and distributed storage in certain geographic regions]. It's really the latter that the industry is going to address out of need for generation support. But I think on the other side, their end-user customer is what is driving very hard the need for the power quality side. So IPPs are not going to be any different than utilities today. They are going to have the same end-user pressure for when they get into wheeling when they get into other things in the unregulated environment, they're going to have to supply power quality initiatives.

One underlying theme in the input from the contributors is the emerging needs of end users. Many people feel that eventually the BES market will shift to enduser needs. As expressed by one vendor:

My opinion is that in terms of the hierarchy of need, large scale BES systems can provide some useful benefits to the generation, transmission, and distribution side in the electric energy dispatch chain. But on the customer end, the end-user customer is the greatest beneficiary of BES. My opinion has to do with a whole new emerging field of customer oriented services which can be derived from the use of BES.

Outside of the common themes discussed here that may point at customer segmentation, others separately felt that no entities were particularly likely BES customers. Alternatively, some felt all the groups were as likely as any others to be BES customers.

In conclusion, the emerging issue of end-user participation in electricity-providing decisions is a driving force behind BES customer segmentation. 


\section{BES Customer End-Use Appli- cations}

Many contributors felt a large potential for end-user utilization of BES. In regard to applications, many speculate that end-user power quality issues will drive end-user acquisition of BES.

In numeric terms, several separate contributors offered numeric estimates of the size of this potential market, although quantification of the end-user market size is discussed in a separate category. Opinions given by respondents were split between large and small estimates, with a large vacuum in between. For instance, a large battery supplier that also manufacturers BES systems estimated the market in 2005 to be $\$ 2$ billion to $\$ 3$ billion.

Niche markets, such as electricity providers on islands or in remote continental off-grid locations, are deemed as being an appreciable market for BES. The inherent problem with this market, regardless of it being considered appreciable, is its size; the niche "island" market may not be large enough to support vendor manufacturing efforts.

Secondly, end-user applications in niche markets may be similar to end-user needs for on-grid end-users, but niche markets may be small.

Said one respondent:

Compared to the whole power generation segment it's very tiny [the niche BES market]. I would guess-if I had to pick a number-I would guess less than 1 percent of the whole power generation market.

A different contributor thought the BES market would be comparable to the PV market.

End-user needs when compared to the utilities' propensity and ability to deal with those issues may force vendors and utilities to address that market. Addressing the BES market at the end-user level, in spite of the growing demand for power quality, is difficult. Several respondents indicated that they were not always successful in receiving help from utilities to identify end-users who are potential customers for BES.

Furthermore, if the end-user market becomes as large as some have predicted, methods for identifying those customers will be developed by vendors. One con- tributor targeting potential commercial and industrial end users pointed out that the demand for BES systems presently exists:

Because, once again, the customers at the end of the distribution chain are the ones who suffer the greatest losses in the event of disturbances.

In addition, two vendors actively pursuing the enduser market are looking for the customers with the largest losses in revenue because of product spoilage and downtime caused by power outages. Those customers, they say, are the ones who have chosen to go outside the utilities for solving their power quality needs.

As discussed in other parts of this section, power quality issues are at the heart of end-user demand for BES. However, end users are also looking to BES to help reduce high peak-demand charges. One respondent estimated that the BES power quality market will grow to $\$ 150$ million in the next five years. This power quality market, he stated, will demand BES systems with "up into the several megawatt ranges per installation for short durations up to 10 to $30 \mathrm{sec}$ onds."

Several contributors felt cost would be an overriding factor that would play into identifying end-user applications. These opinions were discussed in other categories but were included in this discussion to demonstrate how some respondents felt about the topic of end-user applications.

Regarding cost, one contributor's opinion is included here:

I think the market is substantial for end-user applications. I don't foresee a substantial market in residential applications; however, the key to success and penetrations will be cost. With existing lead-acid technology the market will be of no significance.

A different opinion, this one relating to BES in general, stated:

The potential is there, there is no question about it....The demonstration projects, the real projects-everything is running fine.... The potential is there, but people don't seem to want it. 
In conclusion, information gathered from supplier and independent consultant interviews indicates that power quality is perceived to be the largest application for BES.

\section{Barriers to BES Acceptance Among Electricity End Users}

One of the largest barriers to end-user acceptance of $\mathrm{BES}$ is showing that using the system is beneficial. In the end-user market, power quality and peak shaving were two BES applications that, if proven, might help open doors. The first dilemma to be overcome is proving to the end user the financial viability of using BES. One contributor stated that companies, if interrupted for only seconds, lose a great deal of money. In turn, they look to buy some sort of technical insurance to offset or eliminate those spoilage costs.

Once the end user is shown the potential savings, it has to financially justify the capital expenditure. Separate contributors feel end users, as opposed to utilities, must realize the capital expenditure payback in less than 24 months.

Utilities, on the other hand, are viewed as having longer payback horizons; one participant indicated the utility payback can extend from four to eight years. Other contributors expressed similar views. Several indicated BES cost at the end-user level might be a considerable barrier preventing deployment.

Frost \& Sullivan would like to point out that endusers and utilities might see cost in comparison to benefits in different ways. Furthermore, uncertainty created by deregulation may nullify traditional 4 - to 8-yr payback, forcing many to cease capital purchases or to choose safe and proven technologies such as UPS or serial power supply (SPS) systems.

Compared to utilities, who may use BES for similar or different applications than end users, end users do not traditionally allocate a section to their budget for electricity-providing technologies. Examples of these end users may include commercial and industrial companies. Some see this unfamiliarity as a barrier to end-user acceptance:

It's harder for them [end users] to take on a major project to store a lot of energy because that is not the business they've been in. I think utilities would be an easier market to penetrate than the end-users.
Deregulation may play an increasingly crucial role in changing the barriers to BES acceptance at the enduser level. End users currently have the option to purchase BES systems through vendors. In some instances end users can look to utilities to help solve electricity reliability issues. When and if the effects of deregulation are fully felt, intermediaries might help facilitate the erosion of BES barriers. Assuming the end-user market for power quality and peak shaving is addressable, third-party competitors may emerge to serve the end users more efficiently than existing entities, utilities, or vendors.

One consultant offered his view on this discussion:

I think on the end-user side, the fact that you are seeing lots of third parties-whether they are energy service companies or other similar organizations that do consulting or turnkey operations or whatever-directly for end-users is going to facilitate the market for batteries because those kinds of organizations are much more likely to know about and be comfortable with installation of new technologies such as batteries.

This last response might show how third-party suppliers in a deregulated environment can possibly open the doors to an explosive BES market.

In a thought not related to the general line of discussion in this section, a respondent estimated the enduser market to be approximately $\$ 20$ billion a year; that number represented revenues lost to product spoilage and downtime from power outages. Thirdparty competitors could feasibly add another link to the vertical BES market-they could interface between BES vendors and end users. This could possibly help strike down barriers to BES acceptance because, as a previous quote indicated, third-party electricity providers could "facilitate the market for batteries."

\section{Electricity End-User BES Market Estimates}

Projections of the size of the end-user BES market are based on estimates gathered from study participants. Most respondents were unable or refused to estimate BES market size in a forecast period beginning in 2000 and ending in 2010. In the absence of historic BES growth trends, those who did make estimates either made outright guesses or used a 
percentage of total load growth as a basis for their estimates.

In 2000 , the electricity end-user market for BES was projected by BES suppliers to be $496 \mathrm{MW}$ (see Table 5-1). This number was forecast to grow to $805 \mathrm{MW}$ by 2005 . In 2010 , survey participants expect the market to be $965 \mathrm{MW}$. These estimates are based on total estimated megawatts of installed BES capacity for each of those years; these numbers are not aggregate. Out of 17 respondents, six supplied estimates used for this projection. Of the six, four were contributed by suppliers, two by consultants.

Lacking a central infrastructure for information collection, no proven BES market predictions have been widely disseminated. If any type of standardization in the BES market existed, it would be logical to assume some version of a BES market model would be in circulation. Although a current or standardized model for estimating the potential end-user BES market is not in circulation, some vendors have indicated they have developed methods for determining this market.

Several vendors currently targeting the end-user market measure estimated demand in gigawatts of BES capacity.

One participant stated:

I think the market is going to be power quality areas, one. The other area is going to be peak shaving. When deregulation hits they may find more financial incentives to do these kinds of things themselves.
Another contributor added to this sentiment:

I think 80 percent or more of batteries that are out there for companies are going to be power quality related.

\section{End-User Battery Technology Preference}

Feedback from study participants indicates that three factors drive end-user battery technology preference: application requirements, cost, and maintenance factors. These three factors vary depending on battery technology.

VRLA batteries are favored in the end-user market over most other battery technologies for a given set of applications. End users may include telecommunications companies, semiconductor manufacturers, food processors, mold makers, and many others. It would be safe to say most end-user companies do not employ a staff of battery experts, and that therefore their battery selection is largely influenced by their direct contact with consultants and vendors. Under the assumption of total knowledge of battery technology, VRLA batteries are viewed as maintenance-free and safe.

Maintenance appears to be a critical factor in enduser battery selection. One respondent stated:

VRLA cells to some extent obviate the hydrogen problem. They also obviate some of the concerns about acid spills, as do things like sealed nickel metal hydride.

Table 5-1. BES Market: Supplier and Consultant Estimates of the Electricity End-User Market (in Megawatts) (U.S. and Puerto Rico), Years 2000, 2005, and 2010

\begin{tabular}{ccc}
\hline Year & Megawatts of BES Capacify & \$ (Millions) \\
\hline 2000 & 496 & 372 \\
2005 & 805 & 443 \\
2010 & 965 & 434
\end{tabular}

Note: All figures are rounded. 
Another respondent stated that the less the end user:

Has to bother with it the more they like it. So I guess they would like a battery they could put in and forget it.

Another respondent repeated this sentiment and mentioned a specific technology:

I don't think [end users] care as long as they don't have to worry about all kinds of maintenance. Right now people trust lead-acid more because of experience....So I would think that they [utilities] would probably prefer lead-acid over some of the newer ones right now just because of lack of experience.

This respondent's opinion was targeted at utilities, but this sentiment is shared by contributors' opinions of end users.

Although maintenance and potential environmental threats impact battery technology selection, the application requirements demanded of a system should ultimately determine the battery selection. This opinion is mentioned several times in responses. Stated one consultant:

If people want a lot of energy storage they go to these flooded cells...People want high power, they will go to the sealed for short durations.

This type of response indicates how battery technologies may be reduced to simple generalizations without naming any particular battery technology. One respondent repeated this popular theme:

In other words somebody wouldn't come up and say it has to be nickel cadmium battery or lithium polymer or has to be nickel metal hydride. They indicate more cycle life and low maintenance as being the requirement of the battery.

\section{Competitive Analysis}

Contributors to this particular discussion were asked to give their impressions of BES vendors (most of the contributors were vendors). The names of companies the contributors were able to recall as vendors included AC Battery, GE, GNB, C\&D, Yuasa-Exide, Westinghouse, ABB, Siemens, Kenetech, Silicon Power, Nissho Iwai, East Penn, Horizon, Japan Stor- age Battery, JCI, Delphi, and Habaka Avarta (this vendor's proper spelling could not be confirmed. It is believed to be a European vendor and was only mentioned once throughout the study).

Most contributors were aware of several vendors, though some contributors did not offer their opinions. Furthermore, contributors seem to be aware of and offer names of the vendors and BES facilities they have participated in.

One vendor of complete systems offered his opinion of AC Battery:

They have no particular core technology in batteries, their PCS system is fine, and they've selected lead-acid as their primary battery technology, and their PCS system is designed to match their lead-acid system. So, I think AC Battery is a key player, in terms of BES as a system. That's the only system I'm familiar with that has done an adequate job.

Only one other vendor specifically mentioned AC Battery as being relatively successful. A different vendor named an Alaskan BES project, citing GE, and said GE has probably been the most successful of known vendors so far.

Several respondents were keen to point out the "demonstration nature" of existing BES systems, and based their opinions on those projects and the lack of a BES market. In short, a majority of respondents feel current vendors have not been successful overall. Furthermore, the lack of a full-scale market with large unit shipments precludes an accurate assessment of vendor success.

Some respondents felt that the success of BES vendors can be measured by the current size of the BES market. However, in a market characterized by lowvolume unit shipments, it would be erroneous to imply that it is the vendors who are at fault for the slow growth of the market. Factors other than lack of adequate market demand should be brought into question when measuring a vendor's success or lack of success.

One consultant expanded this discussion by offering his opinion on the changing nature of utilities. He illustrated how the internal utility functions may affect the BES market and, indirectly, how this may affect vendors: 
They do fine [regarding vendors], but their market maybe a thousand times what we do [consulting], so they're fine for other reasons. That's another thing that's sort of funny about this industry is that $I$ think these giant battery companies come and keep their eyes open on this utility stuff so that if something ever does happen, if the market happens they'll be there and they'll understand what they have to do. But none of them are really like putting huge efforts into building the market themselves because utilities will come and go. A utility will get some excited research guy coming out and saying this is great and they get the battery guys excited and then the next year comes and the planning budget changes and the research guy goes "well, we're not going to do a lot." So I don't know, I sort of see these battery guys as sitting on the fence waiting for a real market to appear and they have been waiting for a while.

A supplier had this to say about BES vendors:

I think most of us have some idea that we want to attract some portion of the market. We're all trying to find our niche, we're all trying to find out what we're best at, what our battery is best applied to. I think there's room for all of us, really.

\section{Vendor Perspectives On Exist- ing BES Projects}

Perspectives of vendors and consultants on existing BES projects are based on tours of facilities and second-hand information.

The respondents capable of discussing this topic mentioned facilities at Chino, California; Vernon, California; Crescent Electric Cooperative; and Puerto Rico. Alaska was mentioned, but no individual BES system was referred to. Two more responses separately referred to the BES facilities at Crescent Electric and the BEWAG plant in Germany.

Most respondents seemed informed on the well-being of existing BES facilities.

Based on interviews with vendors and consultants, opinions of existing BES projects are cautiously optimistic. The use of the word "cautiously" should not imply that respondents were not pleased with existing facilities. Instead, it means that respondents see batteries at installed sites boosting the BES market although they have pointed to the perceived problems.

A minority of respondents referenced this discussion to utilities. Most offered opinions of existing BES facilities and simultaneously pointed to the successful and unsuccessful features of those they were familiar with. Other respondents made bold generalizations about existing BES facilities, either pointing to a technological flaw or capital/revenue shortcoming.

The next quote is from another supplier:

I think they are happy in Vernon with what they've accomplished. I think the Chino facility maybe didn't accomplish all of the goals they wanted to accomplish. I think it was expensive, a maintenance headache, and a bit of a disaster from that end, but SCE seems happy at least they have it on line.

This person added:

I think they are accomplishing a lot of the things that we want to accomplish with the units that we have.

The supplier who made these last two statements praised the Puerto Rico facility, citing management's satisfaction with the BES system. Another respondent whose complete quote was not added also praised Puerto Rico for its performance. In the typical fashion of some responses, he pointed out equipment failures, then stated that the facility "is providing the benefits that justify it in the first place."

Regarding end users, one respondent commented that BES benefits the end user more than the utilities for power quality and reliability. Referring to the utilities again, a different respondent stated that:

Utilities are trying to prove out the costeffectiveness of BES, and to make some evaluations made on a small sampling size.

Not all respondents are as optimistic as others. Several negative opinions were contributed by suppliers and consultants. Comments seem to focus on general shortcomings rather than technical overall performance.

Along this line, one supplier commented: 
I think they've disassembled Chino. That tells you something, you know. If it was practical, why didn't they continue with it?

In conclusion, a wide disparity in opinions exist within the BES supplier community on this subject, with significant numbers of suppliers and consultant organizations on either end of the debate.

\section{BES Manufacturing Develop- ments}

During interviews with Frost \& Sullivan, contributors were requested to give their opinions regarding necessary future BES manufacturing developments. Opinions of future manufacturing developments reflected BES market estimates presented to contributors by Frost \& Sullivan (see Appendix B, question 12).

A large proportion of contributors' opinions indicated a belief that the existing BES production infrastructure would be capable of handling future market demands. Two responses supporting this consensus said future demands could be met by shifting personnel, and with "none or minimal expansion of manufacturing if lead-acid is used."

Some companies producing batteries for the BES market are also involved in battery production for other industries, specifically the automobile industry. In 2002 , approximately 100,000 zero-emission automobiles are slated to be sold in California alone. In order to meet this demand for batteries, assuming lead-acid is used for batteries in those cars, the potential for restructuring manufacturing facilities could occur. One contributor expressed his thoughts about this potential issue:

I would say that today's LA [lead-acid] battery industry can handle this. There might be some production required if all the other applications also go up in demand. For example, [if] the California electric vehicle [EV] market had come on board, then we couldn't have absorbed the energy storage market. This can be handled easily by the existing factories with some removal of bottle-neck capacity.

This comment brings up the risk that parallel manufacturing for BES batteries and electric vehicle batteries may still be an issue in 2002 . However, another contributor commenting on the same issue believes electric vehicles will evolve out of lead-acid technology by 2003 .

In conclusion, most contributors do not feel future BES demand will exert pressure on manufacturing unless advanced batteries are required. In that case, serious production bottlenecks might occur.

\section{BES Marketing Developments}

In addition to the manufacturing theme discussed, Frost \& Sullivan contributors were also requested to give their opinions regarding necessary future BES marketing developments. Responses discussed in this section were based on the same market figures presented to contributors in the previous category (see Appendix B, question 12).

BES vendors and consultants were asked what BES marketing developments would have to occur to meet forecasted demand. Notwithstanding the variety of opinions expressed in this discussion, common themes emerged-legislation, customer satisfaction, industry/utility awareness, technological developments, and power quality.

The current BES market is characterized by low utility demand, mixed optimism by suppliers, relatively high cost, varied perceptions of BES by customers, and a mixture of competing technology price profiles based on application.

Although the federal government has continued to provide funding for BES development, some electricity providers believe more help is needed. One BES supplier theorized that government intervention could be in the form of government subsidies. BES system cost is high compared to that of other technologies such as gas turbines or diesel generators. A subsidized environment could reduce the issue of cost as a driving force behind capital equipment selection, but the concept is believed to be of dubious political and social merit.

Another factor that could possibly assist BES market development is environmental regulation. The respondent who presented this opinion stated:

It would help if there were some environmental laws that require them [electricity providers] to use BES instead of fossil fuel burning peaking technologies. 
If the price of fuels for competing technologies increases, customers may see an incentive to buy BES systems. This scenario assumes a situation in which BES and competing technologies could be used in similar roles.

In addition to changes in government subsidies and environmental legislation, changes in customers' financial methods and accounting policies are also a possibility. One respondent saw this as one avenue of opportunity for stimulating the BES market:

I think just a realization of the problems they have out there and $I$ think a lot of it would be to defer capital investments in the utilities and end-users. If they looked into the real benefits of it I think that's what it would take to do it.

A different respondent voiced a similar opinion:

You would have to show you could defer significant amounts of distribution investment so that it would make sense to use them heavily on the distribution side as well. I just don't think the market is there on the generation side.

Focusing on greater utility involvement, in a market characterized by virtual inactivity such as the BES market, a convenient paradox describing that market is often used: Customers will not purchase BES systems until the cost decreases, and cost will not decrease until manufacturers' production levels reach economies of scale.

Only one respondent cited this paradox; others felt the only way to stimulate market demand for BES is by pushing for deployment regardless of cost. This approach will probably not be acceptable to electricity providers or end users.

Two respondents who contributed opinions to this study felt that unless some kind of immediate actions are taken to create a BES market, the benefits of BES will never be fully realized:

We need to immediately and as soon as possible demonstrate the economic viability of BES systems at customer end-use sites and also at the utility generation and transmission sites. The technical feasibility can be demonstrated in deploying hardware. So you can literally point to hardware deployed in measuring the economic benefit stream that came as a result of that hardware.

This respondent stated that his company will primarily serve the end-user market but could link multiple BES units for larger utility applications if that demand surfaced. An interesting point should be made here-BES systems for utility applications could recognize lower cost through economies of scale in the end-user segment of the market.

One supplier believes one of the ways to meet forecast demand is through the cost savings awareness of BES systems. When the customer, and others, can clearly see the savings and productivity of employing a BES system, awareness will spread.

The concept of utility and end-user separation is implied. They are two different markets, but they are interrelated in the sense that success in one market should benefit the other.

Under deregulation, utilities will have the option of generating revenues by catering to the power quality needs of end-use customers. If they choose not to address these previously nonexistent pressures, customers will likely turn to off-grid power quality suppliers. Therefore, utilities might be faced with the option of sharing revenues with third parties if they do not respond to the power quality needs of endusers.

Looking at the market developments that would be needed to meet the forecasted demand on which respondents based their opinions, several pointed out potential for greater utility action.

In the words of one supplier, if the utilities are:

Willing to install [BES systems] across a wide variety of applications or situations, then I think the whole thing will take off. I think then the people like Duke Power and the City of Austin and some of these municipals-some of those will march in lock step and they will buy it also and say, "It worked there, I better get on board." And that's what happens in the utility market. There are just a few innovators and the rest of the group kind of marches along in lock step.

The truth of this person's statement is debatable, but market awareness through demonstration is the most 
viable option that could develop a large BES market to meet forecasted demand.

Two other opinions aimed at utilities point to the potential for coordination inside the utilities, and of utilities as a whole. Proving that BES systems have multiple benefits and clearly demonstrating the value of those BES benefits in a multiple application environment may broaden awareness of the uses of BES. Secondly, one respondent felt that utilities' internal "cost sharing" efforts may become one market development mechanism to drive BES demand.

Several respondents did not directly address the market development question posed to them. Instead, one respondent noted the lack of awareness in the electricity provider industry. This respondent asked a utility several questions, trying to discover if the utility was open to BES. In response, the utility asked if a BES system could be installed on a telephone pole.

Another respondent summarized his thoughts on vendors and the BES market by saying:
People basically say, "Yeah, its here and if it comes we will make it [a BES system]." I don't think too many people are counting on this market.

Another single response indicated the need for greater awareness which could possibly be achieved through a BES web page. Although a BES web page may help educational efforts, it seems unlikely to succeed where previous educational efforts have failed.

In conclusion, BES vendors seem constrained by high BES costs, which make demonstration projects difficult. Also, incomplete BES awareness among utilities keeps them from driving demonstration projects. Interestingly, little discussion was given to subjects such as the development of sales, distribution, installation, and maintenance infrastructure. The lack of discussion is inconsistent with the current lack of this kind of infrastructure in the current BES marketplace. 
Intentionally Left Blank 


\section{Regulatory Agency and Industry Group Perspectives on Battery Energy Storage}

\section{Introduction}

The regulatory agency and industry group surveys included in this study are intended to gauge the awareness of and appreciation for BES in those two bodies. Twelve separate entities were contacted and interviewed for this chapter using the questionnaire found in Appendix C.

Input from the 12 entities varied widely, as does their influence on the end-users of BES. The extent to which these bodies influence BES depends on legislation, national resource trends, deregulation, and demand side management (DSM). Compared to utilities or BES vendors, these organizations generally maintain a broad view of energy resources, among which BES may or may not be singled out.

\section{List of Contributing Regulatory Agencies, Industry Advocates, and Professional/Academic Associations}

Analysis of varying BES perspectives was based on contributions made by the following entities.

Regulators:

- California Public Utilities Commission

- Florida Public Service Commission

- Maryland People's Counsel

- Massachusetts Department of Public Utilities

- New York Public Service Commission

- Public Utility Commission of Texas

Industry Groups:

- Alaska State Division of Energy

- California Energy Commission

- Environmental Defense Fund

- National Association of Regulatory Utility Commissioners

- National Rural Electricity Cooperative Association (NRECA)

- U.S. Rural Utilities Service
Chapter Structure

The following discussion is divided into six sections. Each section discusses the responses to the questions from Appendix $\mathrm{C}$ based on the collective input of the 12 entities interviewed for this study by Frost \& Sullivan.

\section{Regulatory Agency, Industry Advocate, and Professional/ Academic Opinions of BES}

Responses from the listed entities demonstrate the varying degrees of BES knowledge from one entity to another. With this in mind, responses can be used as a tool for measuring exposure to and awareness of BES within these organizations. If an entity has experienced strong exposure to BES, its opinion may be based on technical or actual operational knowledge of BES systems in the field. No exposure to BES may be reflected by the response "no opinion of BES."

Results indicate that an entity with no opinion of BES generally has had little exposure to BES technology. This premise is supported by several entities that neither took a position on BES nor were actively engaged in identifying particular storage technologies. These entities later explained that they receive little news or feedback on BES.

Exceptions to this rule do exist. Some entities do not maintain an opinion of BES but are aware of the technology. Such entities may simply regard BES as one of several storage technologies. Their depth of BES knowledge is difficult to ascertain, but these entities demonstrated familiarity in discussing. issues of BES cost, BES system success or failure in the field, and/or the need for BES improvement.

Many regulatory agencies and industry groups maintain a working knowledge of popular technologies, either by necessity, through experience, or word of mouth. For example, one entity was firmly aware of the pricing and energy density issues regarding one proposed Alaskan BES system installation, having 
obtained this information through informal industry channels.

In a more broadly defined scope, another respondent demonstrated his organization's knowledge of BES by stating:

I'm not sure our organization has formed a specific opinion on BES.

Later, the same person stated that:

While BES systems seem to form an important and sound operation part of distributed energy applications, we're always interested in more improvements.

If asked, "What is your opinion of combustion turbines?" the same respondents might call on their collective knowledge of combustion turbines with the same vague uncertainty they did with BES. If the same respondents were asked their opinions of hydro power, they might recite one or two popular hydro projects. Fewer hydro projects exist than combustion turbines, and even fewer installed BES systems exist.

The point is that despite the disparate number of turbine, hydro, and BES installations, the 12 contributing entities sometimes view the technologies as homogeneous. This is ignoring the vast technological differences involved, however.

Often the controversial nature and novelty of a technology dictates the amount of attention allocated to it. Nuclear generation, for example, is a widely debated technology and may evoke a greater response because of its unique nature. On the other hand, BES may linger in the shadows indefinitely before people register opinions about it.

Some entities may be familiar with the term "BES" and yet have no opinion of it. Lack of awareness, refusal to maintain an opinion, and absence of technical knowledge have been widely observed in the regulatory agency responses. To some extent, this may underscore the regulatory agencies' homogenous perception of the technologies.

However, the assumption that regulatory agencies are devoid of practical and technical energy storage knowledge is unfounded. In general, the broad roles of regulatory agencies may preclude them from developing opinions on particular technologies.
Furthermore, the trend toward market-based technology selection has distanced regulatory agencies from deciding which technologies will be employed by utilities. Regulatory agencies play a role in reviewing electricity providers' integrated resource planning when requested, but their knowledge base on particular technologies seems to be diminishing.

\section{Regulatory Agency, Industry Advocate, and Professional/ Academic Promotion of BES}

The willingness of the entities surveyed to promote any particular technology in the electric industry is low. The word "promotion" dictates that one technology is preferable to another, holding everything else equal. In the electricity market, a technology may be promoted for its efficiency regarding fuel input, kilowatt output, and capital cost. Outside these boundaries, a technology may be promoted because it holds set characteristics not duplicated by other technologies.

The cost of BES in relation to competing technologies is viewed as the main factor retarding promotion by regulators and industry groups. To change this, the BES pricing profile would need to become more competitive with popular technologies for a given set of common applications. However, regardless of the cost barrier, other obstacles to BES promotion are widely perceived.

As an example of a noncost barrier, one regulatory body stated:

That would depend on the information provided to us. I don't know that we have the information now to take a position. We could probably take a position through our role in reviewing $R \& D$ activities at [the local utility].

This person indicated a potential for their regulatory body to form an opinion. However, a common theme in this discussion is not the regulatory bodies' failure to promote BES, but rather their inability to give technology opinions outside their juristic role. Industry groups included in this study seemed to share that attitude. The National Rural Electric Cooperative Association (NRECA) indicated that it does not actively promote BES, but its research on BES has proven positive. Furthermore, NRECA recognizes the need for lower-cost BES systems. 
In addition to other factors inhibiting promotion, regulatory agencies are playing an increasingly smaller role in determining technologies employed at utilities. Deregulation is forcing a shift in the industry to market-driven decision making. As regulatory agencies move away from their traditional, more active role, their likelihood of performing technology promotion is reduced dramatically.

In summary, regulatory agencies traditionally handed approval to or endorsed actions taken by electricity providers. Now, the limits of regulatory agency oversight are measured by the actions utilities can take without regulatory approval. Thus, electricity providers today are more free to pursue technology deployment and research efforts than in the past.

BES is generally regarded as an opportunity to prove the usefulness of renewable technologies. On this issue, some respondents promoted BES openly. Others either promoted BES directly or indirectly by encouraging continued research of BES itself. One respondent stated:

Implicitly, our organization has been a part [of] the sustainable energy budget coalition in Washington to ensure sound funding for renewable and energy efficiency programs...DOE funding...I think as part of that coalition we'd be supportive of continued federal work in technology development. We support more investments in efficient energy technology and renewable energy technology development.

Another respondent stated that his organization did not uphold an active policy on BES but that BES was promoted at the staff level.

Responses indicated other factors besides cost and agency impartiality that hinder BES promotion. General uncertainty about the environmental consequences of BES and electricity pricing scenarios also stand in the way of promotion.

Although ultimately BES customers will decide the validity of environmental factors, uncertainty in these areas has reverberated at the regulatory agency level. Without education, negative perceptions and lack of opinion at the regulatory level will probably not change much.

\section{Benefits of BES}

An overwhelming association of BES benefits and DSM/distributed resources by respondents indicates the evolution of power quality issues at the end-user level. It appears that most respondents see more benefits at the electricity end-user level than at the utility level.

Part of this perception may be attributed to the lack of awareness of the benefits obtained by existing BES systems. Few people, residential or commercial, express gratitude when power quality is maintainedthey are not aware of this maintenance. Yet homeowners and business owners are certainly aware of the inconvenience caused by power lapses, power outages, and brown-outs. Residential individuals complain, and business customers-tired of revenue losses-choose a new power supply.

The development of DSM and distributed resources illustrates an increasingly popular trend among electricity end-users. The perception and subsequent testing and deployment of BES systems at the enduser level demonstrate the usefulness of BES as a tool for breaking away from traditional utility-provided electricity/power quality. BES did not create this evolving practice; it only offers flexibility of system design when other options are not available.

Reduction in peak demand and load stabilization are areas believed to generate the greatest savings when employing a BES system at the end-user level. In addition to providing insurance against power outages, BES systems offer end-users the option to shave peaks.

The need for flexibility of control over supplied power and the ability to save electricity costs are the greatest end-user benefits derived from BES. As a result, end-user markets may emerge as the largest recipients of BES systems. BES system flexibility may also be proven through DSM application packaging. In this scenario, BES systems would be coupled with other technologies designed to meet customer needs.

\section{Estimates of Load Growth}

Load growth and forecasted load growth should immediately affect the consequential selection, employment, and/or deferment of electricity technologies. Electric utilities are the most affected; 
end-user power quality issues are not directly influenced by load growth.

The link between load growth and BES deployment may have greater meaning in the future. Competition spurred by deregulation, coupled with increasing industrial and commercial growth, will likely force electricity providers to look for new ways to retain customers.

Also, the costs and difficulties of siting a new transmission and distribution infrastructure should force greater reliance on distributed generation to alleviate system bottlenecks. Greater interest in distributed generation should benefit BES, since BES is better suited for distributed applications than for central applications.

Load growth in southern and coastal regions is expected to grow at a reasonable rate of 2 to $3 \%$ in the foreseeable future. Load growth in the central and midwestern areas can expect to experience almost no growth. Load growth of 1.5 to $2 \%$ in the eastern states is forecasted. An allowance for the uncertain impact of deregulation is implicitly factored into these forecasted load growth rates.

\section{BES and Deregulation}

The uncertainty in today's electricity market is chiefly caused by deregulation. In the face of looming deregulation, many utilities are limiting, and sometimes completely stopping, capital expansion.

Many respondents see deregulation as creating opportunities for customer-oriented electricity service companies. Companies may specialize in one service area or offer solutions to many problems. Opportunities for distributed generation solutions may include BES:

Once you can add storage you can kind of get effective capacity off intermittence and therefore you have more people who might be able to buy them. That's dependent on restructuring, producing more opportunities for new business entrants and therefore more choice of customers.

Opportunities for third party companies lie in solving power supply problems at the end-user and customer levels. At the same time, utilities, no longer burdened by the requirement to provide end-user service, may prefer to focus in areas such as generation that are not conducive to BES use.
BES systems in a deregulated environment will probably continue to compete against two existing factors. One is other power supply technologies. Input by respondents indicates that natural gas, diesel, and potential encroachment by other developmental technologies will likely compete against BES for common applications. The market success of BES in relation to these other technologies will probably depend on cost factors. In addition, other BES perception barriers mentioned in this chapter should play a role in decision making.

One respondent commented on the topic of BES's market success by saying:

[BES] has a niche of its own because there are various other ways to [store energy] also. For electricity you can have liquid fuels. You can have natural gas and use it when you need it. You can store electricity through compressed air energy storage. You can store it as a modular pump hydro. It depends on the need for the site, and accordingly, you select the best storage mechanism.

One organization stated:

In a deregulated industry with the price of electricity dropping, it is making it much more difficult for the fringe, not-yetdeveloped industries, such as renewables, such as biomass, such as batteries, to be able to economically compete in the market.

In utility applications, wheeling, capital divestment, and uncertain investment climates may retard the proliferation of BES in a deregulated environment.

\section{Industry Feedback on BES}

The differing types of BES feedback must be separated to appropriately determine if channels for feedback do exist. BES opinions regarding cost of system, maintenance factors, and output vary by individual and organization. Particular opinions held by individuals or organizations may be outdated, subjectively influenced, or correspond with current BES market trends.

The responses of organizations contributing to this study indicate that many do not receive BES feedback from other members of the electric power industry. 
One respondent demonstrated that particular technologies are not differentiated and that BES is appropriated no special status:

There are hundreds or thousands of $R \& D$ projects either being considered or in progress. So unless one really stood out, I wouldn't be familiar with it.

That was a common sentiment among respondents.

Another respondent stated his knowledge of BES was limited "to the extent it filters through IRPs and certain conferences that we attend."

$\mathrm{BES}$, as a technology, lacks the promotional infrastructure that other technologies have. Fuel cells and small turbines are actively promoted, Internet access allows browsers to retrieve technical information, and generation technology information can be found in trade journals. In contrast, BES technical and product literature/studies are produced solely by research laboratories and BES suppliers and are not widely distributed. BES suppliers do not seem to be publicly promoting their products.

More direct avenues of feedback exist for some respondents. One respondent stated:

We are sensitive to claims by energy producers that BES [systems] are expensive or have limited applications. So they're always saying, "Well, they're too expensive or they don't provide enough on the energy productions side..." Therefore, they're not used by the utility guys. Then the latter point on the end thing [ending discussion]; they form as part of a kind of balance of system cost for renewable energy systems...there are market barriers implicit in consumer understanding of how BES systems work...how they can be effectively sized, how much they cost as part of the whole system.

Another respondent stated:

We do work with developers like the national labs who are involved in that. We also work with utilities, we read their reports and see how the batteries are performing, what impacts they are having on the ability to manage the loads or use the assets in another way. We are also interested in battery technologies particularly for creating a value out of renewable energy sources.

Feedback does exist for some people that are directly involved in the industry. However, interested people outside the electricity provider market appear to have difficulty obtaining BES information. 
Intentionally Left Blank 


\section{Study Assumptions and Risk Assessment}

\section{Explanation of Assumptions and Risk Assessment}

This section of the report contains a discussion of the assumptions of this report and issues that might affect the BES market in ways that cannot be foreseen. Providing this information is vital to understanding the market estimates given in this study and the context in which this information is provided to the reader.

\section{Study Assumptions}

The principal assumption in this study is that of the continuance of the normal economic cycle in the U.S. economy. The U.S. economy has been in a period of prolonged, gradual recovery since the last recession, which ended in 1991. During that time, load growth in the United States has averaged about 1.5 to 2 percent per year, significantly higher than the average during the period of recession in 1990 and 1991.

Another assumption of this study is that organizational changes within individual electric utilities will not significantly affect the market for BES.

To a great extent, this assumption emerged out of the survey results of electricity providers, discussed in more detail in Chapter 4 of this report. During that survey, electricity providers were asked which groups within their companies would be responsible for BES procurement and how this might change with deregulation. The results of the survey indicate that deregulation will probably have limited organizational effects on BES procurement.

\section{Industry Deregulation}

The impact of deregulation is probably the least predictable major factor affecting the electric utility industry. Most major electricity providers in the United States are confronting market uncertainty for the first time in their existence. Many of these organizations are still relying on assets, organizational structures, personnel, practices, and technologies intended for use in a regulated monopoly environment.
When asked to project their future business activities, few electricity providers were absolutely confident that their companies will still be market leaders, or even independent organizations, in 10 to 15 years. To a great extent, this insecurity also affects all industries that sell capital equipment to electricity providers. Unsure that they will be able to recover a capital investment because of competitive pressures, electricity providers naturally retreat from making such investments.

The specific form that deregulation will take is also difficult to predict. The Federal Energy Regulatory Commission (FERC) has mandated open transmission access at the wholesale level but has left the retail market in the hands of the individual states. Each state has the right to craft its own solution or do nothing, as they see fit. Different states will provide different solutions to nagging questions such as stranded costs, universal access, and residential competition.

Currently, very little certainty exists over how deregulation will affect the various levels of customers within the electric power industry. What is certain is that electricity providers will have to spend more time and effort trying to understand and serve the actual electricity end-user. Whether competition will reach all the way down to the individual residence on a national basis is difficult to project, but regardless, certainly large industrial and commercial customers will receive direct access to the electric power market.

As for the impact of deregulation on BES demand, there is also little certainty. Currently, BES is viewed with mixed feelings within the utility industry. The technology has a reputation for being expensive, high-maintenance, and too short-lived. At the same time, the economic benefits of storage versus production are accepted, and the customer, environmental, and operational benefits of BES are also understood. Either set of factors could come to the fore in a deregulated environment, depending primarily on the performance of the BES industry.

The success of BES in a deregulated environment will depend largely on the BES industry lowering BES cost, increasing its density/storage, and actively promoting the product. The electricity provider in- 
dustry must receive consistently positive messages about BES. This will likely require making each additional BES a success in cost/payback, achieving expected benefits, and BES system performance.

Until the issue of cost is settled through new, yetuntapped economies, to justify cost, the BES industry's claims must focus on BES's system-level benefits when compared to those of competing technologies.

Unless BES cost and operating characteristics are improved, the negative opinions and fixed perceptions of BES technology may bridge over to the deregulated environment. BES marketing must reach all prospective BES users and try to ease any fears or misgivings about BES.

\section{Network Reliability}

In July and August of 1996, transmission line failures caused major outages across the western United States. Fortunately, the worst of these disturbances occurred on a weekend, reducing both the economic damage and the physical danger posed by such a large outage. These and other outages-attributed to new, bottom-line concerns among the utilities-may cause electricity end users to question the reliability of their services.

Such uncertainty could create an increased market for BES, primarily in the form of UPS applications. Electricity end-users may eventually want quality power for their ever-increasing amount of critical load. They will either have this power supplied to them by electricity providers or turn to technologies such as BES.

\section{Electricity End Users}

A limitation that had to be accepted in producing this study is that the report does not attempt to obtain a genuine set of electricity end-user perspectives on BES. To do so would have required more resources than were available for this study. Instead, the focus of the study was placed on the electricity provider and BES supplier industries.

The problem with this approach is that most BES vendors seem to view the electricity end-user market as the present and future of BES. This is understandable, considering the amount of storage end-users keep in the form of UPS. One of the most successful new battery products, AC Battery's PQ2000, is similar to a UPS in that it enables the provision of continuous power to customers. However, the PQ2000 provides only very short-term storage; it is designed to provide electric power for 10 to 15 seconds to ride through brief outages.

Despite some successful end-user BES projects, the widespread deployment of BES has not occurred at the end-user level. Respondents believe this is partly because many utilities discourage the use of peak shaving, since demand charges make up a significant amount of revenues. Because end users' local expert on electric power discourages the deployment of BES for peak shaving, this makes it difficult for end-user personnel to justify BES purchase to their management.

Other factors restraining end-user BES sales include the difficulty BES suppliers are having in targeting specific end users and the relative youth of BES products. 


\section{Conclusions and Recommendations}

\section{Conclusions on the BES Marketplace}

\section{Challenges to BES and the BES Industry}

Battery energy storage does not exist in a vacuum. It must be deployed in competition with other energy supply technologies within a technically complex industry. This industry is also in the greatest period of competitive transition since its formation. In this framework, it seems that the BES industry faces the following major challenges identified by respondents of this study:

- Reducing the capital cost of BES to levels where it is competitive with other energy supply technologies.

- Improving BES product life span.

- Reducing BES maintenance expenses.

- Increasing BES energy density.

- Identifying, segmenting, and targeting specific applications and technical solutions that best serve potential clients.

- Educating industry decision makers and gatekeepers about the benefits and viability of BES as opposed to other competing technologies.

- Overcoming an existing utility industry and power provider bias toward power generation technologies.

- Dealing with organizational conflicts and confusion at the customer level over which groups within potential client organizations would be responsible for BES funding, authorization, and procurement.

\section{Improving BES Cost, Life Cycle, and Maintenance}

The first three points on the list above are basically all technical in nature. These points were derived from responses to the electricity provider question- naire and are discussed in detail in Chapter 4. To some extent, all of these points will be addressed through the research and market expansion that is currently under way. As manufacturing infrastructure is built and as BES research becomes finalized, Frost \& Sullivan expects the cost of BES to fall.

To a lesser extent, the market growth and research that is now under way should improve the life cycle and operations and maintenance issues discussed in the second and third points. As more advanced batteries and BES are deployed, greater knowledge of battery behavior should improve performance in both of these areas.

The BES industry seems to suffer from negative word-of-mouth among both electricity providers and end-users stemming mostly from poorly conceived and planned projects. In many of these projects, batteries were not properly specified, installed, or maintained by the contractor, leading to shortened battery life cycle and greater maintenance problems for clients. This in turn has led to a significant amount of hesitation among prospective BES customers to rely on anything having to do with "batteries."

\section{Increasing BES Energy Density}

One of the shortfalls of available BES technology most commonly noted by respondents was its low energy density. This low energy density increases the per-kilowatt-hour cost of BES. Also, possible storage capacity is reduced in batteries that must be sited in physically small places, as would be found in many distributed generation and end-user sites.

There seems to be no significant prospect of improving BES energy density using lead-acid technology, but both zinc/bromine and sodium/sulfur batteries hold great promise in improving BES performance in this area.

Developers indicated to us that zinc/bromine batteries currently display a threefold improvement in energy density over lead-acid technologies, and sodium/sulfur batteries offer about eight times the energy density of lead-acid. Of course, both zinc bromine and sodium/sulfur technologies are not fully 
developed, but further research on advanced batteries may alleviate this problem.

\section{BES Market Targeting and Segmen- tation}

Based on the research performed during this study, it seems that most BES manufacturers and many of the other major participants in the industry have not spent a sufficient amount of time identifying and targeting specific BES market segments and applications.

No single monolithic BES market exists. Instead, several smaller markets exist within the larger BES market, and no one vendor is positioned to serve all these smaller markets. To illustrate this point, currently successful BES projects are examined below. These seem to fit within the following models:

\section{The PREPA Model}

PREPA is currently operating the largest BES system in the world, a 20-MW/14.1-MWh flooded lead-acid facility that began operation in November 1994. The system is designed to provide spinning reserve and frequency regulation on the PREPA system.

PREPA has been pleased with the operation of the system to date, describing the system as an "effective, practical solution to the need for instantaneous reserve and economical frequency control." However, they have delayed building follow-on systems because of their need to build new generating plants.

It is interesting to note that PREPA is not taking advantage of battery energy storage to store cheap offpeak power to dispatch at peak load. The difference between on- and off-peak power costs at PREPA is too small to justify load leveling on a significant scale.

\section{The Crescent EMC Model}

Crescent EMC has been using a 500-kW/500-kWh BES for peak-shaving purposes since 1983. By using the BES, Crescent has been able to significantly reduce the demand charges that they pay to their supplier, Duke Power.

Even though Crescent did not respond to the electricity provider questionnaire, the fact that they are still operating their BES after so many years speaks for itself. Since the installation of the Crescent EMC project, both San Diego Gas \& Electric (SDG\&E) and Southern California Edison (SCE) have installed and then decommissioned BES systems.

Obviously, Crescent EMC must be experiencing some level of success with its BES, since it does not have the technical resources that SCE and SDG\&E have to maintain their systems and yet Crescent has avoided decommissioning its BES system.

\section{The Vernon Model}

Earlier this year, GNB Batteries installed a 2-MW/5-MWh BES at its Vernon, California, battery recycling plant. This system functions both as a short-term UPS to back up critical environmental loads at the plant in the event of failure and as a peakshaving device to help the Vernon plant cut its demand charges. Since the Vernon BES offers peak shaving as a service to GNB's recycling operation, it is somewhat similar in function to the Crescent EMC model.

It is difficult to evaluate this project objectively because GNB is a producer of battery cells and is therefore using the Vernon installation as a technology demonstration project. Because of this, it is not in GNB's interest to portray the project in anything but a positive light. However, GNB's battery recycling plant in Vernon seems to be happy with the results so far.

\section{The AC Battery Model}

$\mathrm{AC}$ Battery is now beginning to mass-produce and mass-market its PQ2000 BES. The PQ2000 is designed to provide $2 \mathrm{MW}$ of current for roughly 10 seconds to provide short-term UPS service at the electricity end-user level. The purpose of the PQ2000 is to provide system owners . with ridethrough on the $95 \%$ of power quality disturbances and outages that last less than 10 seconds.

Currently, two PQ2000s are in operation at industrial sites being served by Pacific Gas \& Electric and Oglethorpe Power Corporation. Another seven units are on order or are in the sales process. Based on this reception, it appears that the $\mathrm{PQ} 2000$ is going to be a successful product, especially if AC Battery can build direct contact with power-quality-conscious electricity end users.

Examining all of these models, a few similarities between these four projects can be seen. First, each of these systems is or was provided to meet a specific need that the buyer truly needed to have met. This 
meant that the customer for each of these systems was committed to making the BES work, because the BES was crucial to their operations.

In the case of projects that have not succeeded, the owner/operator of the system was really using the $\mathrm{BES}$ as a technology demonstration, and the system had no relevance to the owner/operator's ongoing operations.

In some of the cases mentioned above, a significant amount of thought has been put into the packaging of the BES product. The AC Battery PQ2000 is not very useful in any role other than what it does bestproduce a significant burst of power for a short time. It does not have the storage capacity necessary to make it an adequate peak-shaving device, and it is not designed to be cycled often.

As a short-term power quality device, however, the product is quite successful. The PQ2000 is relatively cheap because it uses mass production batteries with little storage capacity. This and its electronic power conversion system make the PQ2000 very competitive with other UPS technologies.

In too many past BES projects, little effort has been spent on segmenting and targeting markets and developing products to suit these markets. Instead, efforts have been made to try and make BES into both a dispersed storage technology and a genuine replacement for generation technologies such as combustion turbines. Instead, BES should be viewed as a complement to generation technologies and should focus on dispersed applications and system-level applications where its competitiveness with planned and existing generation technologies can be proven.

For example, one of the applications found on the list of applications that is found in Appendix D of this report is generation deferral. Based on the replies received during this study, no significant market for $\mathrm{BES}$ as a generation deferral tool exists.

Indeed, because the current cost of BES is higher than the cost of most generation technologies, using BES for this role seem economically inefficient. Instead, utility input received during this study unequivocally suggests that BES is engaged in cutthroat competition with most generation technologies for resources and attention.

\section{The Level of BES Education}

The results of this study suggest that both electricity provider and regulatory body awareness of BES can be significantly improved. Many of the responses received during the survey of electricity providers strongly indicate that awareness of even the basic product characteristics of BES is mixed. Some personnel surveyed at major utilities indicated that they had almost no knowledge at all of BES but were interested in the concept.

At the regulatory agency level, knowledge of BES is especially undeveloped. The regulatory agencies rely almost entirely on the utilities within their jurisdiction for information on generation and storage technologies, and they are not getting any significant feedback on BES. Instead, interest seems to be focused on combustion turbines, combined cycle plants, and renewable energy.

\section{Technology Bias Toward Generation}

During surveying of the energy provider industry, significant evidence was uncovered regarding a strong bias within the industry toward power generation technologies as opposed to energy storage. Several companies mentioned that even if the price of BES fell to levels where it would be competitive with generation technologies, they would still favor generation technologies over BES because generation was "familiar."

\section{Organizational Obstacles to BES Procurement}

Currently, significant obstacles to BES procurement exist at the organizational level, with the different departments at electricity provider organizations unable or unwilling to reach a consensus on their shared interest in BES. This is partly due to the highly compartmentålized structure of many energy providers, remains from their days as a regulated monopoly.

As the electric power industry restructures, there is some possibility that this rigid corporate structure will break down and that technologies like BES that rely on the cooperation of several constituent groups within the client's organizations will benefit from this restructuring.

However, some risk is present that restructuring of the electric power industry will hurt BES sales by 
forcing the spinoff of many operational areas now found within the vertically integrated utility.

Eventually, generation, transmission, and distribution operations could be spun off into separate organizations, reducing the likelihood that these operational functions will cooperate with each other to install technologies such as BES. Economically, deregulation can cause a drop in the difference between onand off-peak electricity prices, reducing the advantages of storage.

\section{Communications in the BES Market- place}

The results of this study indicate that communications in the BES industry are inadequate on several levels. Specifically, the low level of BES knowledge and education exhibited in many of the responses gathered during this study shows that educational communications within the BES community need to be improved.

Also, significant obstacles to clear and understandable communication between BES suppliers and developers and electricity providers exist. This is probably more important than the educational communication issues, because it significantly affects the basic way in which many of the parties in the industry relate to and perceive each other. These communications difficulties seem to be affecting the proper development of the BES market. Further discussion of this communications topic will be found in the recommendations section of this study immediately following.

\section{Recommendations for SNL}

Frost \& Sullivan offers the following recommendations to SNL in the hope that they will provide value in the future and stimulate consideration of approaches that might improve the viability and performance of SNL's BES development efforts.

\section{Focus on Potential BES Applications and Products}

The results of this study indicate that the energy provider sample surveyed is interested in deploying BES in a wide variety of applications, but only a few specific applications were mentioned by three or more energy providers. These specific applications are:
- UPS/power quality

- Reliability

- Peak shaving

- Load leveling

- Electric vehicle charging

Of these five applications, UPS/power quality was mentioned most frequently, cited by 13 electricity providers. This is an application that should gather even more attention at the electricity provider level because many of the electricity providers surveyed have not made the transition to the competitive market yet.

Many electricity providers are still operating under the "regulated monopoly" mindset and regulatory environment. They have not yet become customerfocused organizations. In the future, as electricity providers become more externally focused, they will probably be even more enthusiastic in their support for UPS/power quality technologies.

Reliability and load leveling were cited by four electricity providers as the BES applications they were interested in. Load leveling is of course the classic energy storage application, so its mention by multiple respondents was not surprising.

Reliability is interesting, since electricity providers mentioned it as a system level application, and it did not appear on SNL's BES applications list (see Appendix D) as such. This indicates that there is significant interest in using BES to avoid system-level voltage sags and spikes and other events that might compromise system reliability.

Peak shaving was mentioned in three responses. Peak shaving is another application that should receive mounting interest as the electric power industry becomes more competitive. Electricity providers will probably have to respond to customer demands to a much greater degree than they do today.

Electric vehicle charging was mentioned in three responses and is another application that was not on SNL's list of proposed BES applications. Additionally, it is another application in which interest could increase over time. Currently, many electricity providers do not promote electric vehicles in an aggressive way.

Many electricity providers are interested in and in favor of the success of electric vehicles, but they do not view them as a way of significantly increasing 
their revenues. As electric vehicle technology improves, more utilities will be inclined to promote electric vehicle use more aggressively, increasing the need for electric vehicle charging stations.

Interestingly, an applications area that received very little comment was ancillary services. This is due in part to the formative state of utility deregulation. Electricity providers are not yet able to determine exactly what ancillary services will mean to them in a deregulated environment. Therefore, the whole discussion of ancillary services seems very academic and theoretical. Also, utilities have not identified significant flaws in the current methods of delivering ancillary services and do not see why these methods should be changed in the future.

In light of these response patterns, Frost \& Sullivan suggests that SNL focus its BES research efforts on the five applications listed by multiple electricity providers. Trying to address the wide range of applications proposed by electricity providers on this topic would require significant resources.

For example, the issue of ancillary services seems to have been greeted by the electricity provider sample with relative indifference and does not seem to deserve a major research commitment by SNL.

\section{Strengthen BES Industry Partner- ships}

To advance BES, Frost \& Sullivan recommends that SNL emphasize long-term commitments from the organizations it works with in the electric power industry.

The best illustration of this is the Chino, California, battery energy storage system (BESS) facility that is being run by SCE. The Chino facility was primarily developed and financed by SCE and the Electric Power Research Institute (EPRI), and its closure did have a negative impact on the perception of BES among other energy providers. They have seen the closure of the BES not as the end of a demonstration project but as evidence of the ineffectiveness of BES.

SNL was involved in the project in a limited supporting role, and at the time of its construction, the Chino BES represented the largest and most visible application of battery energy storage in the world. This visibility made the success of the Chino BES of vital interest to SNL's energy storage development efforts.
As mentioned earlier in this report, SCE has now scheduled the Chino BES for decommissioning. This is despite the fact that the Chino facility still has approximately 40 to $50 \%$ of its usable life remaining and that the acquisition of the system was largely funded or underwritten by EPRI and the International Lead Zinc Research Organization (ILZRO). SCE's position on the shutdown is that the Chino facility was too expensive to continue operating, especially considering the impending deregulation of California's electric power market.

The immediate result of the Chino decommission has been a significant increase in industry-wide skepticism about the merits of BES. This conclusion has been formulated from responses received from both the BES supplier community and the electricity provider community, some of which are directly quoted in this report. The shutdown of the Chino facility under the circumstances listed above has perpetuated the image of BES as being an expensive and undependable technology, the opposite result from that which SNL and EPRI wanted from the project.

SCE is concerned about its profitability in a newly competitive marketplace. SCE also has to be concerned about maintaining its reputation as a technological leader in electric power technologies, a factor that no doubt contributed to their selection of the Chino BES in the first place. At the same time, it must be realized that the Chino facility represented a minute fraction of SCE's generation and storage infrastructure and therefore risked being lost among much larger issues that SCE's management has to face every day.

On the other hand, SNL and its fellow research organizations have to be concerned solely with the successful demonstration of BES and with the collection of valuable data on the operating characteristics and problems of the Chino BESS over its full lifespan. The decommission of the Chino BES under the current circumstances has denied these outcomes to SNL, EPRI, and the BES supplier community.

In the future, Frost \& Sullivan suggests that SNL pay particular attention to the screening of all of its partners in BES development. Partners should be evaluated and selected based on their commitment to BES development and their willingness and ability to see any development or demonstration projects through to the point where they are successful or conclusively proven to be unsuccessful. 
SNL should also take steps to ensure that future development and demonstration projects provide longterm value to any organizations with which SNL partners. This value can include economic value, publicity value, and the value of any technological and operational insights gained from the project.

In the future, perhaps SNL can avoid the problems that arose in the Chino project by offering certain performance guarantees that would make future projects of at least nominal ongoing value to SNL's partners. Similar guarantees are found throughout the energy services industry and might be a valid model on which to base future development and demonstration projects.

A second approach might be to form independent energy services corporations to demonstrate future BES projects. These corporations would underwrite and cover any costs involved in operating and maintaining the project. They would generate at least some of the revenue needed to cover these costs through the provision of services offered by the BES to a utility or electricity end-user partner at a mutually acceptable price guaranteed by a contract lasting the life of the project.

Both of these approaches would require significant contractual obligations on the part of SNL and its partners, but it is trusted that these obligations will not be so onerous that they will defeat every potential project that might be considered.

Additionally, Frost \& Sullivan understands that as a governmental organization, SNL faces both statutory and budgetary limits on its operations. However, SNL does have an established base of partners within the BES industry that are not so constrained and may be able to take the lead in some form of collaborative effort with SNL along the lines listed above.

\section{Focus on Lower-Cost, Higher-Density Battery Technologies}

The current generation of BES products suffers from two critical handicaps that retard the large-scale acceptance of BES outside of customer-end power quality applications. Namely, these handicaps are the current high capital cost and the less-than-adequate energy densities of available battery technologies.

The reduction of capital costs is an explicit assumption of this study (see the per-kilowatt cost figures used in Appendix A). Also, some respondents must have made the assumption or detected Frost \& Sullivan's or SNL's assumption that this issue would be dealt with during the later portion of the study's forecast period. With this in mind, the capital cost and energy density issues must be addressed over the forecast period for the BES industry to achieve the levels of market penetration discussed in this report.

Of the four battery technologies that SNL included in this study, zinc/bromine batteries seem to hold the best promise of low construction and material costs and improved energy densities that would deliver concrete progress on the capital cost and energy density issues.

However, within the broader context of the needs of potential customers within the industry, the exact technology used to meet existing market requirements hardly matters. The marketplace is prepared to accept whichever technology meets its demand, as long as that technology is not flawed as to make its use impractical.

Therefore, whether the solution to cost and energy density issues is based on zinc/bromine batteries, advanced lead-acid, nickel metal hydride, or any other battery technology does not matter. BES customers are looking for a solution to their problems, not for a technology to champion. If the technology works, a plethora of customers will likely be ready to champion it at that time.

In short, Frost \& Sullivan suggests that SNL make every effort to develop a new generation of battery technology that would enable BES systems to better deal with capital cost and energy density issues. The responses received during this study clearly indicate that those were the central product features that potential BES customers within the electricity provider industry felt were missing. Undoubtedly, success in dealing with these issues would also be welcomed by the electricity end-user community, since it would make their customer-side systems easier to locate and cheaper to acquire.

\section{Facilitate Clearer Communications within the BES Industry}

Another issue affecting the BES industry is the lack of clear, consistent communications within the industry. In any developmental industry, clear communications are likely to be lacking, since the technical options available within the industry and the state of the many parties that make up a successful industry 
will be unstable, creating uncertainty. However, the BES industry seems to be particularly affected by communications problems.

In particular, Frost \& Sullivan would like to draw attention to two concrete issues. The first of these is the extremely high level of dissonance within the BES industry on the subject of the viability of the battery technologies in use or being considered for use within the industry. The second issue is the somewhat contentious and unclear communications that exist between many of the parties within the supplier, technology developer, and electricity provider communities within the BES industry.

Determining which of these two communications issues is more serious is difficult, since no effort to do this was made as a part of this study. Therefore, no attempt will be made to attach a relative importance to either issue. However, the presence of both issues serves to confuse and alienate valuable relationships that would greatly assist the successful development of BES.

Dissonance over battery technologies is the first communications issue covered here. Being in the market research business, Frost \& Sullivan has many opportunities to perform research on new products and markets. As a result, project teams are usually acquainted with the types of behavior that are displayed within developing markets. In the case of the BES market, the Frost \& Sullivan project team working on this study felt that the level of dissonance and disagreement within the market was as high or higher than that of other markets they had studied previously.

Mainly, this dissonance is occurring over the issue of the commercial and technological viability of the available and planned battery technologies that the BES industry has to draw from. A wide variety of battery technologies are available to draw from, most of which are not yet commercialized. Nevertheless, the amount of contention over battery technologies within the BES community is extremely high.

The situation has now reached the point where various industry parties are not only championing their own favored technology but are actively undermining other competing battery technologies. Perhaps this situation does not concern the technologists that currently hold sway in the industry. These technologists are equipped with the technical knowledge they need to refute arguments and maintain a focus on what they are trying to achieve.
However, as BES becomes more commercialized, the industry is expected to move increasingly into the hands of the managerial and procurement personnel that will make the economic decisions that will decide the success or failure of BES. The current level of dissonance may alienate and confuse these procurement and managerial personnel, reducing their willingness and enthusiasm to procure BES systems. Currently, the BES industry makes it too difficult for nontechnologists to determine which battery technologies might provide them with potential solutions to their problems. Also, the dissonance issues are affecting the ability of some developing battery technologies to get the backing they deserve.

The only battery technology that the industry seems to agree on is sodium/sulfur, and the general opinion on this technology is that it will not succeed. However, nobody has finished a utility-scale sodium/sulfur demonstration project, which leaves the possibility that the general industry mood toward this technology may be mistaken.

The second communications issue, the lack of clear and consistent communications in general, is more difficult to assess. In general, the problem seems to be that parties within the BES industry seem to talk past each other instead of talking to each other. This is particularly prevalent in the relations between BES suppliers and electricity providers. These two groups are beginning to alienate each other, thereby risking the long-term viability of the BES market.

Not all BES suppliers and electricity providers are part of the communications problem, but enough of them are to have created a significant problem. Specifically, the results of this study and contacts with BES industry professionals have led Frost \& Sullivan to believe that the problem on the BES supplier side seems to stem from too much concentration on technology as opposed to customer solutions. Also, that some vendors expect electricity providers to help them develop BES markets seems to be unreasonable.

The situation is more confusing on the electricity provider side. This study has clearly shown several instances in which stated public opinions of large utilities and other electricity providers have contradicted the private survey responses from these same organizations. Not only has this happened on an organizational level, but high-level utility personnel have also demonstrated these differences between their public positions and survey responses. 
Lacking hard evidence, the cause of this unusual behavior can only be speculated upon. A possible explanation is an attempt to curry favor in the BES industry publicly while deflating expectations privately. Also, the "junket mentality"-whereby personnel away from the office get swept up in the spirit of events and make overly optimistic projections, only to discover later that the actual office environment will not support those projections-may be a factor. Or perhaps the discrepancy is due to a "programmed optimism," where the respondent approaches any situation from the standpoint that tomorrow will be a better day.

These various behaviors were demonstrated and discussed at several points over the course of this study and have doubtless led to a certain amount of the tension between electricity providers and the other parties within the BES industry.

Frost \& Sullivan recommends that SNL discourage the behaviors discussed above. Specifically, it should broaden the base of industry forums in which it participates to include more managerial and planninglevel personnel and input. Doing so should heip considerably with communications with the electricity provider industry. SNL already has a program along these lines to improve its own communications with electricity providers; perhaps this can be expanded to improve industry-wide communications.

The dissonance issue is a little harder for SNL to cope with, because some of the parties that have created the dissonance have links to SNL's ESS Program. However, anything that SNL can achieve regarding these constraints would be an improvement.

\section{Perform Studies of Electricity End Users and Cooperatives}

At this point, the accepted logic in the BES industry is that the electricity end-user market is the best market for BES products. Unfortunately, this market could not be covered in this study. Frost \& Sullivan recommends that, in the future, SNL undertake or encourage studies of both the end-user market and the potential BES market among electric cooperatives in the United States.
A cooperative study may be conducted with the NRECA, which expressed interest in such an endeavor, and perhaps also the BES supplier community and the ESA. With the cooperation of these organizations, the study will be easier to finance. Additionally, the endorsement of such organizations may make the survey process more acceptable to potential electric cooperative participants.

The end-user study can be financed using a somewhat similar alliance of organizations. However, the enduser study will probably require more attention to issues of proper questionnaire and sample development before the study commences. This is because electricity end users are engaged in a wider range of disparate businesses, as opposed to the more homogeneous electric cooperative industry.

\section{Closing Remarks}

Even though the results of this report are not as universally positive as some BES industry professionals may have hoped they would be, the results clearly demonstrate that a market for BES does exist. Even if the technology does not advance beyond its current level, there will probably be a market for a limited number of BES systems serving specialized but vital applications at the utility level.

If the technological and market issues discussed in this report can be dealt with more comprehensively, Frost \& Sullivan expects BES- to become a significant electricity supply option, with a potential market reaching into hundreds of millions of dollars per year at the utility level alone by late in the next decade. Because of the unique, highly responsive, very modular, nonpolluting nature of BES, the national benefits of forecast BES expenditures are expected to be many times the nominal value of the BES market.

Frost \& Sullivan would like to express its gratitude to SNL for choosing the company as the contractor for this study. This study has provided unexpected insights into the BES market that neither SNL nor Frost \& Sullivan originally intended to receive. These insights should be of ongoing value to the development of BES as a viable electricity supply option within the utility industry, which was the original intent of this study. 


\section{Appendix A: Electricity Provider Questionnaire}

\section{Sandia BES Market Potential Survey}

Date:

Company:

Division:

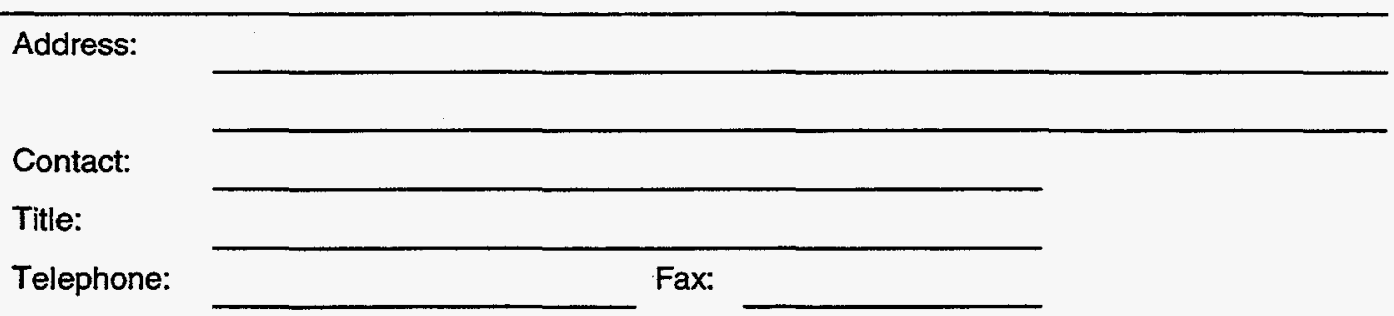

\section{Electricity Provider Questionnaire}

1. On a scale of one to ten ( $1=$ very unlikely, $10=$ very likely), how would you characterize your company's interest in deploying battery energy storage (BES) systems as a part of its generation, transmission, and distribution assets in the following years?

2000:

2005:

2010:

2. What is your company's opinion of current battery storage technology? What strengths or weaknesses do you see the technology having that would affect its deployment at your company?

3. What department(s) in your company would be responsible for authorizing and funding the acquisition of battery energy storage systems? How do you envision electric utility deregulation affecting BES procurement from this organizational standpoint?

4. What is your opinion of battery energy storage technology versus other energy storage technologies such as flywheels, superconducting magnetic energy storage (SMES), and supercapacitors?
5. What is your opinion of battery energy storage versus pumped hydro and compressed air energy storage (CAES)?

6. What is your opinion of battery energy storage technology versus generation technologies such as gas turbines, diesel generators, and fuel cells in dispersed or central station generation?

7. Identify the generation and energy storage technologies that your company sees as providing superior performance versus battery energy storage.

8. How would being an electricity provider in a deregulated environment affect your interest in energy storage versus operating in the current regulated environment?

9. Please refer to the enclosed list of electric power applications identified as being practical for BES technology. In what applications do you see battery energy storage systems providing the most value to your company?

10. Do you see battery energy storage as playing a role in, for example, the provision of ancillary services to an ISO, or other business opportunities that would exist in a deregulated environment? For reference, below is a list of some ancillary services that have been identified as being necessary in a deregulated environment. 
Scheduling and dispatch

Load following

Reliability

Supplemental operating

Energy imbalance

Real-power loss replacement

Generation voltage control

Transmission voltage control

11. Do you know of any additional applications not included in questions 9 and 10 for which battery energy storage might be used at your company?

12. Are there other applications for battery energy storage that are not in questions 9 and 10 that you see as being valuable to the utility industry as a whole that are not important to your particular company?

13. What technical or product characteristics do you think battery energy storage systems should possess to fulfill the applications discussed in questions 9, 10,11 and 12? Do you feel that battery energy storage for the most part possesses these characteristics now, or does battery energy storage require a significant additional investment of time and money to gain these characteristics?

14. How many megawatts in generation, transmission, and distribution capacity would your company need to provide for both normal load growth and the applications discussed in questions $9,10,11$, and 12 ? Please provide answers for the following years:

2000:

2005:

2010:
15. Of this new capacity required by your company, what percentage do you see battery energy storage providing in the same years? For the purposes of this question, assume that the installed cost of battery energy storage is approximately based on the schedule below. Prices are provided in a range and represent the expected cost of BES systems in each year in constant 1996 dollars. The higher end of this price range is for systems with longer storage capacities (two or more hours of operation at full output) and with lower prices representing the cost for systems with shorter storage capacity (down to 3-4 cycles).

\begin{tabular}{lll} 
Year & $\begin{array}{l}\text { BES System Price } \\
\text { Range }\end{array}$ & $\begin{array}{l}\text { Percent of new } \\
\text { capacity provided } \\
\text { by BES in calen- } \\
\text { dar year }\end{array}$ \\
\hline 2000 & $\$ 700 / \mathrm{kW}$ to $\$ 1,100 / \mathrm{kW}$ & \\
2005 & $\$ 500 / \mathrm{kW}$ to $\$ 700 / \mathrm{kW}$ & \\
2010 & $\$ 400 / \mathrm{kW}$ to $\$ 600 / \mathrm{kW}$ & -
\end{tabular}

16. Does your organization have any projections of what technology(s) will provide your central and/or distributed energy source(s) in 2010? If in 2010 the cost of BES were to be comparable to your preferred option, how much BES would you install?

17. Are there any other contacts at your organization or in others that you think might provide valuable input to this study?

Thank you for your time. 


\section{Appendix B: BES Vendor Questionnaire}

\section{Sandia BES Market Potential Survey}

Date:

Company:

Division:

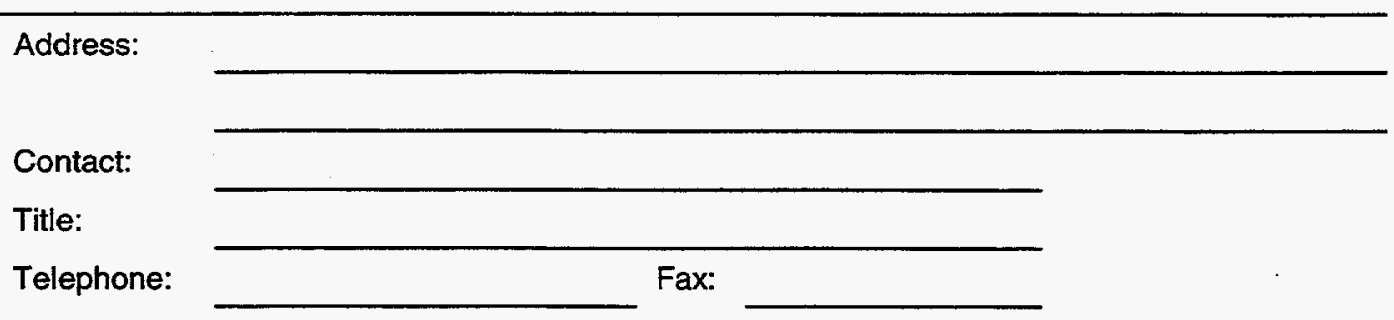

\section{BES Vendor Questionnaire}

1. What products or services does your company currently offer to the battery energy storage (BES) marketplace?

2. Do you currently plan any major changes in your BES product offerings in terms of technology or features by the turn of the century?

3. What developments do you see being necessary for the marketplace preparation of energy storage technologies other than those offered by your firm? Please specify by technology.

4. What barriers do you see to the large-scale acceptance of battery energy storage in the electricity production and consumption marketplace? Please include both technical and nontechnical issues, such as the development of production facilities and a marketing and service infrastructure for BES.

5. Do you see any particular electricity providers (cooperatives, municipals, IOUs, IPPs, etc.) as more likely BES customers? Which electricity providers do you target now? Which are you planning to target in the future?

6. Do you feel that there is an appreciable market for battery energy storage systems in electricity end-user applications? If so, roughly how large do you see this sector of the market being in comparison to the utility/power generator segment of the market?

7. Do you see the barriers to market acceptance and commercialization in electricity end-user applications being different from those in utility applications? If so, how?

8. What do you see the electricity end-user market for BES being in the following years? (in megawatts of capacity)

2000:

2005:

2010:

9. Do you see any type of battery preference from end-users? Does this vary by application?

10. Are you aware of other BES and energy storage vendors? Of which vendors are you aware? How successful do you think these vendors have been?

11. What are your thoughts or observations about existing, installed battery energy storage facilities at either the electricity end-user or utility level?

12. Our preliminary research has produced the following estimates for the U.S. BES market in the 
years 2000,2005 , and 2010 . The market estimates are given in constant 1996 dollars and in megawatts (MW) of installed BES capacity.

\begin{tabular}{lll} 
Year & $\begin{array}{l}\text { Market in } \\
\text { MW }\end{array}$ & $\begin{array}{l}\text { Market in Dol- } \\
\text { lars }\end{array}$ \\
\hline 2000 & 25.9 & $\$ 23,330,000$ \\
2005 & 199.5 & $\$ 119,690,000$ \\
2010 & 490.9 & $\$ 245,430,000$
\end{tabular}

What manufacturing developments would be required by the battery energy storage industry to meet this forecast level of demand? What market developments would be required to meet these same projections?

13. Are there any other contacts at your organization or in others that you think might provide valuable input into this study?

Thank you for your time. 


\section{Appendix C: Regulator/Advocate/Professional Organization Questionnaire}

\section{Sandia BES Market Potential Survey}

Date:

Company:

Division:

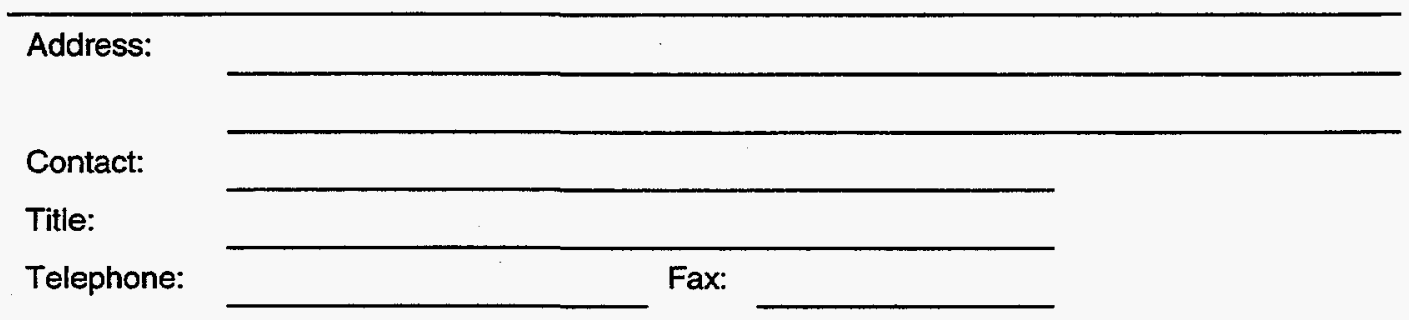

\section{Regulator/Advocate/Professional Organization Questionnaire}

1. What is your organization's opinion of energy storage, especially BES?

2. Would your organization advocate a position on BES? What tools or developments would be necessary for your organization to advocate a position on BES?

3. What do you see the benefits of battery energy storage being versus other competing technologies and programs such as distributed generation or demand side management?

4. If your organization is actively involved in the regulation of electric utilities, what are your estimates of electrical load growth within your jurisdiction for the period between 1996 and the following years?

2000:

2005:

2010: 
5. Do you or your organization have any perspective on how battery energy storage might compete with other options in a deregulated environment?

6. Does your organization get any feedback regarding battery energy storage from electricity producers or input from BES suppliers or electricity end-users? What kind of feedback, and how would you characterize it?

7. Are there any other contacts in your organization who might provide input on this topic? Please identify them:

Thank you for your time. 


\section{Appendix D: Battery Energy Storage Applications List}

\section{Generation}

Spinning Reserve: generation capacity that a utility holds in reserve to prevent interruption of service to customers in the event of a failure of an operating generating station.

Generation Capacity Deferral: ability of a utility to postpone installation of new generating facilities by supplementing the existing facilities with another resource.

Area/Frequency Control: ability of grid-connected utilities to prevent unplanned transfer of power between themselves and neighboring utilities (Area Control) and ability of isolated utilities to prevent the frequency of the electricity that they produce from deviating too far from $60 \mathrm{~Hz}$ (Frequency Control).

Renewables: applications through which renewable power is available during peak utility demand (Coincident Peak) and available at a consistent level (Firming).

Load Leveling: storage of inexpensive off-peak power for dispatch during relatively expensive on-peak hours.

Generation Dispatch: Decommitting and/or more economically dispatching generating units that are operating at inefficient partial loads until system load more closely matches the aggregate capacity of available generating units.

\section{Transmission \& Distribution}

Transmission Line Stability: ability to keep all components on a transmission line in synchronization with each other and prevent system collapse.

Voltage Regulation: ability to maintain the voltages at the generation and load ends of a transmission line within $5 \%$ of each other.

Transmission Facility Deferral: ability of a utility to postpone installation of new transmission lines and transformers by supplementing the existing facilities with another resource.

Distribution Facility Deferral: ability of a utility to postpone installation of new distribution lines and transformers by supplementing the existing facilities with another resource.

\section{Customer Service}

Customer Demand Peak Reduction: storage of offpeak power for a customer to dispatch during greatest on-peak demand as a way to reduce monthly demand charges.

Reliability, Power Quality, Uninterruptible Power Supply-Small \& Large Customers: ability to prevent voltage spikes, voltage sags, and power outages that last for a few cycles (less than one second) to minutes from causing data and production loss for customers. 
Intentionally Left Blank

D-2 


\section{Distribution}

Bechtel

Attn: W. Stolte

P.O. Box 193965

San Francisco, CA 94119-3965

Berliner Kraft und Licht (BEWAG)

Attn: K. Krämer

D-12432

Berlin, Germany

Eagle-Picher Ind., Inc.

Attn: J. DeGruson

C \& Porter Street

Joplin, MO 64802

Energetics, Inc. (2)

Attn: J. Badin

P. Taylor

7164 Columbia Gateway Drive

Columbia, MD 21046

Ergentics, Inc.

Attn: P. Burghart

247 Margaret King Ave.

Ringwood, NJ 07456

GNB Technologies

Attn: S. Deshpande'

375 Northridge Rd.

Atlanta, GA 30350

International Energy Systems, Ltd.

Attn: G. Barker

Chester High Rd.

Nestor, South Wirral

L64 3UE England

Lucas Controls, Inc.

Attn: D. Lucas

P.O. Box 551848

Dallas, TX 75355-1848
National Renewable Energy

Laboratory

Attn: D. Ginley

1617 Cole Blvd. MS3211

Golden, CO 80401

NPA Technology, Inc.

Attn: W. Cranston

Two University Place, Ste. 700

Durham, NC 27707

Pacificorp

Attn: J. Bredthauer

201 South Main, Ste. 2000

Salt Lake City, UT 84140-0020

Sentech, Inc. (2)

Attn: R. Sen

S. Swaminathan

4733 Bethesda Ave., Ste. 608

Bethesda, MD 20814

Sierra Pacific Power Co.

Attn: M. Harris

P.O. Box 10100, S4A30

Reno, NV 89520

Southern California Edison (SCE)

Attn: N. Pinsky

P.O. Box 800

2244 Walnut Grove Ave., Rm. 418

Rosemead, CA 91770

Switch Technologies

Attn: J. Hurwitch

4733 Bethesda Ave., Ste. 608

Bethesda, MD 20814

UFTO

Attn: E. Beardsworth

951 Lincoln Ave.

Palo Alto, CA 94301-3041 
U.S. Department of Energy

Attn: C. Platt

Office of Energy Management

EE-12 FORSTL

Washington, DC 20585

MS-0513, R. Eagan (1000)

MS-0953, W. Alzheimer (1500)

MS-0702, D. Arvizu (6200)

MS-0212, A. Phillips, (10230)

MS-0340, J. Braithwaite (1832)

MS-0343, W. Cieslak (1832)

MS-0953, J. T. Cutchen (1501)

MS-0613, A. Akhil (1525)

MS-0613, D. Doughty (1521)

MS-0614, E. Binasiewicz (1522)

MS-0613, G. Corey (1525)

MS-0614, G.P. Rodriguez, (1523)

MS-0613, I. Francis (1525)

MS-0614, T. Crow (1523)

MS-0614, T. Unkelhaeuser (1523)

MS-0614, D. Mitchell (1522)

MS-0614, K. Grothaus (1523)

MS-0613, N. Clark (1525)

MS-0613 R. Jungst (1521)

MS-0704, P. Klimas (6201)

MS-0708, H. Dodd (6214)

MS-0752, M. Tatro (6219)

MS-0753, C. Cameron (6218)

MS-0753, R. Bonn (6218)

MS-0753, T. Hund (6218)

MS-0753, W. Bower (6218)

MS-1193, D. Rovang (1231)

MS-0613, P. Butler (1525) (60)

MS-0619, Review \& Approval Desk For

DOE/OSTI (12690) (2)

MS-0899, Technical Library (4916) (5)

MS-9018, Central Technical Files (8940-2) 